\title{
AUTO-TUNED MINIMUM-DEVIATION DIGITAL CONTROLLER FOR LLC RESONANT CONVERTERS
}

by

SeyedehMaryam SeyedAmouzandeh

A thesis submitted in conformity with the requirements

for the degree of Master of Applied Science

Graduate Department of Electrical and Computer Engineering University of Toronto

(c) Copyright by SeyedehMaryam SeyedAmouzandeh 2015 


\title{
AUTO-TUNED MINIMUM-DEVIATION DIGITAL CONTROLLER FOR LLC RESONANT CONVERTERS
}

\author{
SeyedehMaryam SeyedAmouzandeh \\ Master of Applied Science \\ Graduate Department of Electrical and Computer Engineering \\ University of Toronto \\ 2015
}

\begin{abstract}
This thesis presents a practical auto-tuned digital controller for LLC resonant dc-dc converters that results in virtually minimal possible output voltage deviation during transients. During transients the controller applies a two-step frequency change algorithm such that the minimum deviation and seamless transition to the new steady state is achieved. The fast voltage regulation is obtained through the output voltage measurements only and fairly simple calculations of the frequency-changing sequence, eliminating fast current sensors and complex calculations usually existing in other fast controllers for LLC converters. Based on the initial voltage deviation the first frequency step of the controller is determined and adjusted through an auto-tuning process. Smooth transition to the new steady state is achieved through the estimation of the new switching frequency from the ripple amplitude. Experimental results obtained with a $350 \mathrm{~W}$, $400 \mathrm{~V}$ to $12 \mathrm{~V}$, isolated LLC converter confirm recovery with practically smallest possible deviation and bump-less transitions to the new steady state.
\end{abstract}




\section{Acknowledgments}

Firstly, I would like to express my sincere gratitude to my advisor Prof. Prodic for the continuous support and guidance in all the time of research and writing of this thesis and also throughout the two years of my graduate study. His encouraging words throughout my research motivated and kept me going which was invaluable to my thesis. I could not have imagined having a better advisor and mentor.

Besides my advisor, I would like to thank all my friends and peers in the Laboratory for Power Management and Integrated Switch-Mode Power supplies. I am grateful to Dr. Behzad Mahdavikhah for his patience, motivation, and immense knowledge. Without his precious support it would not be possible to conduct this research. To all the rest of my colleagues and friends, Dr. S.M. Ahsanuzzan, Nenad Vukadinović, Mahmoud Shousa, Tim McRae, Amr Amin, Parth Jain and Shadi Dashmiz for providing me support to overcome some of the obstacles and for all the fun we have had in the last two years.

I would like to acknowledge the support of Texas Instruments and Brent McDonald for sponsoring this exciting and challenging project.

Last but not the least, I would like to thank my parents who have provided me with unconditional love and support throughout my life. They have always been an inspiration to me, I know I can never be thankful enough to them. Special thanks to my sisters Zahra and Narges for supporting me spiritually throughout my life. Also, my niece, Atrisa and nephew, Arsam who kept me laughing and smiling through the hard times. 


\section{Table of Contents}

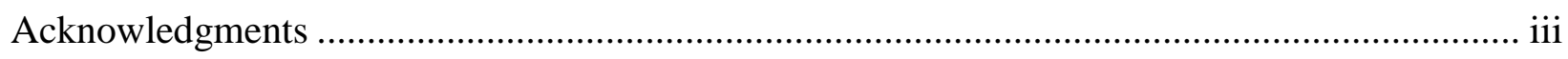

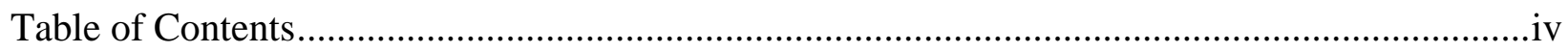

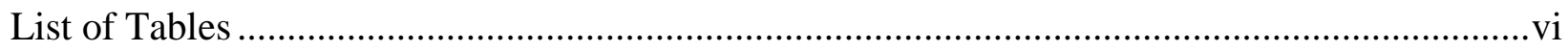

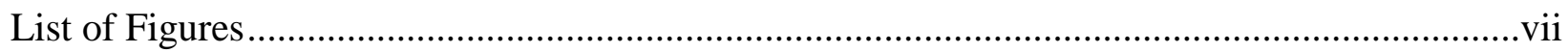

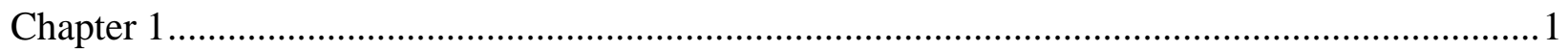

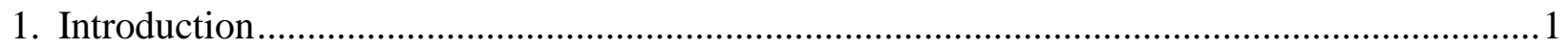

1.1. Background and Objective ………………………...................................................

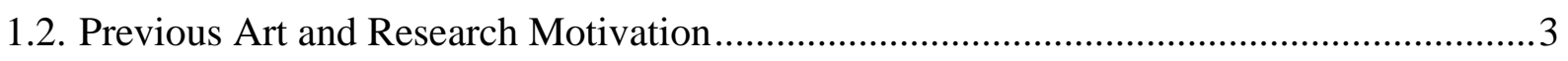

1.2.1. LLC Dynamic Performance.............................................................................

1.2.2. Synchronous Rectification Controller ................................................................

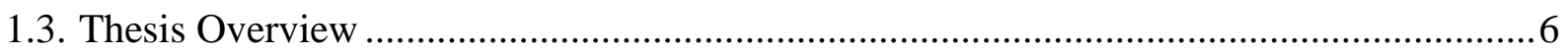

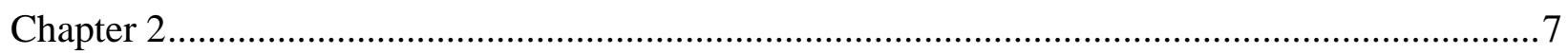

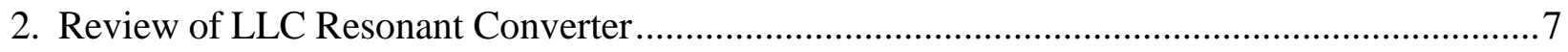

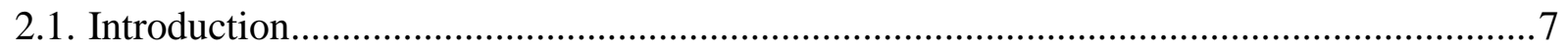

2.2. Resonant Mode Converter Topologies ………………................................................

2.2.1. Series resonant converter (SRC)....................................................................

2.2.2. Parallel resonant converter ................................................................................

2.2.3. Series parallel resonant converter ................................................................... 11

2.3. LLC Resonant Converter Principles of Operation............................................................ 12

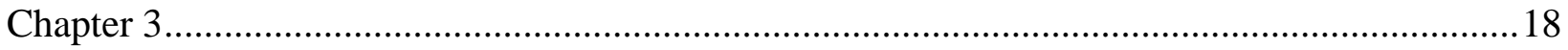

3. Auto-Tuned Minimum-Deviation Digital Controller for LLC Resonant Converters.................18

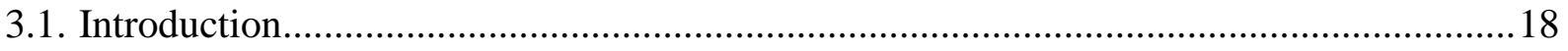

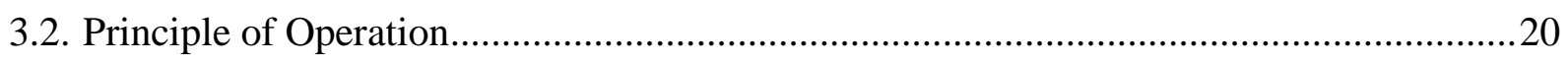

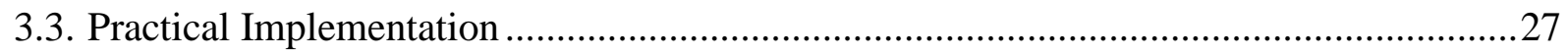


3.4. Simulation Results

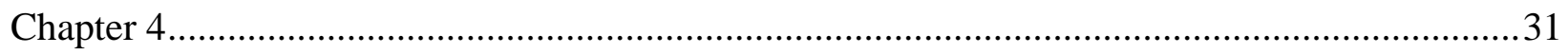

4. Digital Synchronous Rectification Controller …………......................................................... 31

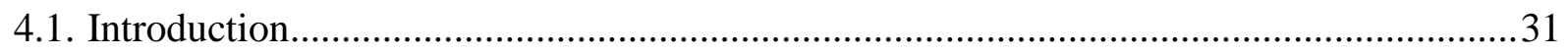

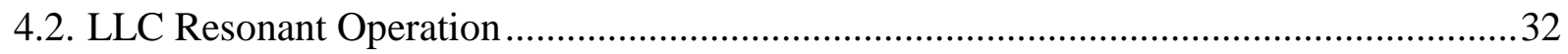

4.2.1. LLC Resonant Converter with Diode Rectifier ........................................................33

4.2.2. LLC Resonant Converter with Synchronous Rectifier ............................................36

4.3. Principle of operation and Practical Implementation ...........................................................36

Chapter 5

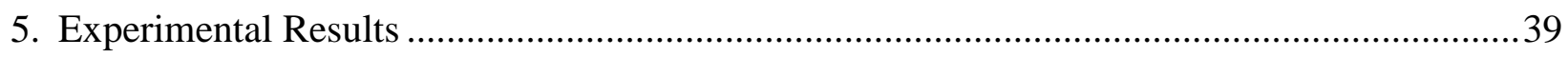

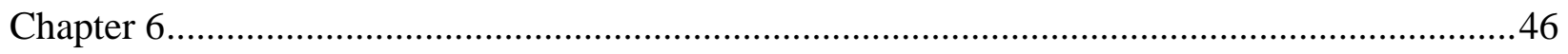

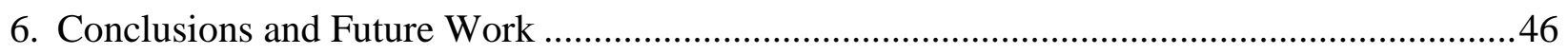

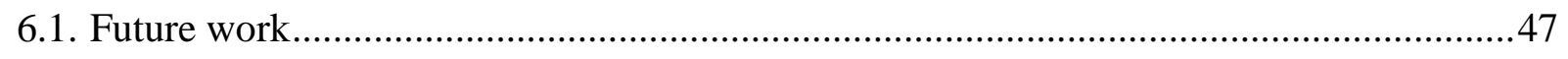

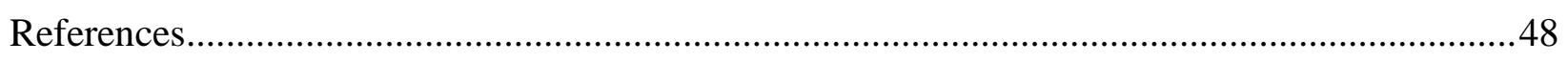

A Optimal Trajectory Analysis for Load Transients ……………….........................................51

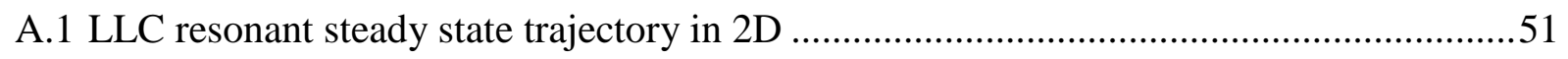

A.2 LLC Load Transient Trajectories in State-Plane ...............................................................58

A.2.1 Light to Heavy Load Transient...........................................................................58

A.2.2 Heavy Light to Load Transient.............................................................................61

B Implementation of Functional Blocks.................................................................................64

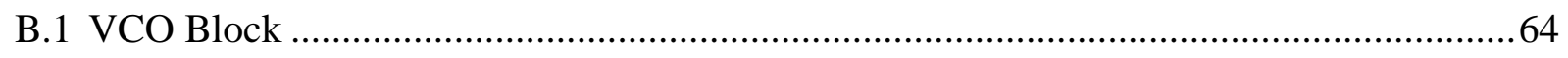

B.2 Voltage Deviation, H2L and L2H Detection ...................................................................66

B.3 Ripple measurement and PID Re-Initialization ................................................................67

C Approximation for the Charge (Equation (3.13)) ...................................................................6 


\section{List of Tables}

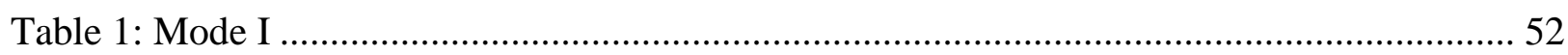

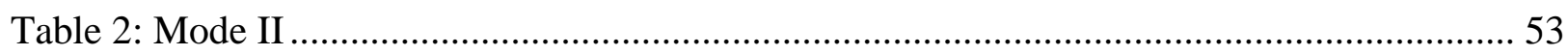

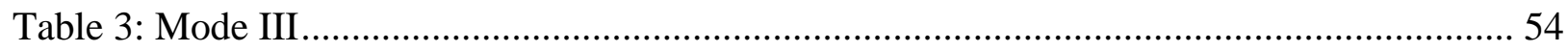

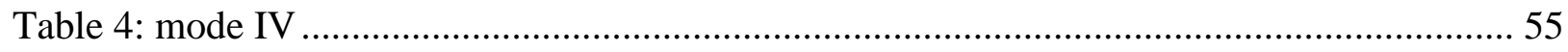

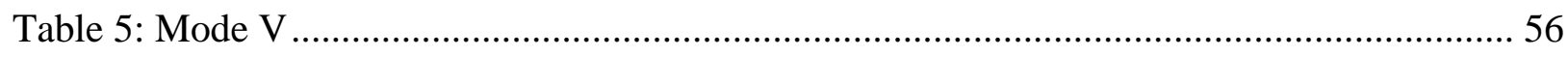

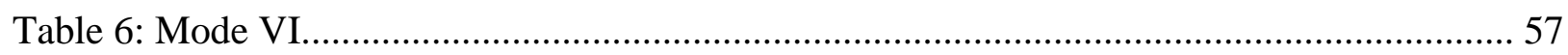




\section{List of Figures}

Figure 1-1: Distribute Power System (DPS)

Figure 1-2: half-bridge LLC resonant converter .2

Figure 1-3: LLC resonant converter with synchronous rectifier on the secondary .5

Figure 1-4: Primary side current sensing for SR driving .5

Figure 2-1: Circuit diagram of a half bridge Series Resonant Converter (SRC) 8

Figure 2-2: DC voltage gain characteristic of series resonant converter (SRC)........................8

Figure 2-3: Circuit diagram of a half bridge Parallel Resonant Converter (PRC) ......................10

Figure 2-4: DC characteristic of Parallel Resonant Converter (PRC) .10

Figure 2-5: Half bridge SPRC, LCC resonant converter .12

Figure 2-6: DC characteristic of LCC resonant converter 12

Figure 2-7: Half-bridge LLC resonant convert. .14

Figure 2-8: DC characteristic of LLC resonant converter .14

Figure 2-9: LLC resonant converter waveforms at the resonant frequency 15

Figure 2-10: LLC resonant converter equivalent circuits operating below resonance. 15

Figure 2-11: LLC resonant converter waveforms operating below the resonant frequency. .17

Figure 2-12: LLC resonant converter waveforms operating above the resonant frequency. .17

Figure 3-1: LLC resonant converter with PID and transient suppression controller. 20

Figure 3-2: Key waveforms of LLC resonant converter during transient. Waveforms from top to bottom: output voltage; load current; switching signals; tank and magnetizing inductor current; and switching frequency..... .21 
Figure 3-3: Magnetizing and tank current, output capacitor voltage, and output capacitor current waveforms from simulation .25

Figure 3-4: Comparison between function $\mathrm{Y}$ of equation (3-17) and its approximated piecewise linear interpolation. .26

Figure 3-5: LLC resonant converter block diagram with detailed controller blocks. .27

Figure 3-6: Controller flowchart. .28

Figure 3-7: Auto-tuning flowchart of factor $K$ .29

Figure 3-8: Simulation results for a light to heavy load transient with a well-tuned PID compensator. 30

Figure 3-9: Simulation results for a light to heavy load transient with the introduced controller. 30

Figure 4-1: LLC resonant converter with SR on the secondary side and digital controller..... .32

Figure 4-2: Simulation results of LLC operating below resonance; $G_{1}$ and $G_{2}$ are main switches driving signal; $i_{G 1}$ and $i_{G 2}$ are main switches currents; $i_{L m}$ and $i_{L r}$ are magnetizing and tank inductor currents respectively; $i_{D S R 1}$ and $i_{D S R 2}$ are rectifier body diode currents. .34

Figure 4-4: Simulation results of LLC operating above resonance; $G_{1}$ and $G_{2}$ are main switches driving signal; $I_{G 1}$ and $I_{G 2}$ are main switches currents; $I_{L m}$ and $I_{L r}$ are magnetizing and tank inductor currents respectively; $I_{D S R 1}$ and $I_{D S R 2}$ are rectifier body diode currents. .35

Figure 4-5: LLC resonant converter equivalent circuits operating above resonance. .35

Figure 4-6: Simulation results of LLC resonant converter with SR while SR synchronously turns on with the main switch. a) Operating above resonance. b) Operating below resonance; $G_{1}$ and $G_{2}$ are main switches driving signal; $i_{D S R}$ and $G_{D S R}$ are the SR current and driving signals........36

Figure 4-7: a) SR turn off controller flowchart; b) SR turn on controller flowchart.....................38

Figure 4-8: Timing diagram, $I_{S R}$ is the SR current, $V_{d s S R}$ is the SR switch drain to source voltage, $G_{S R}$ is the SR gating signal. .38 
Figure 5-2: Dynamic response of LLC resonant converter for light to heavy load transient. $v_{\text {out }}$ is the output voltage measurement signal $(200 \mathrm{mV} / \mathrm{div}) . i_{\text {Load }}$ is the load step current (10A/div); $v_{s w \_n o d e}$ is the switching node voltage.

Figure 5-3: Dynamic response of LLC resonant converter for heavy to light load transient. $v_{\text {out }}$ is the output voltage measurement signal $(200 \mathrm{mV} / \mathrm{div}) ; i_{\text {Load }}$ is the load step current (10A/div); $v_{s w \_n o d e}$ is the switching node voltage.

Figure 5-4: Transient response of a 3 to 15A load step a) with PID re-initialization, b) without PID re-initialization. $v_{\text {out }}$ is the output voltage measurement signal $(100 \mathrm{mV} / \mathrm{div}) . i_{\text {Load }}$ is the load step current $(5 \mathrm{~A} / \mathrm{div}) ; v_{s w \_n o d e}$ is the switching signal.

Figure 5-5: Dynamic response of LLC resonant converter for light to heavy load transient a) with introduced controller and $\left.C_{o u t}=1645 \mu \mathrm{F}, \mathrm{b}\right)$ with conventional controller and $C_{\text {out }}=2585 \mu \mathrm{F}$. $v_{\text {out }}$ is the output voltage measurement signal $(200 \mathrm{mV} / \mathrm{div})$. $i_{\text {Load }}$ is the load step current $(10 \mathrm{~A} / \mathrm{div}) ; v_{s w \_n o d e}$ is the gating signal; Time scale is 50us/div.

Figure 5-6: Auto-tune of factor $K$ for light to heavy load transients. $v_{\text {out }}$ is the output voltage measurement signal (200mV/div). $i_{\text {Load }}$ is the load step current (10A/div); $G_{1}$ is the gating signal and factor $\mathrm{K}$ is shown in 5 bits; Time scale is $100 \mathrm{~ms} / \mathrm{div}$.

Figure 5-7: Zoomed in version of Figure 5-6 at updating times. .44

Figure 5-8: Experimental results, a) SR driving signals in synchronous with the primary side switches; b) SR driving signals with modified on time. $S R_{D E T 1}$ is the $Q_{S R 1}$ body diode conduction detection signal; $G_{S R 1}$ is the $Q_{S R 1}$ gating signal; $v_{D S S R 1}$ is the $Q_{S R 1}$ drain to source voltage 20 V/div.; $v_{x}$ primary side witching node voltage. Time is 2 us/div. 45

Figure A-1: LLC resonant converter equivalent circuit and its state space trajectory in Mode I...52

Figure A-2: LLC resonant converter equivalent circuit and its state space trajectory in Mode II 53

Figure A-3: LLC resonant converter equivalent circuit and its state space trajectory in Mode III54 
Figure A-4: LLC resonant converter equivalent circuit and its state space trajectory in Mode IV55

Figure A-5: LLC resonant converter equivalent circuit and its state space trajectory in Mode V 56

Figure A-6: LLC resonant converter equivalent circuit and its state space trajectory in Mode VI57

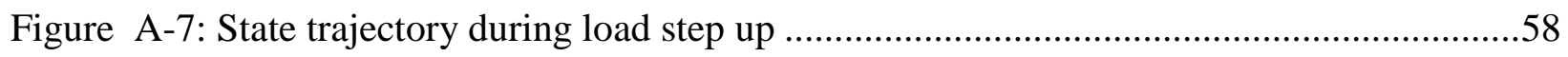

Figure A-8: LLC resonant converter waveforms during load step up ....................................59

Figure A-9: State trajectory during load step down......................................................61

Figure A-10: LLC resonant converter waveforms during load step down .............................62

Figure B-1: Functional blocks used in the introduced controller ...........................................64

Figure B-2: Conventional VCO implementation..............................................................65

Figure B-3: Experimental result using conventional VCO.................................................65

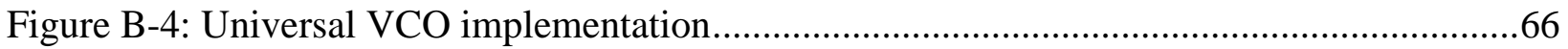

Figure B-5: experimental result using the universal VCO .............................................66

Figure B-6: Driving signal comparison using conventional and universal VCO ......................66

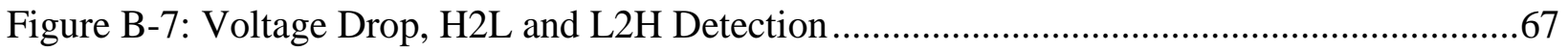

Figure B-8: Ripple measurement and PID Re-Initialization ...........................................67 


\section{Chapter 1}

\section{Introduction}

The objective of this thesis is to design a controller for LLC resonant converters with a fast transient response. In this chapter a literature review on the LLC resonant converter is presented, and its advantages and applications are investigated. The control challenges and the importance of the proper synchronous rectification are also addressed.

\subsection{Background and Objective}

With increasing demand for fast dynamic loads such as telecoms, servers, desktops, laptops and notebooks, Distribute Power System (DPS), has been widely used for its ability to improve the system overall efficiency [10]. As shown in Figure 1-1 in a DSP, power is usually processed by three stages, the first two stages form a front-end converter which is connected to the utility line. In the last stage point-of-load converters are placed close to each fast dynamic load [10].

As shown in Figure 1-1, front-end converter is consist of two conversion converters. First stage usually converts ac input to a $400 \mathrm{~V}$ dc while providing power factor correction (PFC). Second stage is the front-end dc-dc converter, converts $400 \mathrm{~V}$ dc into a $12 \mathrm{~V}$ dc. High efficiency and high power density are desired for front-end converters to reduce the converter cost while having an acceptable performance. Therefore, these converters need to operate at high frequency to have a high power density while maintain high efficiency.

In these applications LLC resonant converters are being widely used as front-end converters because of their ability to achieve higher power density and efficiency than the hard switching solutions. LLC resonant converters are also able to operate over a wide input voltage range. A half-bridge LLC resonant converter is shown in Figure 1-2. 


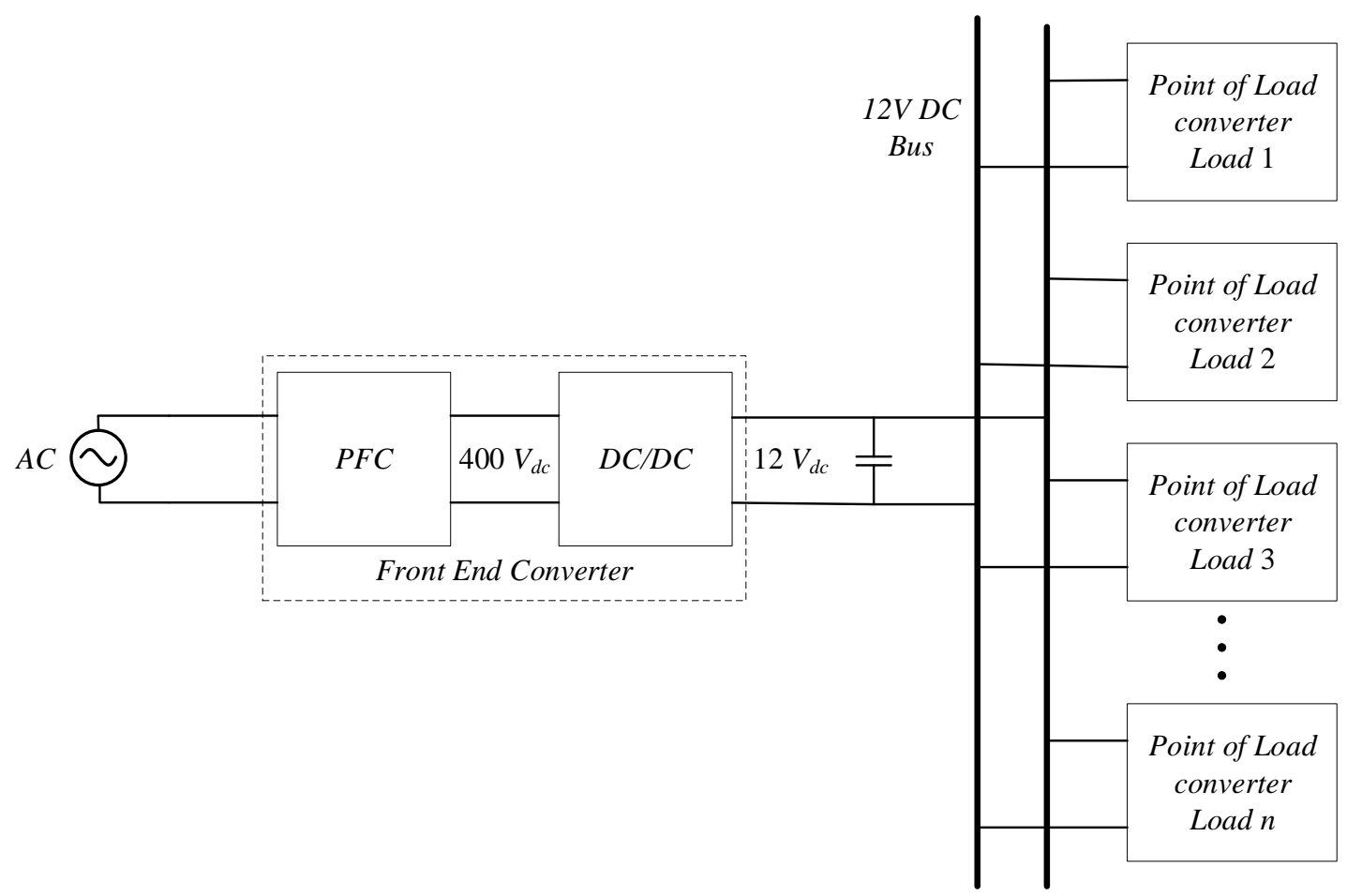

Figure 1-1: Distribute Power System (DPS)

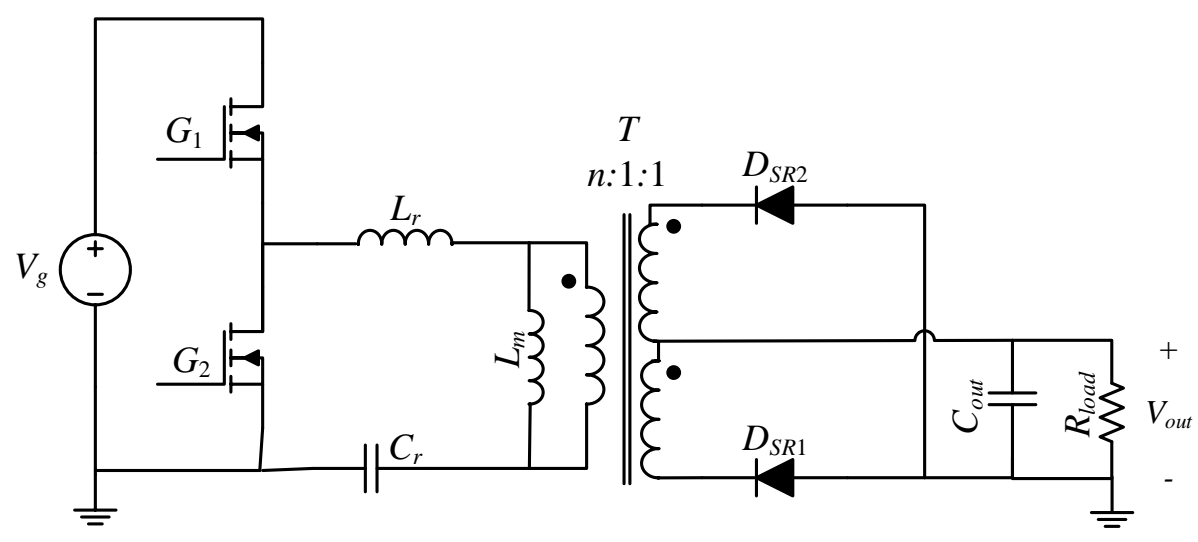

Figure 1-2: half-bridge LLC resonant converter

LLC resonant converter is controlled with pulse frequency modulation technique. However, since dynamic characteristic of LLC converters changes with operation conditions [1], [2], i.e. for various input/output voltages and loads, their control is more challenging than that of hardswitching PWM converters. For PWM converters the natural frequency of the system, L.C. output filter is much lower than the switching frequency. For that reason in the modeling 
process components of switching frequency can be neglected. However, LLC resonant converters usually operate at a switching frequency that is close to the natural frequency of the resonant tank, in order to obtain better power processing efficiency [1]. Therefore, it is much more complex to describe the resonant tank small-signal model [1]-[3].

\subsection{Previous Art and Research Motivation}

As explained earlier, improving the dynamic performance of the LLC resonant converter during transients is challenging due to operating condition dependent characteristics of the converter. Therefore, the main objective of this thesis is to design a simple and reliable controller for LLC resonant converter which improve the transient response using digital controller.

In order to improve the overall efficiency of the converter, the secondary side can be replaced with a synchronous rectifier. The controller to drive the secondary side switches to eliminate the body diode conduction of the switches and avoid any circulating current is also studied. In the following sections a literature review on dynamic performances and control of the LLC resonant converters is presented. Also a review of the previous art on control of synchronous rectifier is given.

\subsubsection{LLC Dynamic Performance}

LLC resonant converters demand tight output voltage regulation while maintaining good dynamic performance during transients. Therefore advanced control algorithm are needed to provide mentioned requirements. LLC resonant converter characteristics changes as the converter operating point change, therefore commonly used analog controllers which are often designed to operate in only one mode, have very limited dynamic performances. Digital controllers allow more complex algorithm and can be implemented for improve efficiency and dynamic performances [12]. Digital controllers are also more flexible, reliable, cost effective and less sensitive to noise and component variations.

To improve dynamic performance of LLC converter controllers, a number of methods has been proposed in the past. 
In [4], the authors implement and compare a digital PID and fuzzy logic controller (FLC) on a half-bridge DC/DC LLC resonant converter. However, since this controller does not require accurate mathematical model of the system it has not demonstrated better small signal performance than standard regulators.

In [5], a sliding-mode control scheme for LLC resonant converter is presented. The proposed controller operates at two fixed switching frequencies. The proposed control method improves the dynamic performance of the converter, but shows sensitivity to converter parameters and the discontinuous high speed switching action results in the chattering problem.

Authors in [6], proposed a simplified optimal trajectory control (SOTC) for the LLC resonant converter. During the steady state, a linear compensator is used, and during load transients, the SOTC controls the system. The SOTC changes the pulse-width of the gate driving signals based on complex calculation to get in to the new state in the optimal i.e. fastest possible time. This method require costly, fast, and accurate load current measurement along with input voltage measurement. The other disadvantage of this controller is its sensitivity to converter parameters.

\subsubsection{Synchronous Rectification Controller}

To reduce the conduction losses on the secondary side of the LLC resonant converter, the synchronous rectifiers (SR) as shown in Figure 1-3 should be employed. However the driving signals for the SR switches need to be carefully timed, since they are not in phase with the primary side signals. Inaccurate timing of SR driving signals decreases the overall efficiency. In the case of shorter driving signals the body diodes of SR switches conduct, increasing the conduction losses. In the case of longer driving signals the circulating current from the load to the source would reduce the efficiency dramatically.

In [19], a method to generate the SR deriving signals based on the SR current sensing by transformers is introduced. This method suffers from additional losses due to high secondary current and energy losses of the transformer windings. 


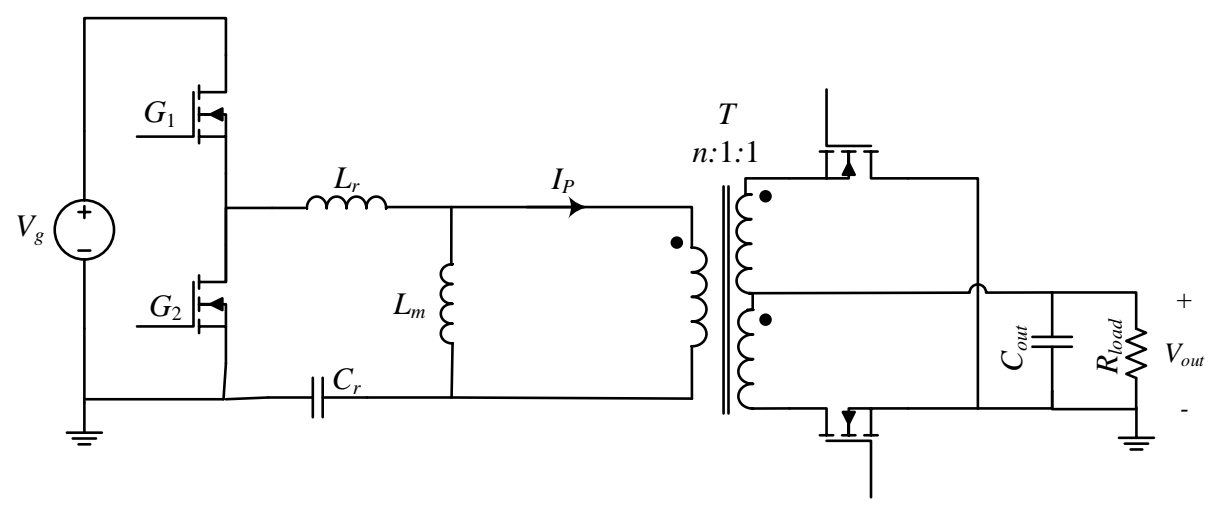

Figure 1-3: LLC resonant converter with synchronous rectifier on the secondary

Authors in [20] are also using a transformer to sense the SR current, however they sense the primary side current since it is smaller compared to the secondary side current. Therefore the losses associated to the transformer windings are lower. However, as it shown in Figure 1-4, $I_{p}$ is proportional to the secondary side current. That means the magnetizing inductance of the transformer needs to be external. As a consequent the integration of leakage, magnetizing inductors and transformer in a single element is lost.

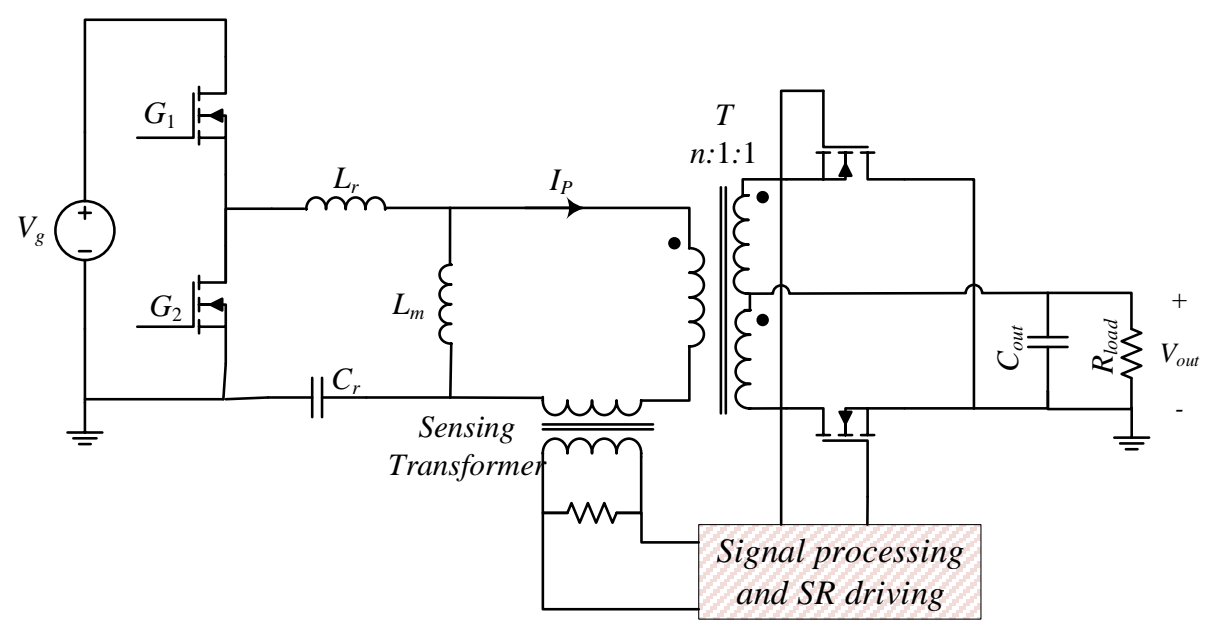

Figure 1-4: Primary side current sensing for SR driving.

In [28], [29] the SR body diode conduction detection circuit is used to detect the forward voltage drop on SR switches. In this method the SR driving signal is tuned until the circuit cannot detect the body diode conduction anymore. The main drawback of this method is a limit 
on the maximum pulse width of the SR driving signal, which cannot be larger than that of the main switch. However during operation above resonance the secondary switches need to remain in on-state longer than the primary side signals.

In [24] a digital auto tuned process for the turn-off instant of the SR is proposed. Although the auto tuned turn off algorithm is precise, the turn-on time instant is in synchronous with the primary side switches. As it will be discussed in Chapter 4, for a realistic converter, the optimal SR turn on time instant is not fully synchronized with the primary side switches and depends on the operating conditions.

\subsection{Thesis Overview}

This thesis is organized into six chapters. In Chapter 1, the motivation to design a digital controller for LLC resonant converter is established. Previous work related to improving the dynamic performance and synchronous rectification are also presented.

Chapter 2 provides a brief review of basic resonant converter topologies and their DC characteristics. The LLC resonant converter is presented in more detail.

In Chapter 3, first the design process of digital transient controller to achieve minimum voltage deviation is presented. Next, simulation results with PSIM software are presented that the results also show the comparisons between the introduced nonlinear controller and a conventional linear controller.

In Chapter 4, first the effect of improper turn on time is addressed and shown through simulation. Then, the digital synchronous rectifier controller algorithm is presented.

Chapter 5 describes the experimental setup and presents results to validating the work done in this thesis. First the experimental results show dynamic performance of the digitally controlled LLC resonant converter. Then the dynamic response of a conventional linear controller is provided for comparison.

Finally, Chapter 6 summarizes the work done in this thesis. Possible improvements and future work are also discussed. 


\section{Chapter 2}

\section{Review of LLC Resonant Converter}

In this chapter several resonant converter topologies are studied and the advantages and disadvantages of each topology are presented. Afterwards, the LLC resonant converter principle of operation, the different modes, and desired regions of operation are discussed.

\subsection{Introduction}

Resonant converters can be designed to achieve low switching losses therefore they are able to operate at high switching frequency. Therefore these topologies are having high efficiency, high power density, i.e. low overall volume, and low profile. To find a topology that could have the optimal performance at normal operation condition, three most popular resonant converter topologies have been investigated here. Series resonant converter (SRC), parallel resonant converter (PRC) and series parallel resonant converter (SPRC) are studied for front-end applications.

\subsection{Resonant Mode Converter Topologies}

\subsubsection{Series resonant converter (SRC)}

Figure 2-1 shows the circuit diagram of a half bridge series resonant converter (SRC) [13]. The de input to output voltage gain characteristic of SRC is shown in Figure 2-2. Here $f_{n}$, the normalized switching frequency is defined as $\frac{f_{s}}{f_{0}}$, and $f_{0}=\frac{1}{2 \pi \sqrt{L_{r} C_{r}}}$ is the resonant frequency of the system. 


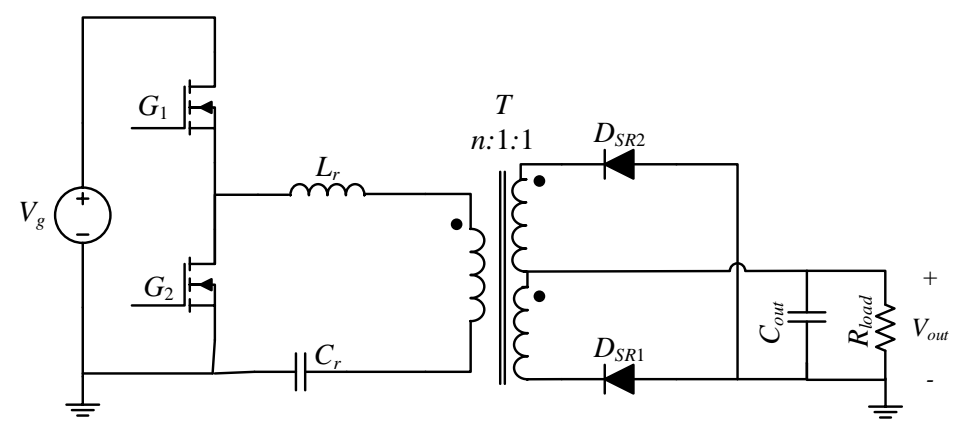

Figure 2-1: Circuit diagram of a half bridge Series Resonant Converter (SRC)

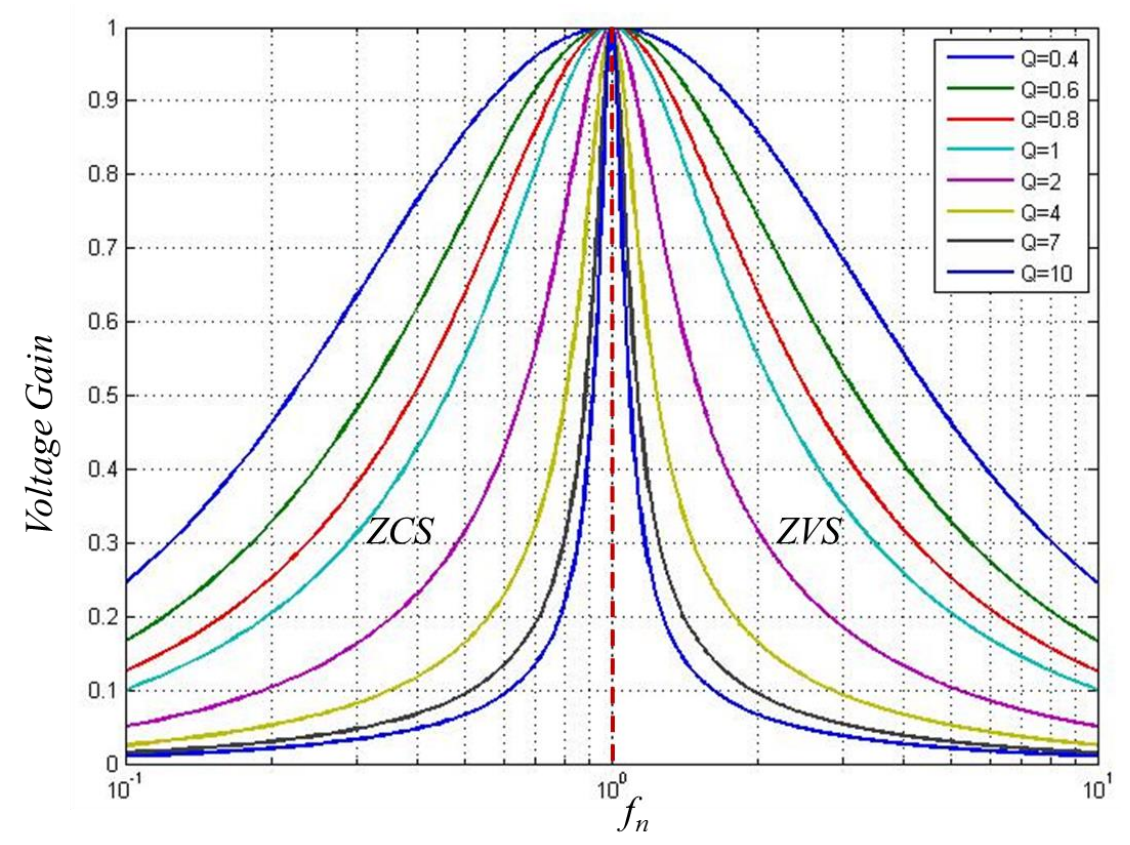

Figure 2-2: DC voltage gain characteristic of series resonant converter (SRC)

In this topology as it is shown in Figure 2-1 the resonant inductor $L_{r}$ and the resonant capacitor $C_{r}$ are in series. They form a resonant tank network which is in series with the load. It can be seen that the resonant tank and the load make a voltage divider. Therefore as it is shown in Figure 2-2 the dc gain for this topology is always less than one. By changing the switching frequency the impedance of the resonant tank changes. The minimum impedance happens at the resonant frequency, thus the dc gain of the SRC is one when the switching frequency is equal to the resonant frequency. 
It is known that the part of the dc characteristic with the positive slope is the zero-voltage switching (ZVS) region, and the part that has negative slope is the zero-current switching (ZCS) region [13]. Therefore SRC can achieve ZVS on the right side of the resonant frequency and ZCS on the left side. ZVS eliminates the switching losses in power switches or power MOSFET, therefore the preferred soft-switching mechanism of MOSFET devices is ZVS. It can be seen in Figure 2-2 that with load variation in order to regulate the output voltage, the switching frequency varies over a wide range of frequencies, especially at light load (smaller Q). This is the main disadvantage for the SRC.

Since it is known that the operation around the resonant frequency has the greatest efficiency, it is desired that converter operate close to the resonant frequency [13]. For a wide input voltage range, as the input voltage increases, in order to maintain the regulated voltage and remain in ZVS region, the converter has to operate of a higher switching frequency. As frequency increases, the impedance of the resonant tank increases, thus more energy circulates in the resonant tank, which increases the conduction losses.

Considering all above points, SRC is not the most suitable candidate for front end applications. Although this converter can achieve ZVS and therefore is able to reduce switching losses, it is not an optimal topology for wide input voltage range and variable load applications [13].

\subsubsection{Parallel resonant converter}

Figure 2-3 shows a circuit diagram of a half bridge parallel resonant converter (PRC) [13]. The normalized dc characteristic of PRC is shown in Figure 2-4 in which $f_{n}$ is the normalized switching frequency $\left(\frac{f_{s}}{f_{0}}\right)$, and $f_{0}=\frac{1}{2 \pi \sqrt{L_{r} C_{r}}}$ is the resonant frequency.

The resonant tank in PRC consists of a resonant inductor $L_{\mathrm{r}}$ and a resonant capacitor $C_{r}$ in series. It is called parallel resonant converter, because the resonant capacitor is in parallel with the load. Similar to SRC, the PRC can also achieve ZVS on the right hand side of the dc gain characteristic and ZCS on the left hand side. The major difference between these two topologies is, unlike SRC, PRC does not need to change the frequency over a wide range to regulate the output voltage. Therefore, the light load regulation problem doesn't exist in PRC. 
Although the PRC does not have problems in regulating the output voltage under no-load condition it has a disadvantage, that the primary side current is almost independent of the load condition. Since the load is in parallel with the resonant capacitor, even at no load condition, the input still sees a small impedance of the resonant tank. This cause a high circulating energy even at no load and light load condition, negatively affecting the efficiency.

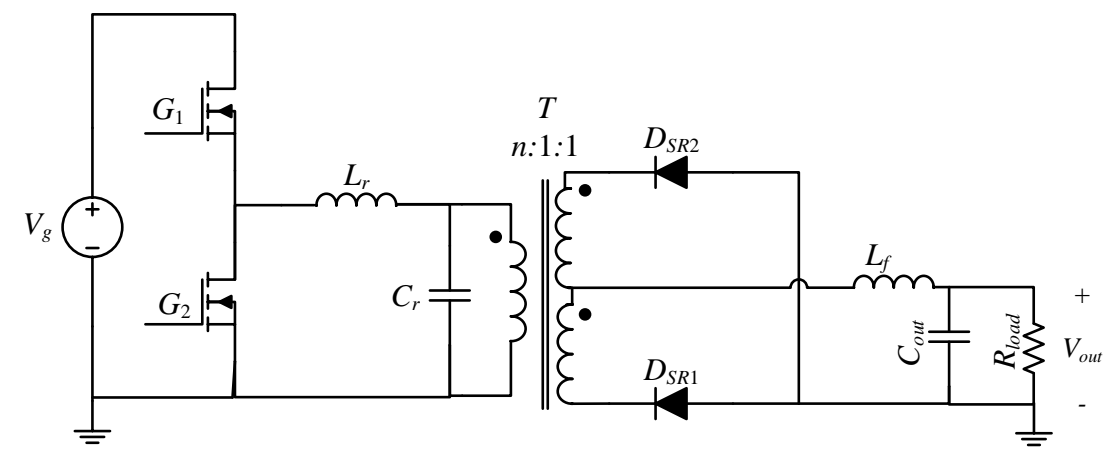

Figure 2-3: Circuit diagram of a half bridge Parallel Resonant Converter (PRC)

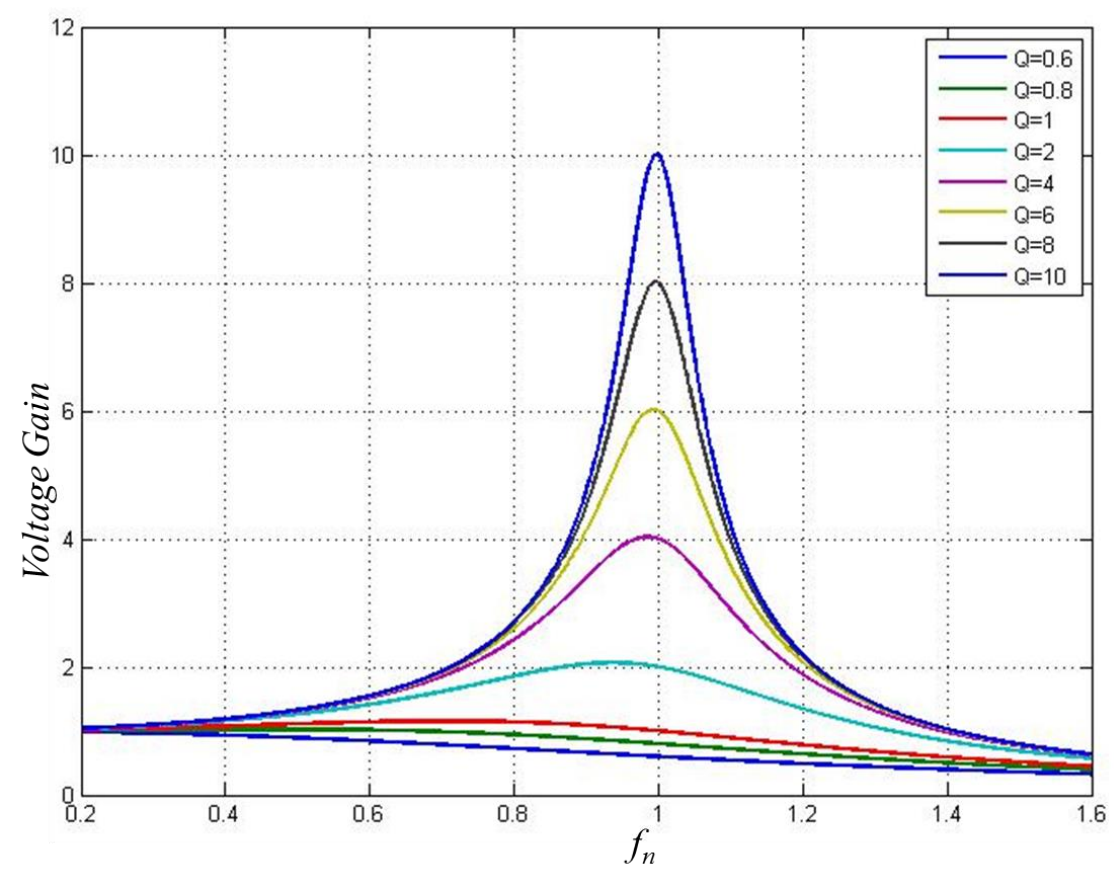

Figure 2-4: DC characteristic of Parallel Resonant Converter (PRC) 
Similar to SRC, PRC circulating current increases as input voltage increases so it is not a proper topology for the applications with wide range of input voltage.

\subsubsection{Series parallel resonant converter}

Series parallel resonant converters (SPRC) consist of three resonant components. They can be divided into two major categories, LCC and LLC. LCC resonant converters have two resonant capacitor and one inductor, and LLC resonant converters have one resonant capacitor and two inductors. Each category has several configurations, depending on the resonant components placement.

Figure 2-5 shows the circuit diagram for one configuration of a half bridge LCC resonant converter this topology consists of a resonant inductor $L_{r}$, resonant series capacitor $C_{s}$, and resonant parallel capacitor $C_{p}$. The normalized dc characteristic of the LCC resonant converter is shown in Figure 2-6. It can be seen that, depending on value of quality factor $Q$, more than one resonant frequency exists, where $Q$ is given with:

$$
Q=\frac{8 \sqrt{L_{r} / C_{r}}}{\pi^{2} n^{2} R_{\text {load }}}
$$

LCC resonant converter, combines advantages of PRC and SRC. The circulating energy is limited, since the load is in series with $L_{r}$ and $C_{s}$, therefore the performance of the LCC resonant converter is better than that of the PRC. Moreover, the parallel capacitor $C_{p}$ helps the LCC converter to regulate the output voltage at no load condition.

Similar to SRC and PRC, to achieve ZVS the LCC needs to operate on the right side of the resonant characteristic. At higher input voltages, the converter is operating at higher frequencies far away from resonant frequency. Similar to PRC and SRC with wide input range, the conduction loss and switching loss will increase at high input voltage.

Although the LCC resonant converter has smaller circulating energy compared to PRC and is not so sensitive to load changes as SRC, it is still not the optimal topology for the wide input voltage range applications. 


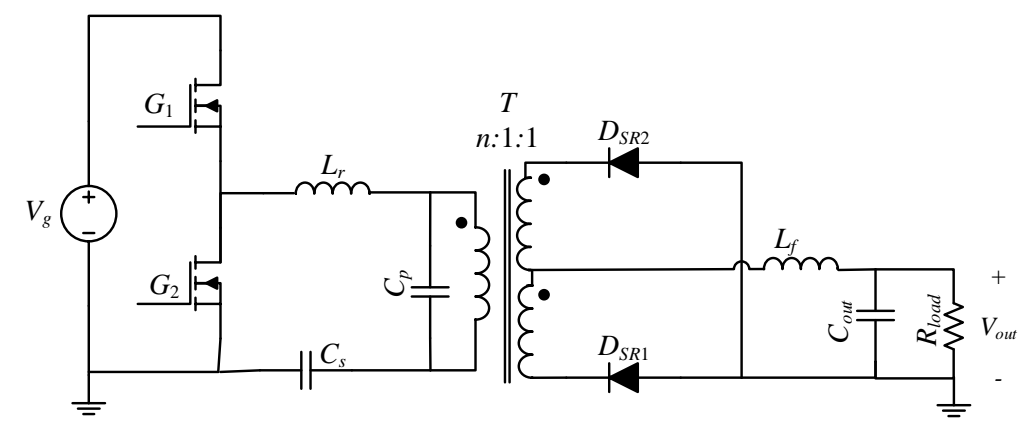

Figure 2-5: Half bridge SPRC, LCC resonant converter

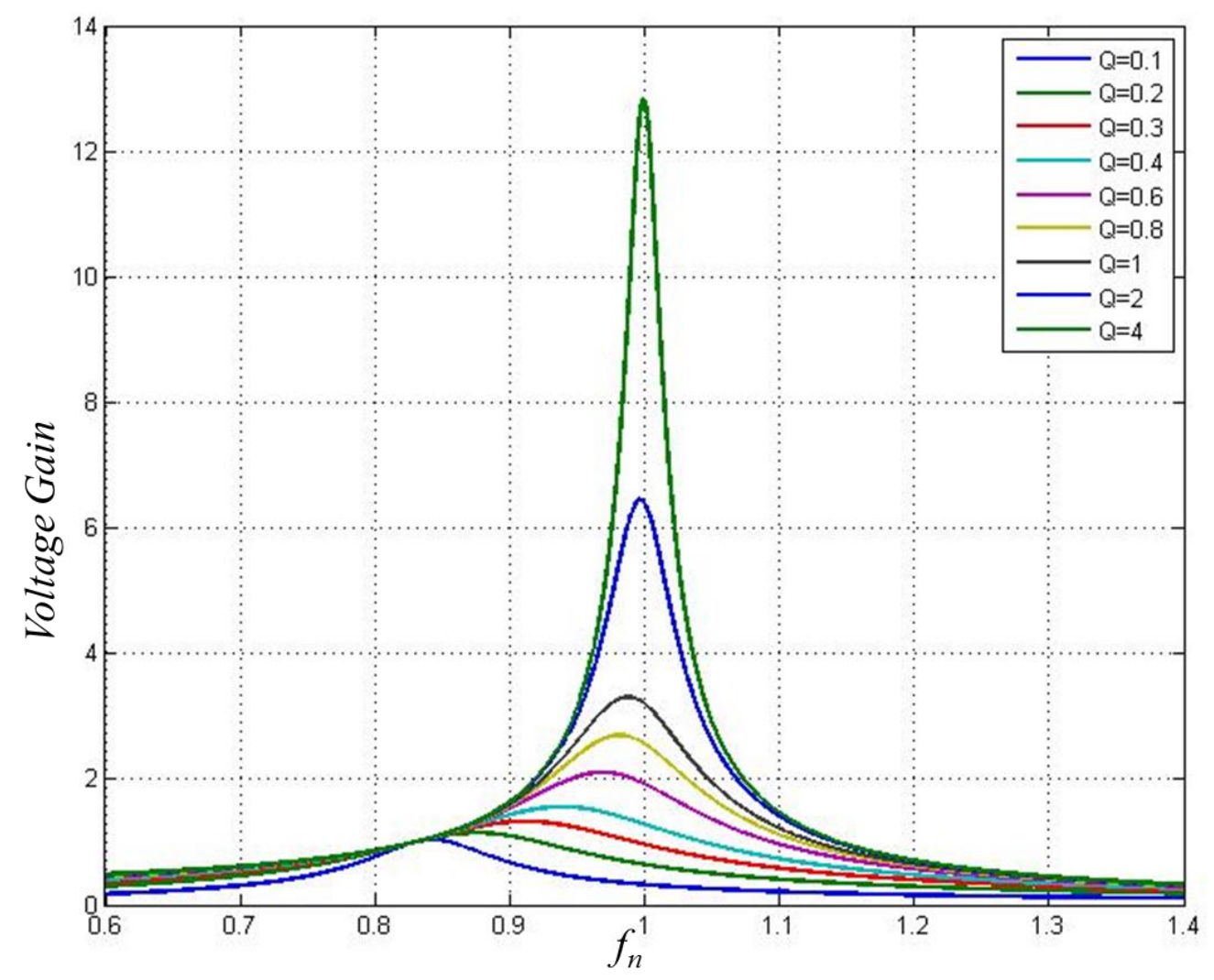

Figure 2-6: DC characteristic of LCC resonant converter

\subsection{LLC Resonant Converter Principles of Operation}

Figure 2-7 shows a half-bridge LLC resonant convert, in this topology the magnetizing inductance of the transformer is utilized as a resonant component. The LLC converter topology 
consists of resonant inductor $L_{r}$, resonant capacitor $C_{r}$, and magnetizing inductor $L_{m}$. There are two resonant frequencies for this converter, $L_{r}$ and $C_{r}$ determine the higher resonant frequency, $f_{0}$. The lower resonant frequency, $f_{p}$ is determined by $C_{r}$ and the series inductance of $L_{m}$ and $L_{r}$. The two resonant frequencies are:

$$
\begin{aligned}
& f_{0}=\frac{1}{2 \pi \sqrt{L_{r} C_{r}}} \\
& f_{p}=\frac{1}{2 \pi \sqrt{\left(L_{m}+L_{r}\right) C_{r}}}
\end{aligned}
$$

The quality factor $Q$ and the ratio $L_{n}$ between $L_{m}$ and $L_{r}$ are:

$$
\begin{aligned}
& Q=\frac{\sqrt{L_{r} / C_{r}}}{n^{2} R_{L}} \\
& L_{n}=\frac{L_{m}}{L_{r}}
\end{aligned}
$$

The normalized dc input-to-output voltage gain characteristic of the LLC resonant converter for different $Q$ is shown in Figure 2-8, in which $f_{n}$, the normalized switching frequency is defined as $f_{s} / f_{0}$. It can be seen from Figure 2-8 that the voltage gain is equal to one for all load conditions at the resonant frequency.

As shown in Figure 2-8 the dc input-to-output voltage gain characteristic of the LLC resonant converter can be divided into three regions, according to different modes of operation. First region is when the converter switching frequency is higher than the resonant frequency $f_{0}$. In this region the gain is always less than one, and the slope of the dc characteristic is negative. So, the zero-voltage switching (ZVS) for primary switches can be achieved. In the second region, the switching frequency is between two resonant frequencies. The gain in this region is more than one and similar to the first region the ZVS for primary switches can be achieved. In the third region the zero-current switching (ZCS) for the primary switches is achievable since the slope of 
the dc characteristic is positive in this region. For MOSFETs, the ZVS operation is preferred so the desired operating regions are 1 and 2. Since ZVS is not achievable in region 3, the converter should be prevented from entering this region.

Figure 2-9 shows the LLC resonant frequency waveforms while the converter works at resonant frequency. It can be seen from Figure 2-9, that the operation of the LLC converter can be divided in six time intervals. The converter's equivalent circuits are shown in Figure 2-10.

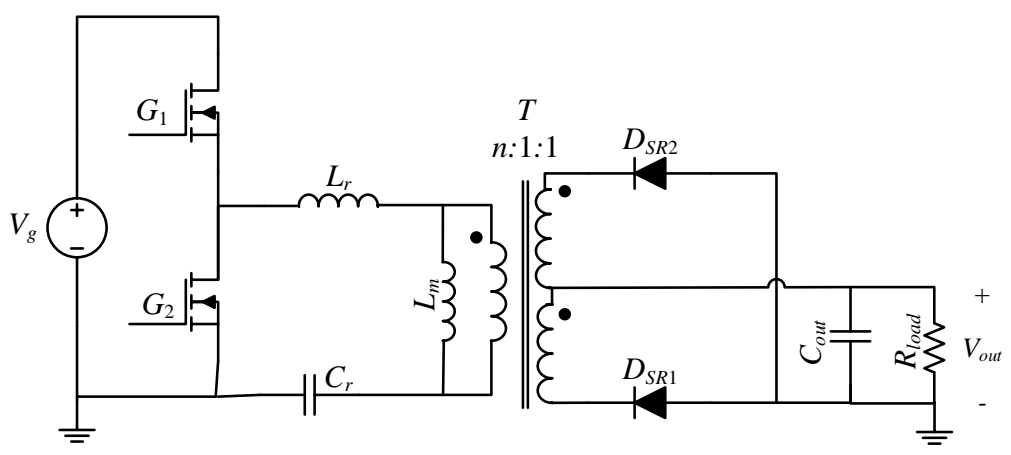

Figure 2-7: Half-bridge LLC resonant convert

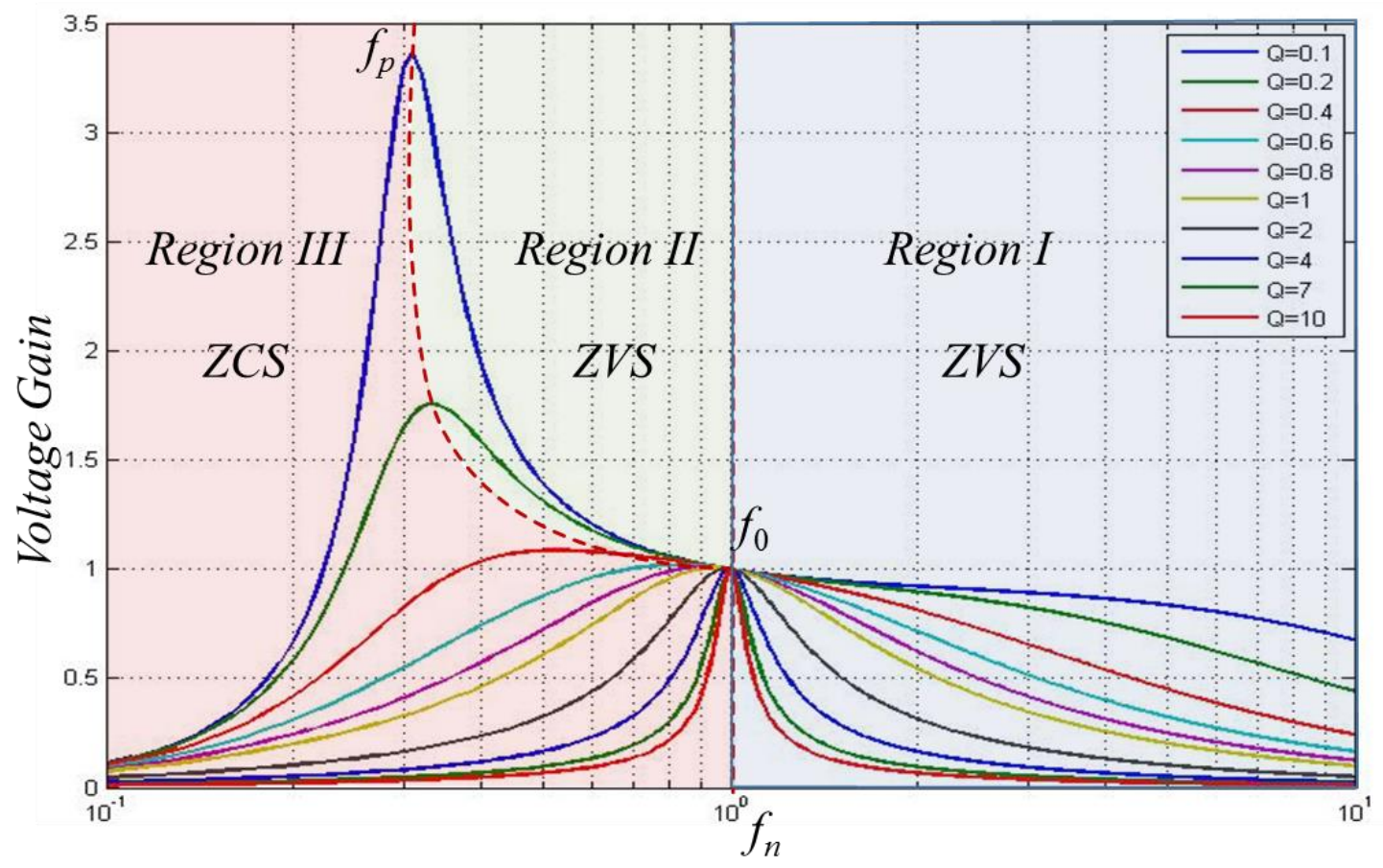

Figure 2-8: DC characteristic of LLC resonant converter 


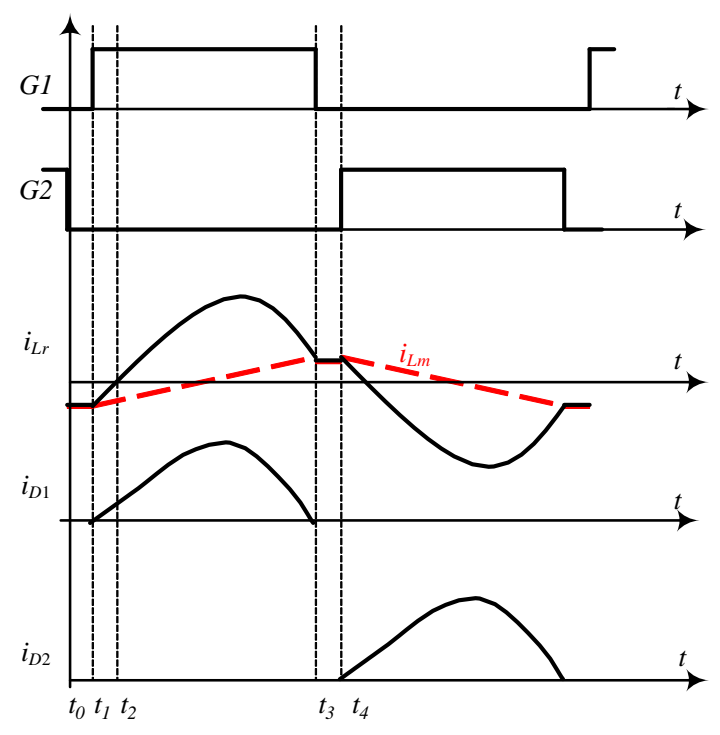

Figure 2-9: LLC resonant converter waveforms at the resonant frequency

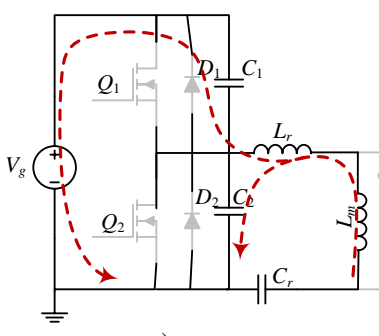

a)

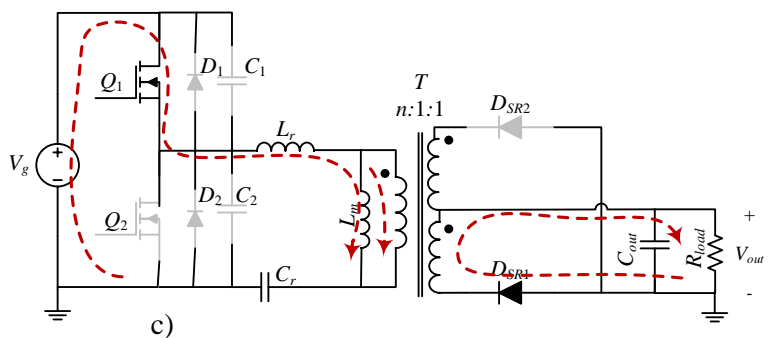

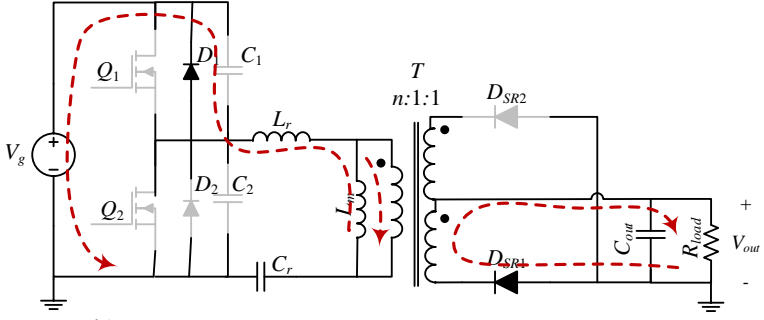

b)

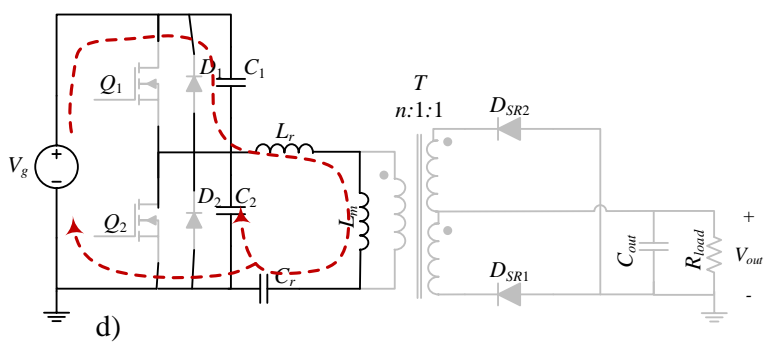

Figure 2-10: LLC resonant converter equivalent circuits operating below resonance.

Between time $t_{0}$ and $t_{1}$, is non-overlapping time. Figure 2-10-a shows the equivalent circuit during this time interval. Both switches on the primary side are in off state and zero current goes through the secondary side. During this time interval magnetizing current on the primary will discharges $C_{1}$ and charges $C_{2}$. 
Figure 2-10-b shows the time interval between $t_{1}$ and $t_{2}$. The body diode of the primary switch $Q_{1}$ is conducting. On the secondary side, the diode $D_{S R 2}$ is conducting. Switch $Q_{1}$ can be turned off at any time during this interval and ZVS can be achieved.

As it shown in Figure 2-10-c, during time interval between $t_{2}$ and $t_{3}$, switch $Q_{1}$ and diode $D_{S R 1}$ are conducting. Power transfer from the primary side to the output load takes place during this time interval. Also the constant output voltage $\left(V_{\text {out }}\right)$ is reflected on the primary, generating the linearly increasing magnetizing current $i_{L m}$. Once the resonant tank current reaches the magnetizing current so the current through $D_{S R 1}$ is zero this interval ends with ZCS. The next half switching cycle is similar to the first half cycle.

While operating at resonant frequency, LLC resonant converter primary side switches turn off time instance is the same time that the resonant tank current needs to reach the magnetizing current, labeled as $t_{3}$.

All previous analysis is for the converter operation at resonant frequency. In the following the differences of the circuit behavior when the converter operates above and below resonance are studied. The LLC resonant waveforms for operation below the resonant frequency are shown in Figure 2-11, and 2-12 respectively.

For the case when converter operates below resonance, fundamental sine wave has a shorter period than that of the switching frequency. The secondary side current reaches zero at $t_{3}$, before the primary switch turns off. After this time, the resonant capacitor forms a resonant circuit with the tank inductor in series with the magnetizing inductor and the current going through the primary is that of the magnetizing current.

For the case that converter operates above resonance, the resonance period is longer than that of the switching period. At the end of a switching half period the tank current is higher than the magnetizing current. This current difference depends on the load condition and the distance of the switching frequency from the resonant frequency. During the dead time interval, the tank current falls rapidly to the value of the magnetizing current. 


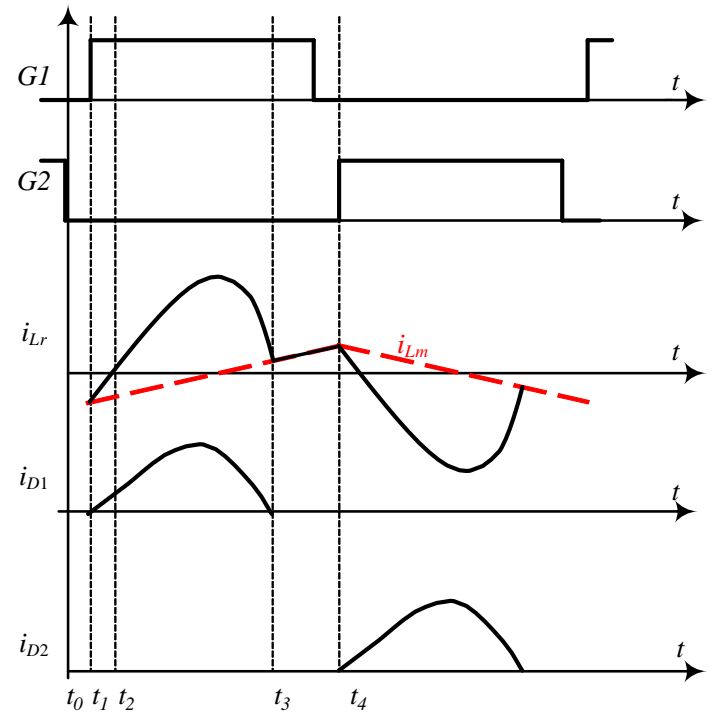

Figure 2-11: LLC resonant converter waveforms operating below the resonant frequency.

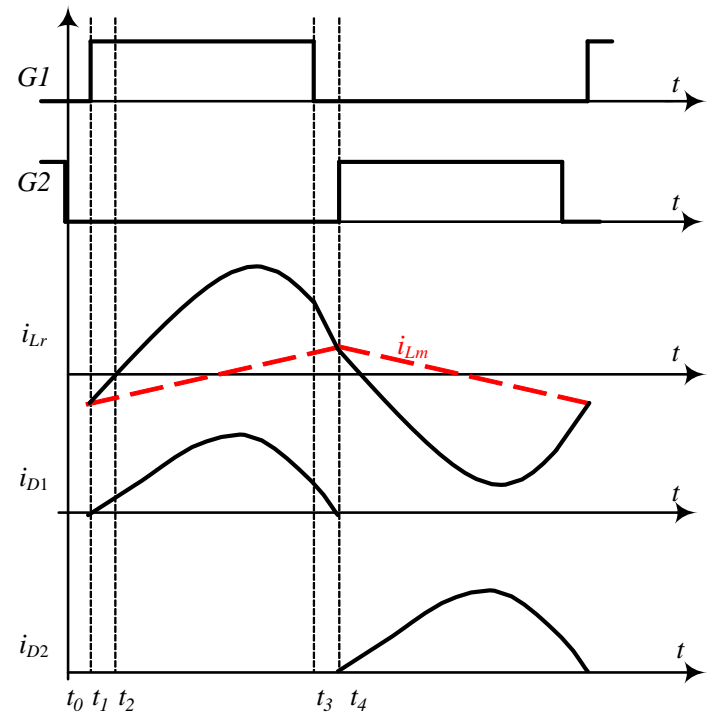

Figure 2-12: LLC resonant converter waveforms operating above the resonant frequency. 


\section{Chapter 3}

\section{Auto-Tuned Minimum-Deviation Digital Controller for LLC Resonant Converters}

In this chapter, a simple digital controller for the LLC resonant converter is introduced. During the steady state, a linear compensator (PID) controls the switching frequency $\left(f_{s}\right)$, to eliminate the steady-state error. During transients the controller applies a two-step frequency change algorithm, such that minimum deviation from the desired output voltage and a seamless transition to the new steady state is achieved. The introduced solution is implemented with an experimental prototype. Obtained experimental results show significant improvement compared to a conventional analog controller.

\subsection{Introduction}

The LLC isolated resonant converters are widely used in dc-dc applications where there is a need to step down high input voltage to a much lower level. As mentioned before, the most common example include front-end dc-dc stages reducing a high voltage obtained from a PFC rectifier to a bus voltage level, for consumer electronics, computers, and telecom applications. The LLC converters are widely adopted because of their high efficiency, high power density, and low electromagnetic interference (EMI) emissions [1-3]. If properly controlled, LLC converters can achieve narrow switching frequency range, zero voltage switching (ZVS) of primary side switches, and zero current switching (ZCS) of secondary switches (or rectifier diodes) [4-6]. By eliminating the need for magnetics on the secondary side, these converters also

minimize stress on rectifier diodes [1],[2]. However, since dynamic characteristic of LLC converters change with operation conditions [3], their control is more challenging than that of conventional hard-switching solutions. Conventional methods such as state space averaging 
have failed to model LLC resonant converters accurately because of the largely varying characteristic with operating condition [3]. Commonly, simulation based methods [2] have been utilized to design linear PID compensator based controllers with fairly low-bandwidth, which provide stability over the full range of operating conditions [2]. The main drawback of this design is a requirement for a large output filter capacitors and, in some cases, increased current and voltage stress of the components [1].

To improve dynamic performance of LLC converter controllers, a number of methods [4-6] have been proposed in the past. Among the most effective are proximity time-optimal controllers, namely the simplified optimal trajectory controller [6] and the sliding mode controller [5]. These controllers achieve virtually the fastest possible response and, therefore, a small output voltage deviation for step changes, allowing for a drastic reduction of the output capacitor. However, the optimal controllers have not been widely adopted, mostly due to relatively high complexity of implementation and, in some cases, sensitivity to converter parameter variations [6]. These digital controllers require costly sensors for fast and accurate current measurement and complex calculation of frequency-changing pattern during transients.

It this thesis a digital controller is introduced that, practically results in the smallest possible output voltage deviation without a need for costly current sensors or complex calculations. The new controller, whose simplified diagram is shown in Figure 3-1, operates in two modes. In steady-state it works as a conventional frequency-regulated voltage mode controller. Once a transient is detected, the key element of the new controller, the transient suppression block, is activated. Based on the output voltage measurements only, this block makes two successive frequency step changes to get to the new steady state. In the first step the effect of the load change on the output capacitor current is reversed in the fastest possible manner. The frequency corresponding to the new steady state is set in the second step.

The first frequency step is calculated from the initial voltage deviation caused by a load transient and adjusted through an auto-tuning process. The new steady state frequency resulting in a bump-less transition from the transient mode is calculated from the ripple measurements. The transient suppression method, which will be described in the following section, is insensitive to converter parameter variations and requires simple hardware for implementation. 


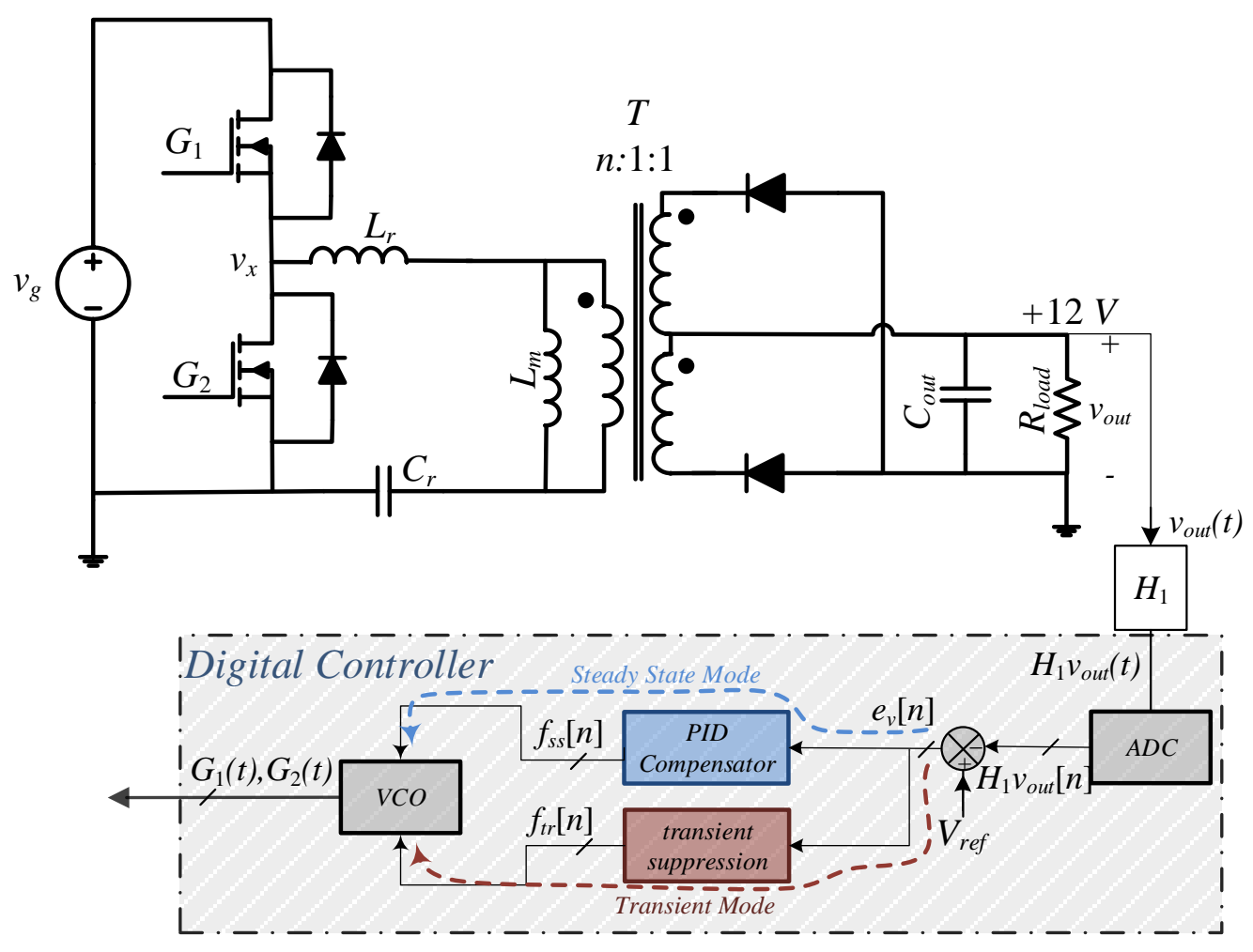

Figure 3-1: LLC resonant converter with PID and transient suppression controller.

\subsection{Principle of Operation}

The operation of the transient suppression logic, which is the key novelty of the controller, is inspired by the minimum deviation method for hard switching converters presented in [13], [14]. Similar to the previous solutions, the goal of obtaining the minimum output voltage deviation is achieved through reversing the output capacitor charging/discharging process until the capacitor voltage deviation, i.e. its derivative, changes the sign and the peak/valley point is detected. At that extreme point the inductor current of the system is also brought to its new steady state and the steady-state PID compensator is reprogrammed and reactivated.

For the LLC converter, which key waveforms during transient are shown in Figure 3-2, the implementation of the minimum deviation method is more challenging than for the hard switching solutions. This is because the relation between the inductor and capacitor charging/discharging current is more complex. Another problem is that, unlike in hard switching 
voltage mode solutions, where for constant input voltage the duty ratio in steady states before and after transient does not change much, the steady-state control variable for the LLC controller varies significantly. As it can be seen from Figure 3-2, the switching frequencies prior to the load transient and in the new state after the transient has been suppressed are not the same. Achieving seamless transition from transient to the new steady state mode is thus more challenging since the control variable value from the prior steady state cannot be directly used.

The operation of the introduced minimum-deviation LLC controller can be explained by looking at the diagram of Figure 3-1 and waveforms of Figure 3-2. The transient suppression block changes the switching frequency of the system after detecting the transient based on the initial voltage deviation $\Delta v_{\text {out }}$. This initial value is used to determine the size of the first frequency step $f_{t r}$ in the recovery process.

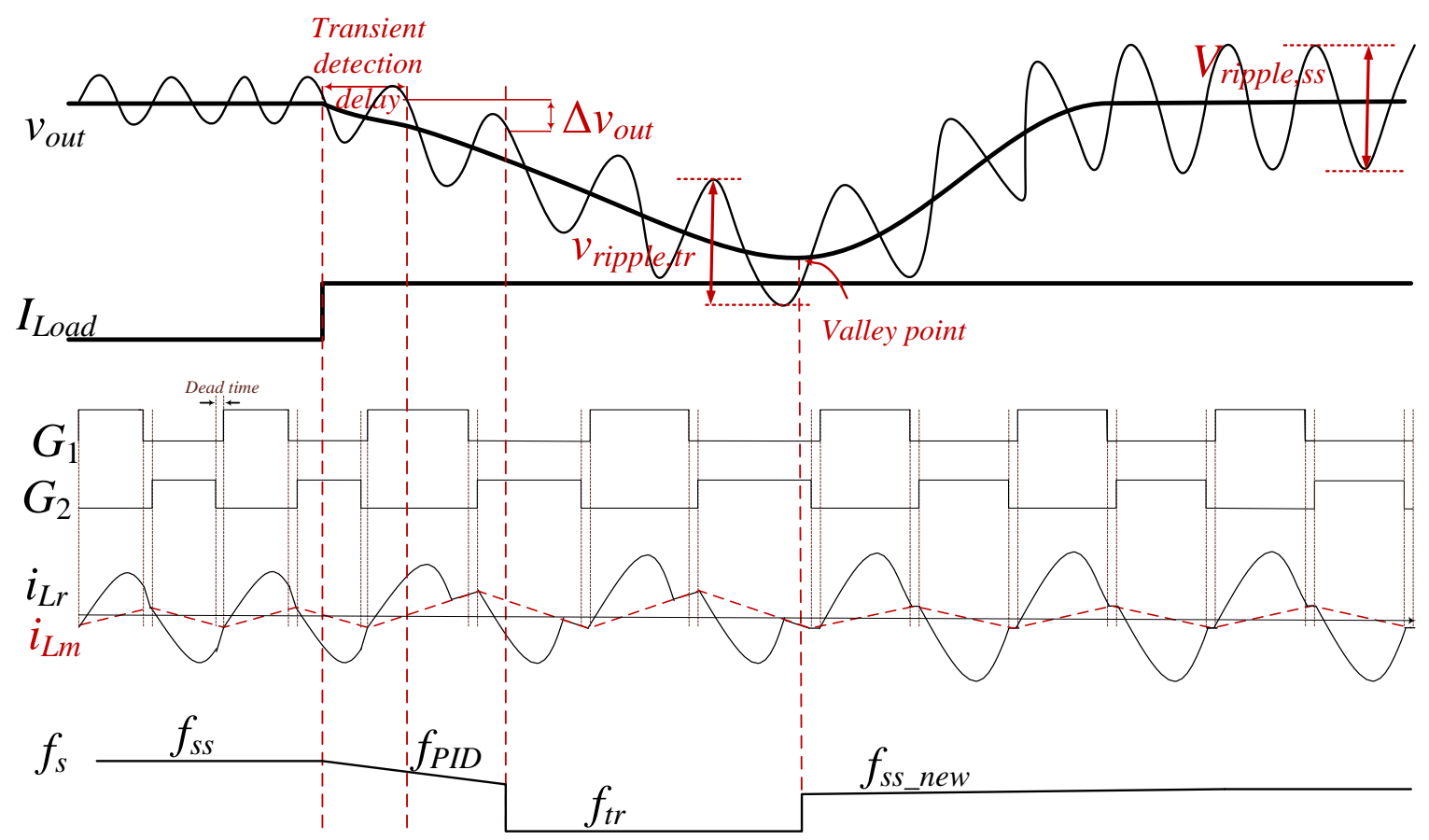

Figure 3-2: Key waveforms of LLC resonant converter during transient. Waveforms from top to bottom: output voltage; load current; switching signals; tank and magnetizing inductor current; and switching frequency 
The value $\Delta T$, changing in pulse width, is calculated starting from the analysis presented in [6]. The complete derivation is given in Appendix A. There, it is shown that the pulse width change for light-to-heavy load transients and the new pulse width for heavy-to-light load transients of a LLC converter resulting in a one-step recovery of the inductor current are:

$$
\begin{aligned}
& \Delta T_{L H, \text { max }}=\frac{L_{m}}{n V_{g}} \Delta I_{L} \quad \text { and } \\
& T_{H L, \text { max }}=\left(1+\sqrt{\frac{I_{L L}}{I_{H L}}}\right) \frac{T_{s}}{4},
\end{aligned}
$$

where $T_{s}$ is the switching period before the transient, $\Delta I_{L}$ is the load step, while, $I_{L L}$ and $I_{H L}$ are load current values at light load and heavy load, respectively. (3-2) can be modified to:

$$
T_{H L, \text { max }}=\frac{T_{s}}{4}\left(1+\sqrt{1 /\left(1+\frac{\Delta I_{L}}{I_{L L}}\right)}\right) .
$$

Also the output current is related to the voltage,

$$
\Delta v_{\text {out }, t r}=\frac{T_{s}}{C_{\text {out }}} \Delta I_{L},
$$

where $\Delta v_{\text {out tr }}$ is the initial voltage deviation caused by the transient and $C_{\text {out }}$ is the output capacitor value.

Form Figure 3-3 load current can be calculated based on voltage ripple ( $\left.\Delta v_{\text {ripple }}\right)$ and the value of the output capacitor which can be calculated from the capacitor charge, $Q . \Delta v_{\text {ripple }}$ in Figure 3-3 is the output voltage difference between two extreme points, point $a$ and point $b$. Points $a$ and $b$ can be determined from solving the derivative of the output voltage equal to zero. The output voltage is:

$$
v_{\text {out }}=v_{c}+E S R i_{c}
$$

Solving vout knowing 


$$
v_{c}=\frac{1}{C} \int i_{c} \cdot d t
$$

$v_{\text {out }}$ can be written as:

$$
v_{\text {out }}=\frac{I_{L}}{C}\left(\frac{-\pi}{2 \omega} \cos \omega t-t+\frac{\pi}{2 \omega}\right)+\operatorname{ESRI}_{L}\left(\frac{\pi}{2} \sin \omega t-1\right)+V_{0}
$$

As it mentioned earlier to find the voltage ripple the points that derivative of output voltage is equal to zero needs to be calculated. The output voltage derivative is:

$$
\frac{d v_{\text {out }}}{d t}=\frac{I_{L}}{C}\left(\frac{\pi}{2} \sin \omega t-1\right)+E S R \cdot I_{L} \cdot \frac{\pi \omega}{2} \cos \omega t
$$

To simplify the equations $\mathrm{E}$ is defined as:

$$
E=C . E S R . \omega
$$

Solving $\frac{d v_{\text {out }}}{d t}=0$, points $a$ and $b$ are determined.

$$
\begin{aligned}
& a=\frac{1}{\omega} \cos ^{-1}\left(\frac{\frac{2}{\pi} \cdot E+\sqrt{E^{2}+1-\frac{4}{\pi^{2}}}}{\left(E^{2}+1\right)},\right. \\
& b=\frac{1}{\omega} \cos ^{-1}\left(\frac{\frac{2}{\pi} \cdot E-\sqrt{E^{2}+1-\frac{4}{\pi^{2}}}}{\left(E^{2}+1\right)}\right)
\end{aligned}
$$

Knowing points $a$ and $b, \Delta v_{\text {ripple }}$ can be written as:

$$
\begin{aligned}
& \Delta v_{\text {ripple }}=\frac{I_{L} T_{s}\left[\frac{-\pi \sqrt{E^{2}+1-\frac{4}{\pi^{2}}}}{2 \pi C}-\cos ^{-1}\left(\frac{\frac{2}{\pi} \cdot E+\sqrt{E^{2}+1-\frac{4}{\pi^{2}}}}{\left(E^{2}+1\right)}\right)+\cos ^{-1}\left(\frac{\frac{2}{\pi} \cdot E-\sqrt{E^{2}+1-\frac{4}{\pi^{2}}}}{\left(E^{2}+1\right)}\right)\right.}{\left.+\frac{E \pi}{2} \cdot \frac{\sqrt{E^{4}+E^{2} \cdot\left(1-\frac{4}{\pi^{2}}\right)+\frac{4}{\pi^{2}}-\frac{4}{\pi} E \sqrt{E^{2}+1-\frac{4}{\pi^{2}}}}-\sqrt{E^{4}+E^{2} \cdot\left(1-\frac{4}{\pi^{2}}\right)+\frac{4}{\pi^{2}}+\frac{4}{\pi} E \sqrt{E^{2}+1-\frac{4}{\pi^{2}}}}}{\left(E^{2}+1\right)}\right]}
\end{aligned}
$$


Since in the experimental setup the ESR is negligible compare to the capacitor size, to find the approximate relation between voltage ripple and capacitor charge from the above equation, ESR is assumed to be zero. The complete derivations are given in appendix C. Through graphical analysis of the waveforms an approximate relation between the lost charge and the new load current value can be found as:

$$
Q \approx \frac{T_{s}}{9.5} I_{L}
$$

so,

$$
\Delta v_{\text {ripple }} \approx \frac{T_{s}}{9.5 C_{\text {out }}} I_{L}
$$

Replacing (3-4) and (3-14) in (3-1) and (3-3), the pulse width variation for light to heavy and the new pulse width for heavy to light load transient based on voltage deviation after transient and voltage ripple are calculated:

$$
\begin{gathered}
\Delta T_{L H}=\frac{L_{m} C_{\text {out }}}{T_{s} n V_{g}} \Delta v_{\text {out }, \text { tr }}=K f_{s} \Delta v_{\text {out }, t r} \\
T_{H L} \approx \frac{T_{s}}{4}\left(1+\sqrt{1 /\left(1+\frac{\Delta V_{\text {out }, \text { tr }}}{9.5 \Delta V_{\text {ripple }}}\right)}\right)
\end{gathered}
$$

Which $K$ is a constant that depends on converter parameters, and will be determined through an auto tuning process. It can be seen from (3-15) that, in order to calculate $\Delta T_{H L}$ (change of switching period) after finding the value of $K$, only a simple multiplication needs to be performed.

As it is shown in Figure 3-4 the term

$$
Y=1+\sqrt{1 /\left(1+\frac{x}{9.5}\right)}
$$



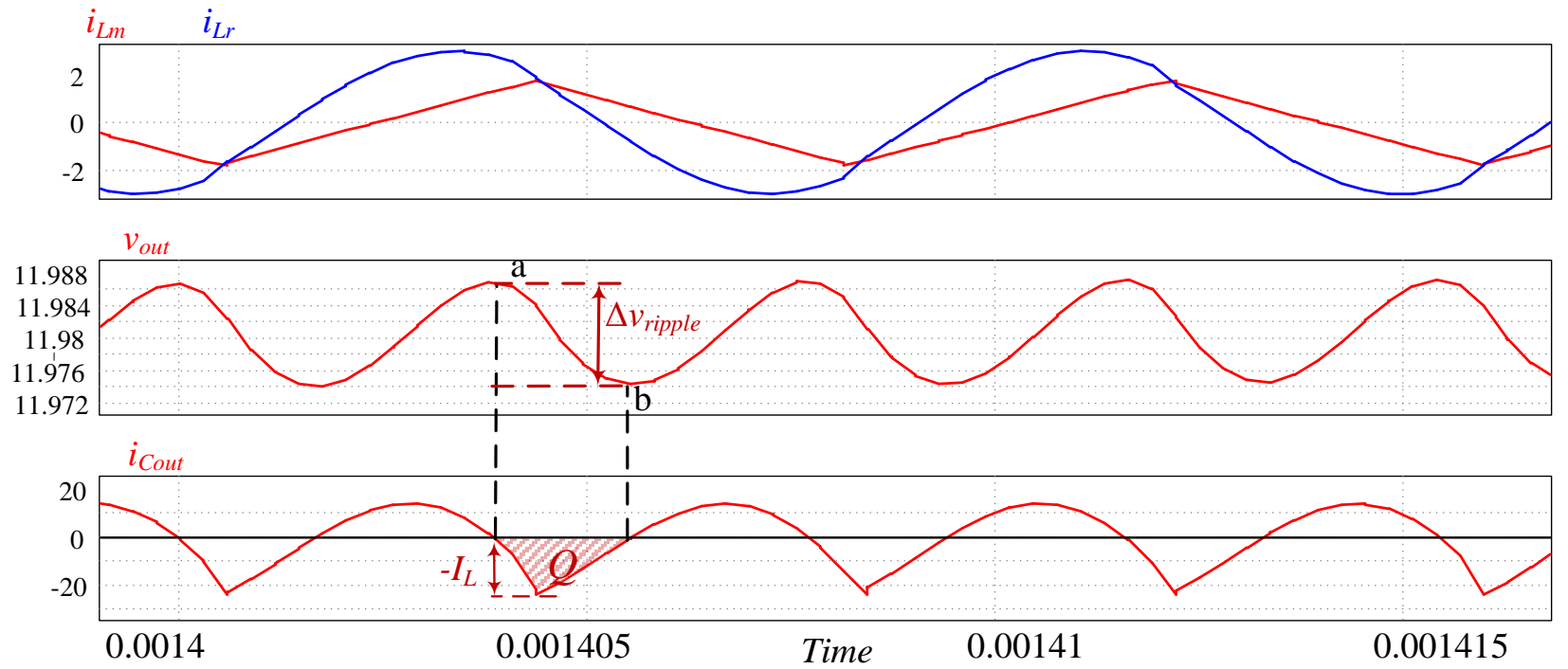

$(s)$

Figure 3-3: Magnetizing and tank current, output capacitor voltage, and output capacitor current waveforms from simulation

in equation (3-16), where $x$ is $\Delta v_{\text {out,tr }} / \Delta v_{\text {ripple, }}$, can be approximated by sampling the curve and interpolating linearly between the points.

At the extreme point, after a transient, PID compensator is enabled and takes over the task of the output voltage regulation. Since the switching frequency in the new steady state, and therefore the output of the PID, will be significantly different from those before the transient, reinitialization of the PID is necessary. As it will be shown in Chapter 5, without re-initialization the PID would restart from a wrong output value and cause sub-transients negatively affecting stability of the system.

To re-initialize the PID it has been recognized here that the ripple value at the extreme point, i.e. at the peak or valley is equal to that of the new steady state, as illustrated in Figure 3-2. This fact is utilized here. At the extreme point the output voltage ripple $v_{\text {ripple }}$ is measured and from the self-populating look up tables (LUT) the new initial value for the PID is determined. The LUT then is self-populated based on the output voltage ripple once voltage reaches the steady state $v_{\text {ripple,ss. }}$ Additional details on the operation of this block are given in the following subsection. 


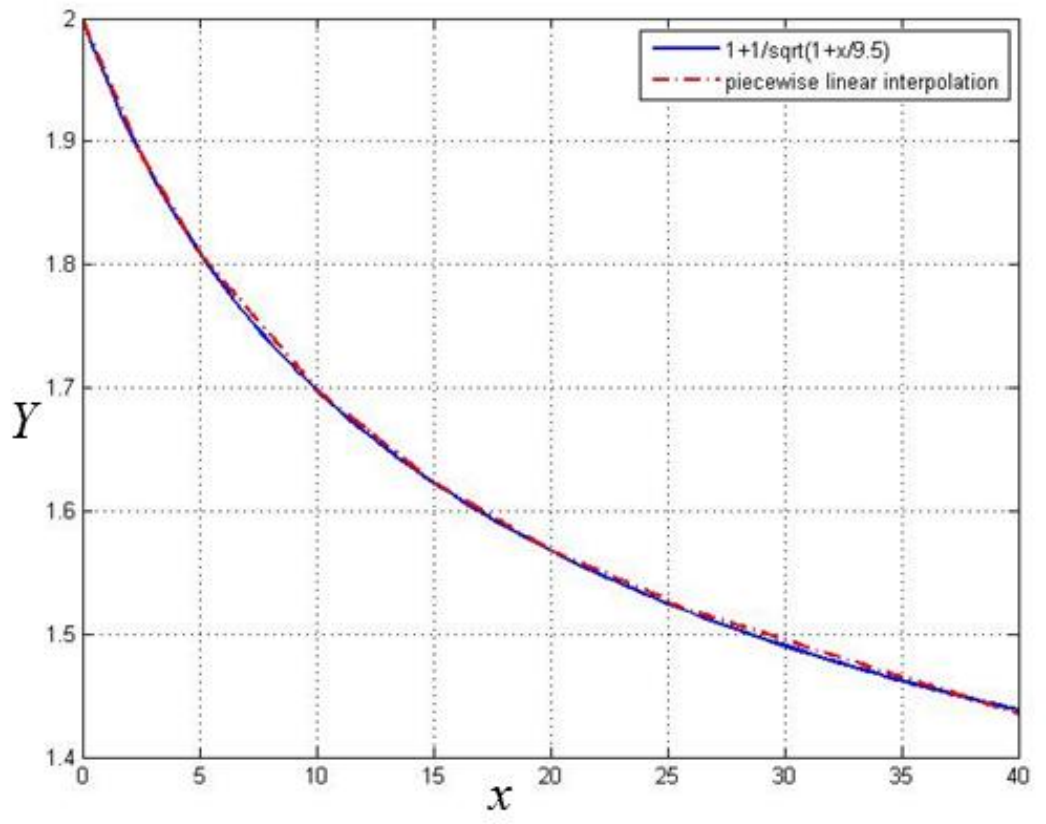

Figure 3-4: Comparison between function $\mathrm{Y}$ of equation (3-17) and its approximated piecewise linear interpolation. 


\subsection{Practical Implementation}

The hardware implementation of the controller is shown in Figure 3-5 and the control algorithm is described with the flowchart of Figure 3-6. As shown in Figure 3-5, in order to produce the gating signals, the controller uses a voltage-controlled oscillator (VCO), which depending on the operating conditions, receives the control variable, $f_{s}[n]$, either from the PID compensator or the transient suppression block. During normal operation, the PID controller is enabled and the analog-to-digital converter (ADC) samples the output voltage once per switching cycle. After a transient is detected by the transient detection block, the ADC starts oversampling. Based on the polarity of the voltage deviation the controller determines whether the transient is heavy to light or light to heavy and selects the frequency sequence calculation protocol accordingly.

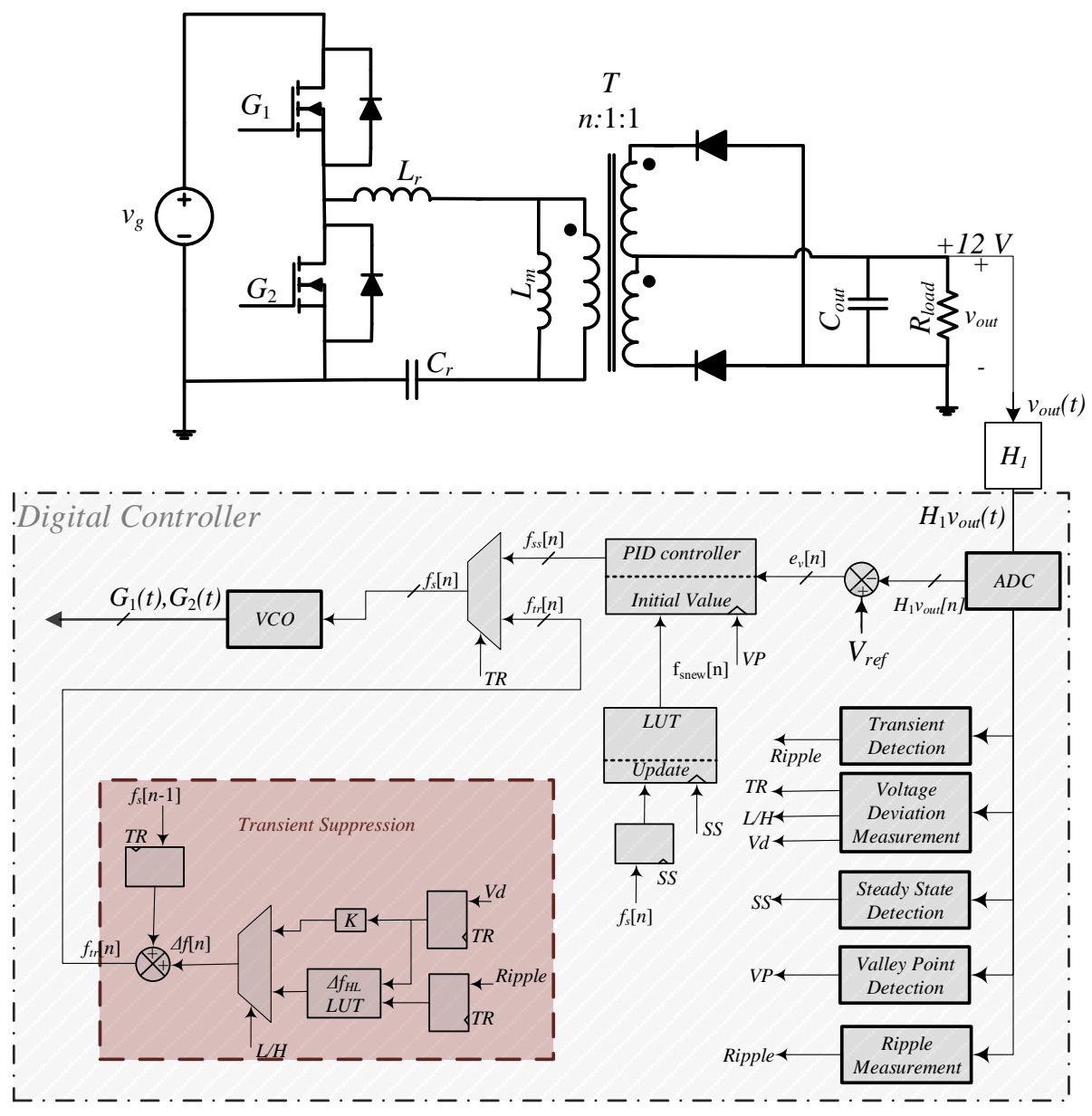

Figure 3-5: LLC resonant converter block diagram with detailed controller blocks. 
In the case of a light to heavy transient, $\Delta T_{L H}$ is determined from (3-15) and the value $K$ is determined through an auto-tuning process. The controller flowchart for tuning $K$ is shown in Figure 3-7. The change of switching period $\Delta T_{L H}$ is calculated and the new switching period is applied in the first switching cycle. If in the next switching cycle transient suppression block is still active, it means the voltage has not reached its extreme point and the counter is increase by one. This means the initial value of $\Delta T_{L H}$ was not sufficient for the system to get to the new state within one cycle. Therefore the value of $K$ needs to be updated for the next occurrence of the transient that does not need to be of the same value.

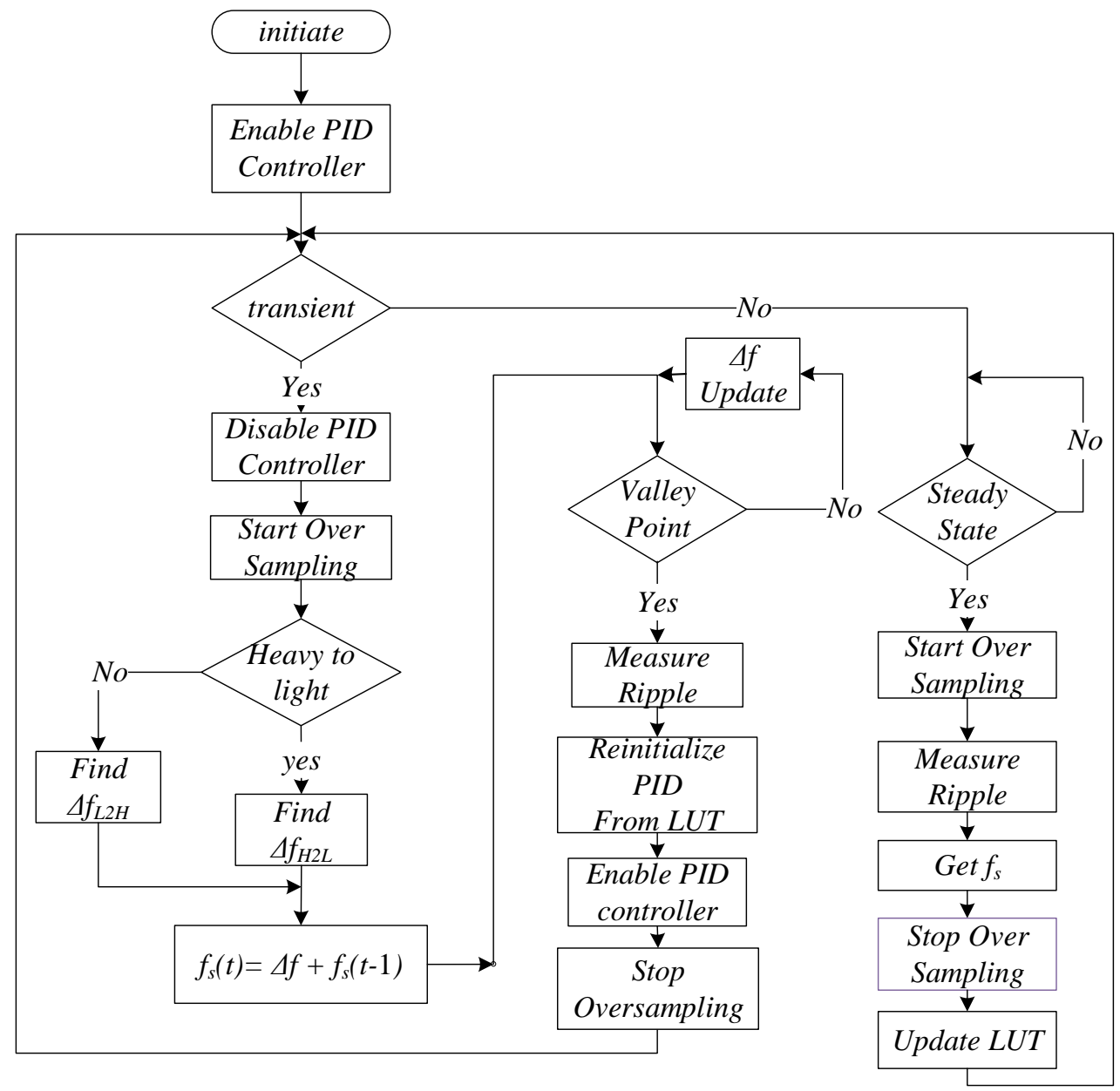

Figure 3-6: Controller flowchart 


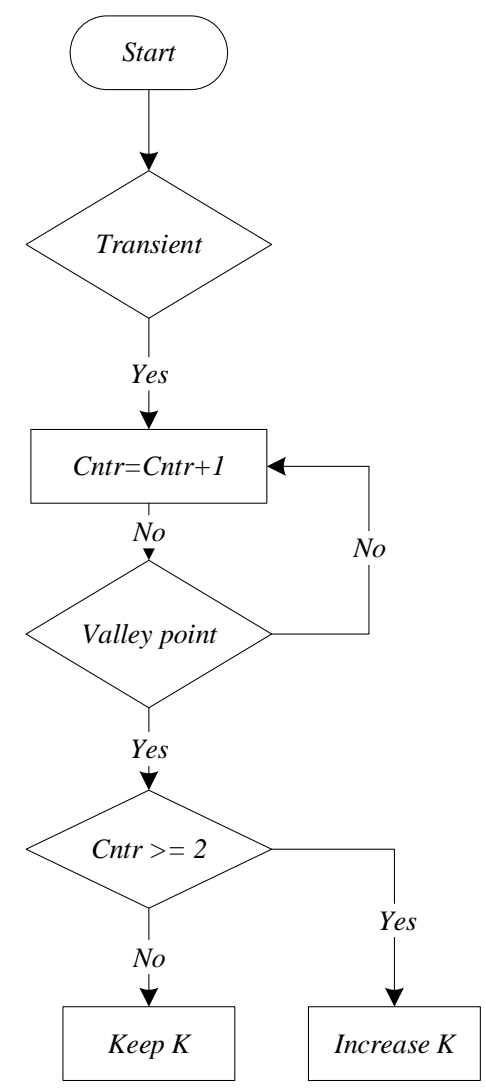

Figure 3-7: Auto-tuning flowchart of factor $K$

In the case of a heavy to light load transient, the value of $\Delta T_{H L}$ is determined utilizing a LUT. Transient suppression logic remains active until the voltage reaches its valley point. At this point the ADC stops over sampling and the PID is restarted with the new initial frequency. As mentioned before, the PID uses the initial value from a lookup table upon starting. At the time in which system gets to steady state operation, and remains in steady state for at least 10 cycles, the value of output voltage is used to update the LUT entries.

\subsection{Simulation Results}

The simulation result of Figure 3-8 and Figure 3-9 show the transient response of the system with a well-tuned PID compensator and the introduced controller respectively. The simulation results show that the system reaches the new steady state with the introduced controller in few switching cycles and, also that the voltage deviation is improved compared to the PID controller. 

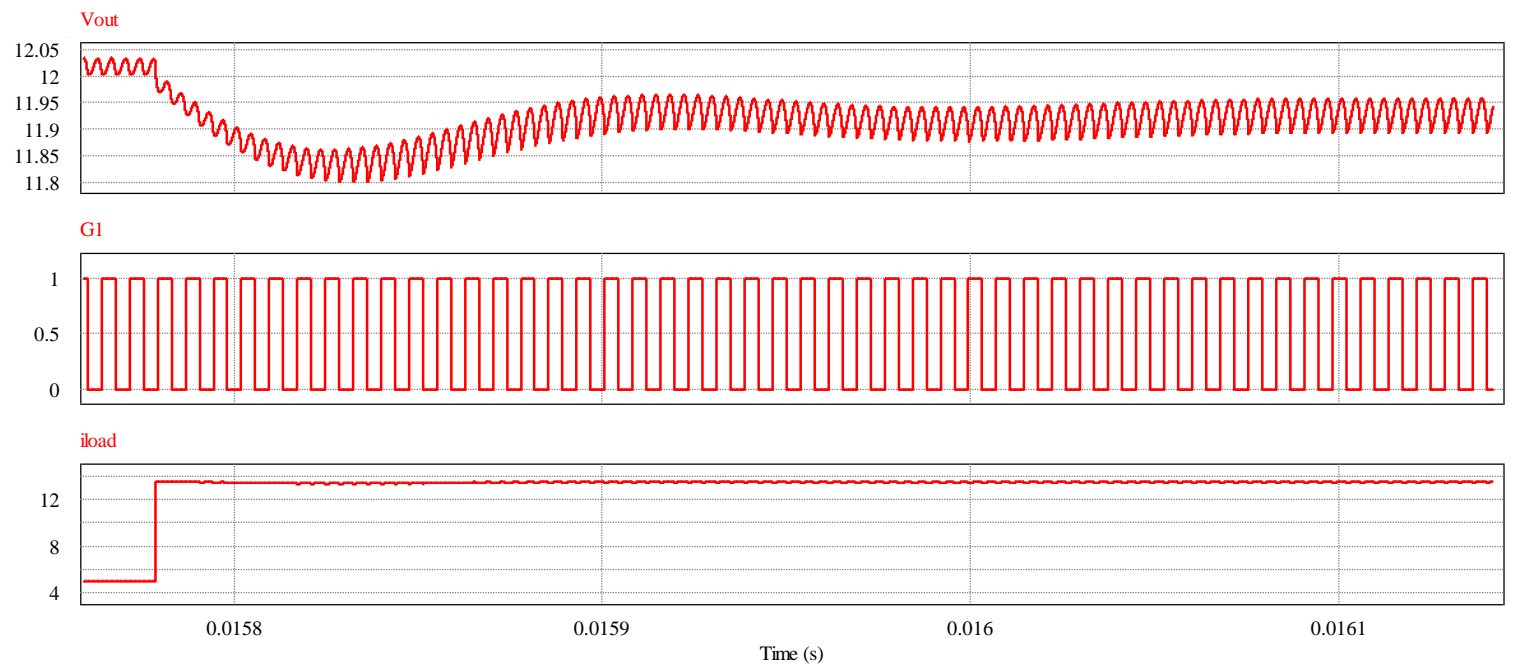

Figure 3-8: Simulation results for a light to heavy load transient with a well-tuned PID compensator.

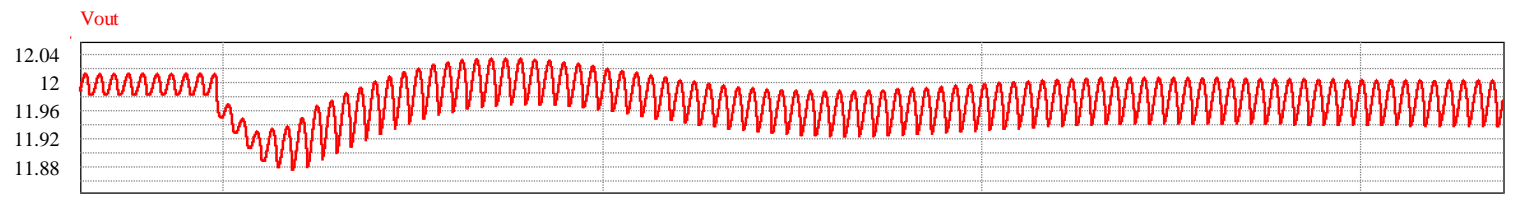
G1
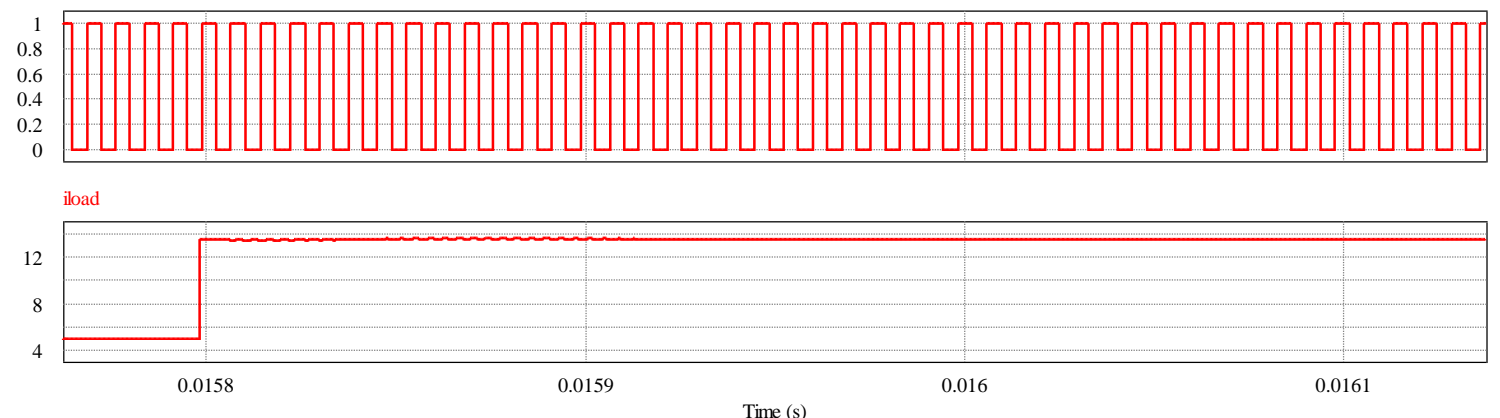

Figure 3-9: Simulation results for a light to heavy load transient with the introduced controller. 


\section{Chapter 4}

\section{Digital Synchronous Rectification Controller}

In this chapter a robust, hardware efficient, mixed-signal in addition to the previously presented control loop is introduced. It governs the switching actions of the secondary-side synchronous rectifier (SR) switches of LLC resonant converters. The new SR timing controller method minimizes switching and conduction losses of the SR switches through online optimization of their on-off timing, using an auto-tuning process that takes into account the effect of parasitic elements, mainly leakage inductances. In this controller, body diode conduction detection circuits across the SR switches, and information about switching frequency available from digital controller are utilized by a digitally implemented auto-tuning algorithm to determine optimal switching times and achieve zero current switching. In comparison with the existing SR controllers, the introduced solution has a more precise driving scheme. Moreover, the controller requires simpler hardware implementation.

\subsection{Introduction}

For improving efficiency of LLC the diode rectifier can be replaced with a synchronous rectifier (SR). However, a major difficulty in LLC converters is determination of the SR gate driving scheme, which needs to be adjusted for different operating conditions.

Figure 4-1 shows an LLC resonant converter with SR on the secondary side. In previous publications [19-26], a number of SR driving schemes has been proposed. The analog solutions are mostly based on the SR current sensing, to generate SR driving signal by use of current transformers, which reduces the efficiency due to extra transformer winding resistance. Digital solutions utilizing computational power, rather than direct sensing, have also been proposed [24], [26]. Among the most effective digital solutions is [24], in which the SR is turned on synchronously with the main switches and the turn off process is auto tuned. However, as 
demonstrated in [27], for a realistic converter, the optimal SR turn on time instant varies with respect the main switch turn on time, depending on the operating conditions. The auto-tuned turn off time adjustment introduced in [24] is precise, improving robustness and reducing susceptibility to the noise associated with the body diode conduction detection circuits. However, the proposed turn-off process is time consuming.

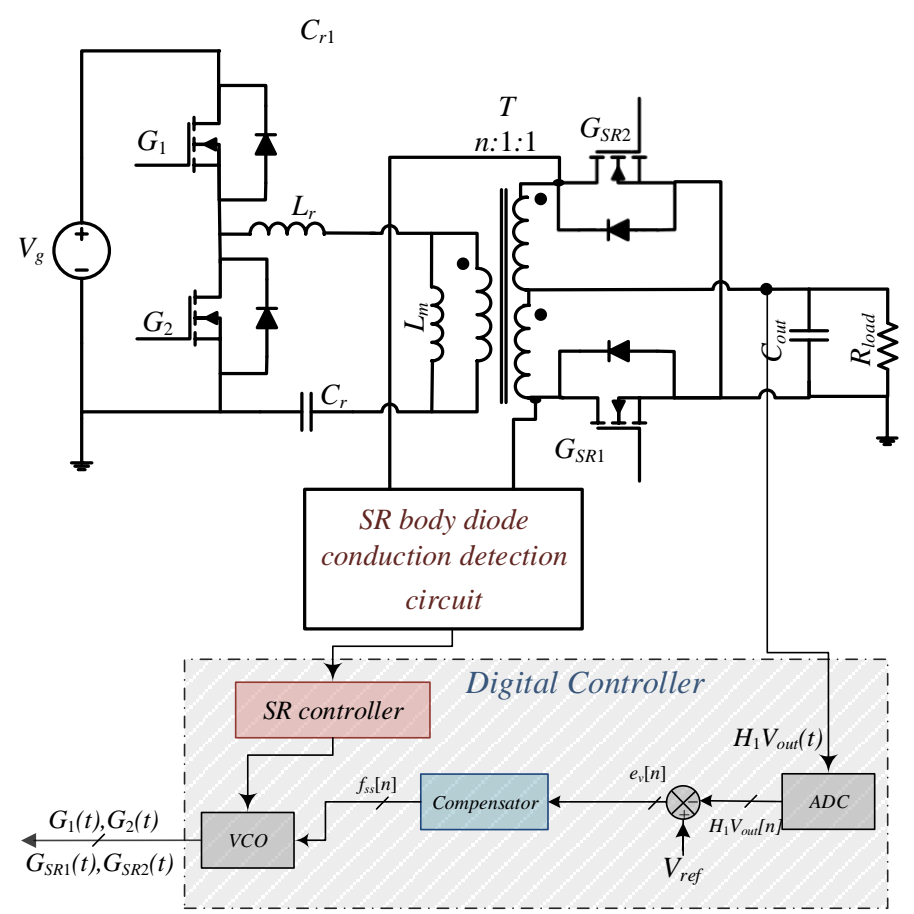

Figure 4-1: LLC resonant converter with SR on the secondary side and digital controller

To minimize losses associated with secondary side switches, a new hardware-efficient control method for driving the SR switches is introduced have the controller shown in Figure 4-1 is independent of the converter's operating condition. The new SR controller utilizes the readily available switching frequency information from the digital control loop and body diodes detection circuits. A simple digitally implemented algorithm adjusts both turn-on and turn-off timing instants, through an auto-tuning process.

\subsection{LLC Resonant Operation}

To show the importance of variable turn-on time of the SR switches with respect to turn on timing of the primary switches, LLC waveforms in the presence of parasticics are analyzed in 
the following subsection. The desired SR gate driving signals for the LLC resonant converter are reviewed for two modes of operation, for operation below and above the resonance, while taking into account the transformer leakage inductance and parasitic capacitance. The analysis presented in [27] and simulation results of the following figures show that in order to achieve ZCS during operation below resonance, the SR must be turned on before turning on the primary side switch. On the other side, when operating above the resonance [27] the SR switch should be turned on after the primary side switch commutation.

In order to achieve ZCS for the secondary side, the SR gating signals should be applied for the same time duration that the SR body diodes are conducting. Therefore, in order to find out the desired SR signals, an LLC resonant converter with a diode rectifier is simulated. Afterwards, the diode rectifier is replaced by a synchronous rectifier and the effect of driving the SR synchronously with the primary side is examined.

\subsubsection{LLC Resonant Converter with Diode Rectifier}

Figure 4-2 shows the simulation results for the LLC converter while operating below resonance and the corresponding equivalent circuits are shown in Figure 4-3. A half cycle, i.e. period from $t_{0}$ to $t_{4}$, can be divided into four subintervals. In the subinterval $t_{0}$ to $t_{1}$, as shown in Figure 4-3-a, the output capacitor of the switch $Q_{1}$ is being discharged while the output capacitance of the switch $Q_{2}$ is charging. At the end of this subinterval the current through $Q_{1}$ is still negative, so the next subinterval $\left(t_{1}\right.$ to $\left.t_{2}\right)$ starts as shown in Figure 4-3-b and the body diode of $Q_{1}$ starts conducting along with SR diode, $D_{S R 1}$. In order to achieve ZVS for the primary side switches, the switch $Q_{1}$ needs to be turned on during this subinterval. Figure 4-3-c shows the $t_{2}$ to $t_{3}$ subinterval in which $Q_{1}$ and $D_{S R 1}$ are on. This subinterval ends when the magnetizing inductor current $\left(i_{L m}\right)$ reaches the series inductor current $\left(i_{L r}\right)$, and the SR current reaches zero. During the fourth subinterval, $t_{2}$ to $t_{3}$ as shown in Figure 4-3-d both diodes on the secondary sides are off and the magnetizing inductor makes a resonant circuit with the resonance capacitance and inductor, $C_{r}$ and $L_{r}$. This subinterval ends when the main switch turns off. The second half cycle is similar to first half cycle. 


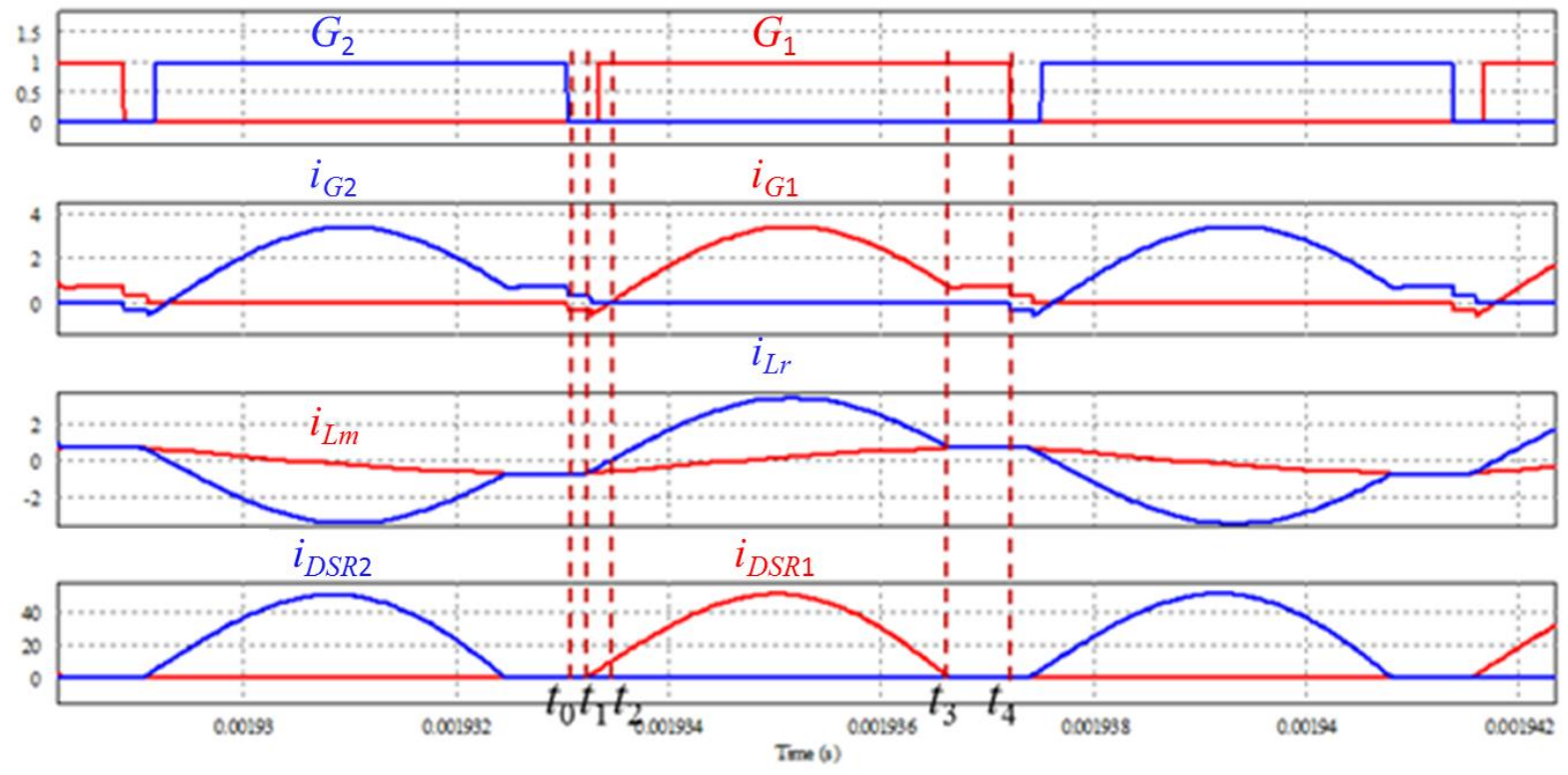

Figure 4-2: Simulation results of LLC operating below resonance; $G_{1}$ and $G_{2}$ are main switches driving signal; $i_{G 1}$ and $i_{G 2}$ are main switches currents; $i_{L m}$ and $i_{L r}$ are magnetizing and tank inductor currents respectively; $i_{D S R 1}$ and $i_{D S R 2}$ are rectifier body diode currents.

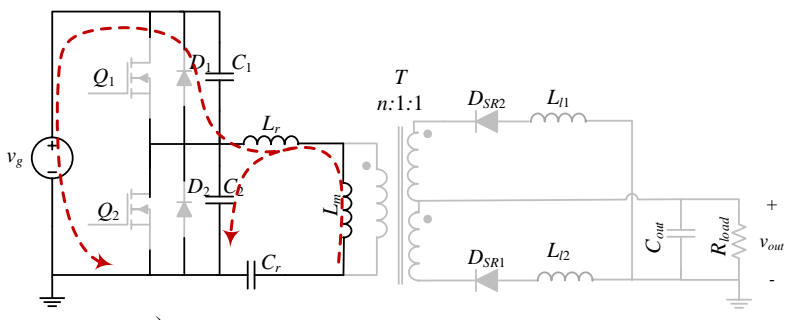

a) $t_{0}-t_{1}$

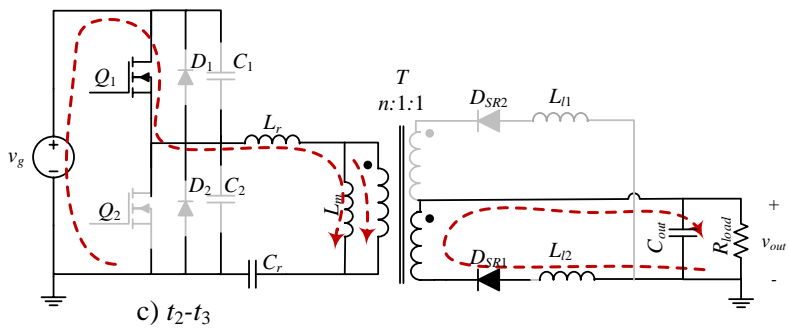

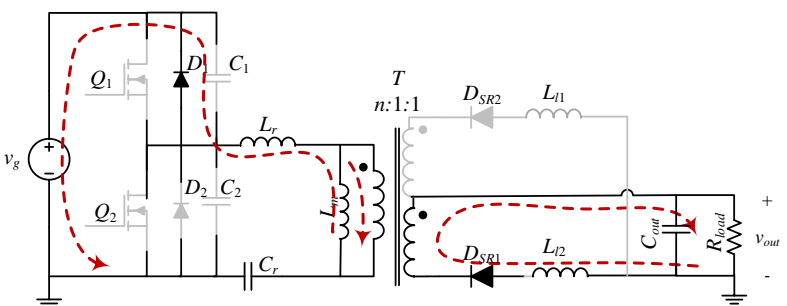

b) $t_{1}-t_{2}$

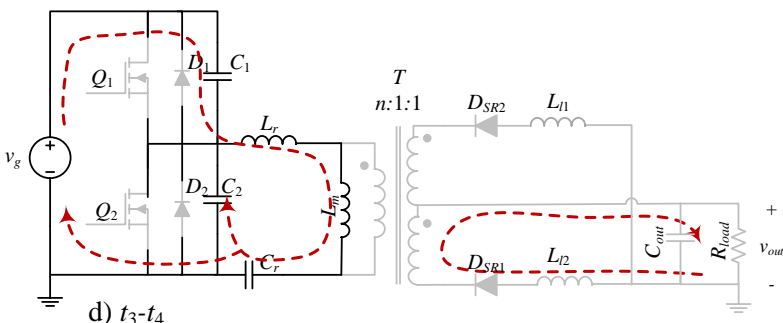

Figure 4-3: LLC resonant converter equivalent circuits operating below resonance.

Similarly, Figure 4-4 shows the simulation results for the LLC converter while operating above the resonant frequency. A half cycle can be divided into four modes of operation. The equivalent circuits are shown in Figure 4-5. 


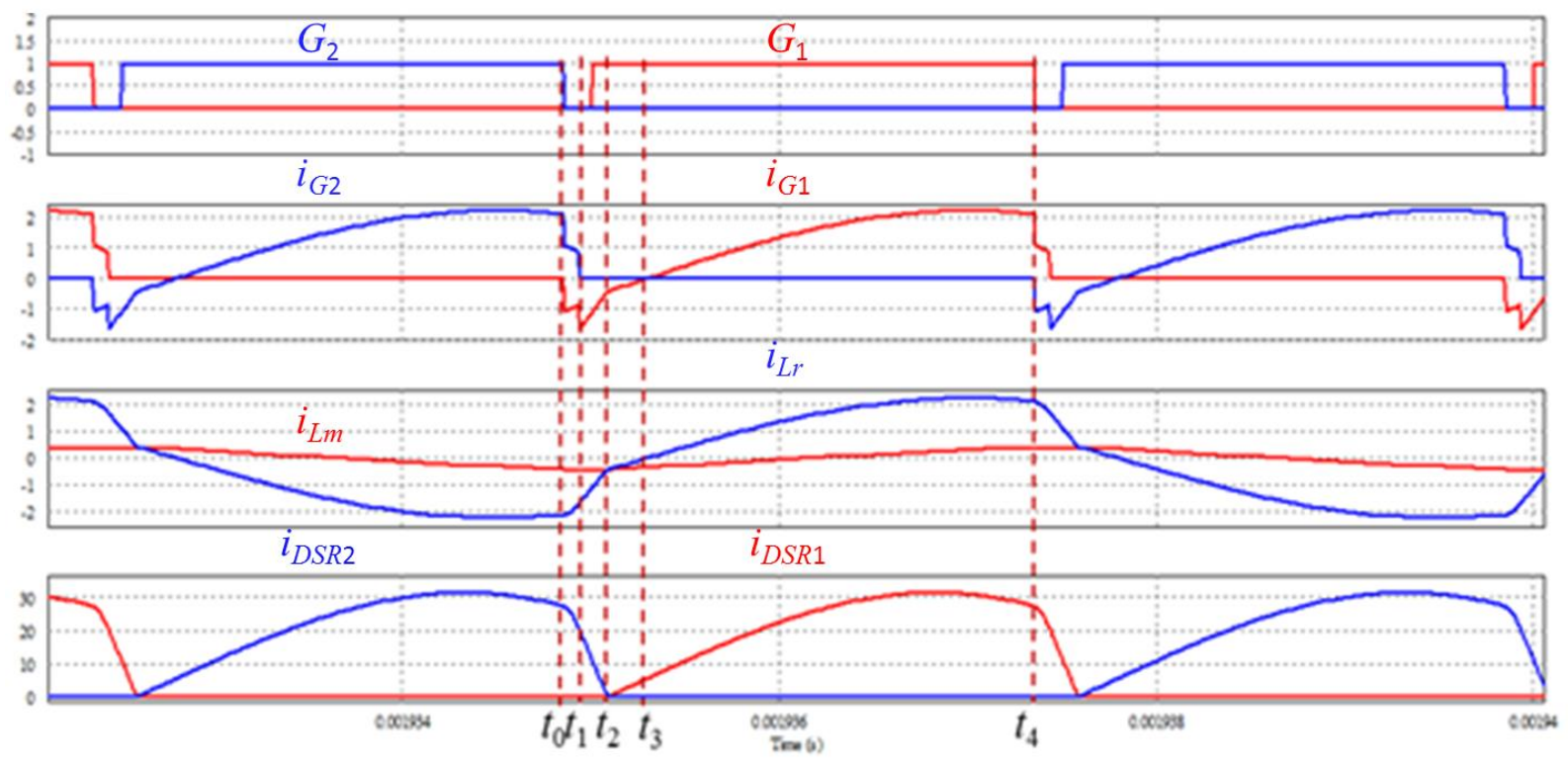

Figure 4-4: Simulation results of LLC operating above resonance; $G_{1}$ and $G_{2}$ are main switches driving signal; $I_{G 1}$ and $I_{G 2}$ are main switches currents; $I_{L m}$ and $I_{L r}$ are magnetizing and tank inductor currents respectively; $I_{D S R 1}$ and $I_{D S R 2}$ are rectifier body diode currents.
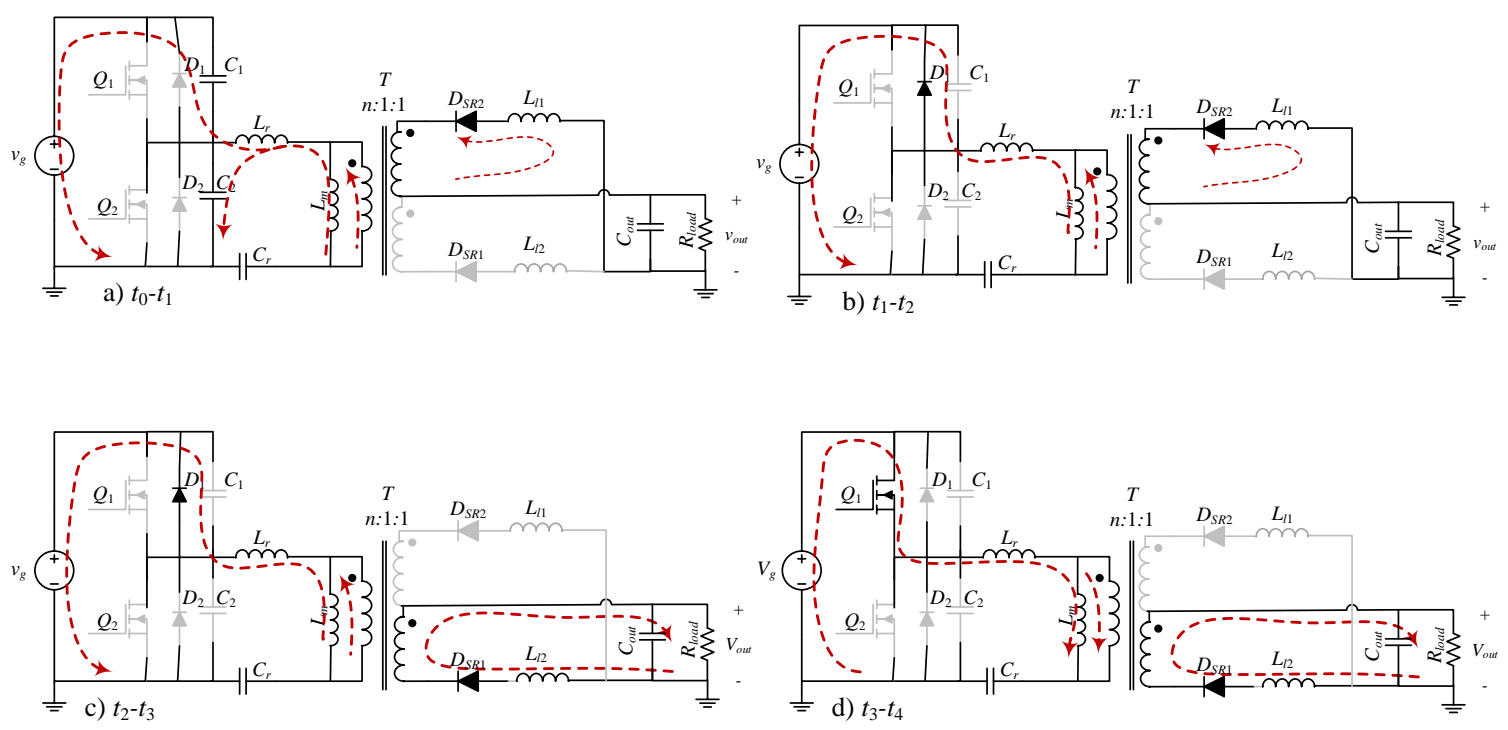

Figure 4-5: LLC resonant converter equivalent circuits operating above resonance.

As shown in the Figure 4-2, and Figure 4-4, the secondary side current starts growing slightly before the turn-on of the main switches while converter is operating below the resonant 
frequency $\left(f_{s}<f_{0}\right)$, and slightly after that when converter is operating above the resonant frequency $\left(f_{s}>f_{0}\right)$. SR turn-on duration also depends on the converter's operating condition. Therefore, if the diode rectifier is replaced with a SR, the SR turn-on and turn-off time instants have to be executed precisely in order to avoid circulating energy or body diode conduction loss.

\subsubsection{LLC Resonant Converter with Synchronous Rectifier}

To examine the effect of inappropriate SR turn on, the simulation results of a LLC resonant converter with a SR on the secondary side are presented here. Figure 4-6-a shows simulation results for operation below resonance and the turn on of the SR happens synchronously with the main switch. During the $\Delta T_{B R}$ as shown in Figure 4-6-a, the body diode conducts while the SR switch turns on after this time. This delay in turn on increases the conduction losses while it can be avoided by proper SR switching scheme.

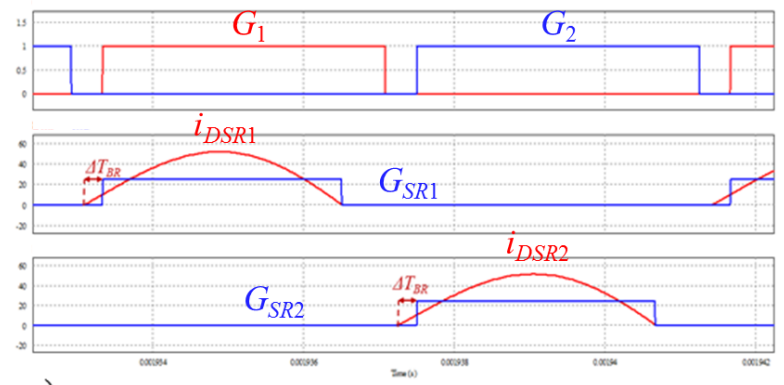

a)

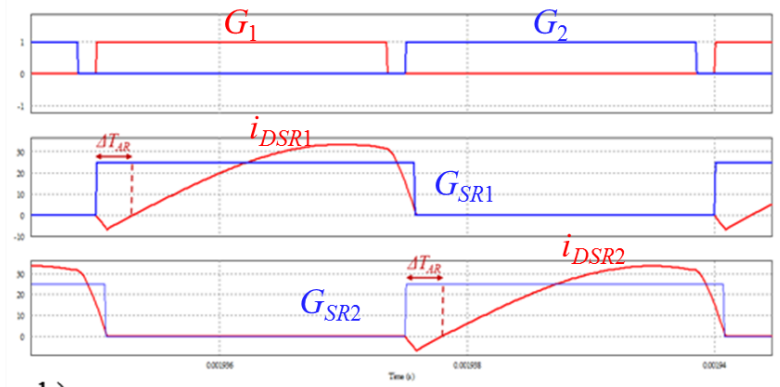

b)

Figure 4-6: Simulation results of LLC resonant converter with SR while SR synchronously turns on with the main switch. a) Operating above resonance. b) Operating below resonance; $G_{1}$ and $G_{2}$ are main switches driving signal; $i_{D S R}$ and $G_{D S R 1}$ are the SR current and driving signals.

Figure 4-6-b shows the same simulation result while operating above resonance. Again the SR turn on is in synch with the main switch. Simulation results show a reverse current through the SR in $\Delta T_{A R}$ time. This reverse current will cause circulating energy and decrease the efficiency.

\subsection{Principle of operation and Practical Implementation}

Here a practical and fast SR control scheme that optimizes switching sequence timing is described. It takes into account all the timing requirements discussed in the previous section. From the previous discussion it can be seen that it is highly desirable to turn on the SR switch 
right before the diode would be starting its conduction and to turn it off right after the diode would stop conducting. Figure 4-7 shows the controller flowchart that explains how these two goals are achieved, i.e. describes the introduced SR driving/control scheme. At the moment the body diode conduction is sensed by the detection circuit as shown in Figure 4-1, the SR turns on and that time instant, with respect to the switching cycle, is captured in a register. In the next cycle, if the switching frequency remains the same, the controller takes into account the registered value, and SR turns on $\Delta T_{\text {on }}$ time earlier than in the previous cycle. Therefore, except for the first cycle in each operating point, all other cycles start without body diode conduction. This process is activated each time a change of frequency is detected and, if the frequency remains the same, the algorithm is restarted every 20 cycles, to prevent possible errors.

A similar algorithm is used to find the SR turn-off time instant. Instantly turn off time is determined based on the maximum allowable switching frequency (minimum time period $T_{m}$ ). When the SR turns off the body diode starts conducting. The extra time that SR needs to remain in the on state is the time duration which the body diode conducts or the duration of the active pulse at the output of the body diode detection circuit. This remaining time $\left(\Delta T_{\text {off }}\right)$ is measured (by a counter and register) and added to the initial value of the turn on pulse width $\left(T_{m} / 2\right)$. In this way the turn off time instant is determined as $T_{\text {off }}=T_{m} / 2+\Delta T_{\text {off }}$. This algorithm restarts every time the switching frequency changes, so it guarantees for all operating frequency regions. The implementation of the fast two step SR controller is shown in Figure 4-8. At $t_{0}$ body diode conduction circuit detects conduction. SR switch turns on and the value of VCO_counter is registered with a Counter_ON variable at $t_{1}$. At $t_{2}$ the on time period reaches the maximum allowable time period and $G_{S R}$ turns off. At this point the body diode starts conducting and Counter_off starts measuring the time until body diode stops conducting at $t_{3}$. During the next cycle, when the VCO_Counter reaches Counter_ON-1 at $t_{4}$, the $G_{S R}$ turns on. At $t_{5}, G_{S R}$ turns off which is the time that VCO_counter reaches Counter_off $+T_{m} / 2$. It should be noted that this method can potentially be extended for other dc-dc converters with synchronous rectifier such as synchronous buck converter. 
a)

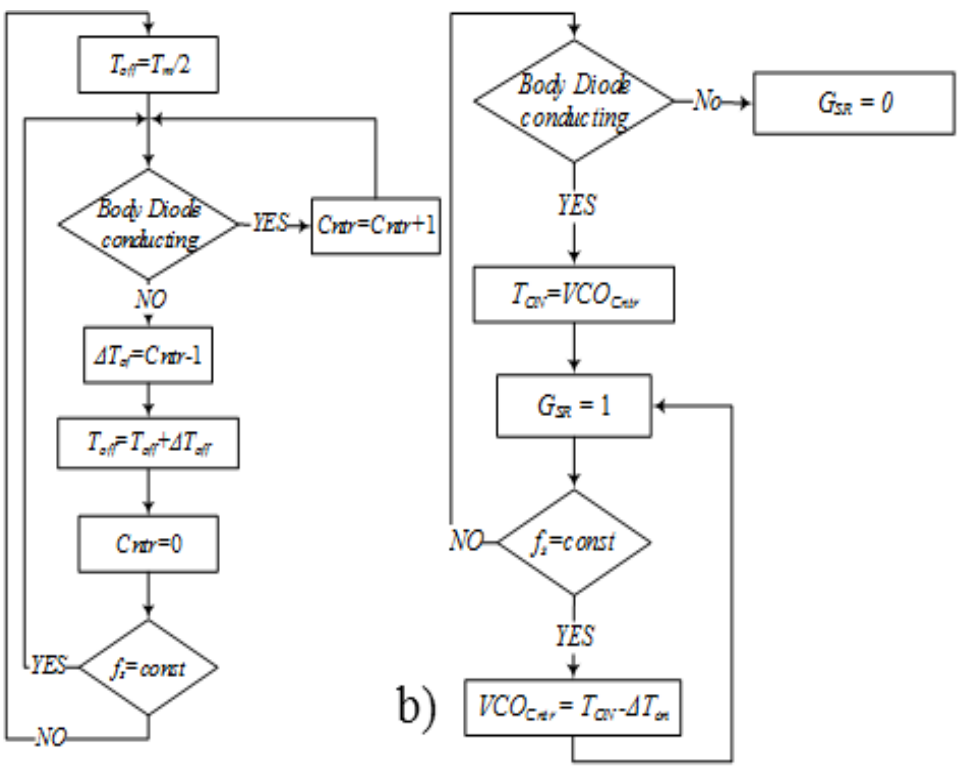

Figure 4-7: a) SR turn off controller flowchart; b) SR turn on controller flowchart

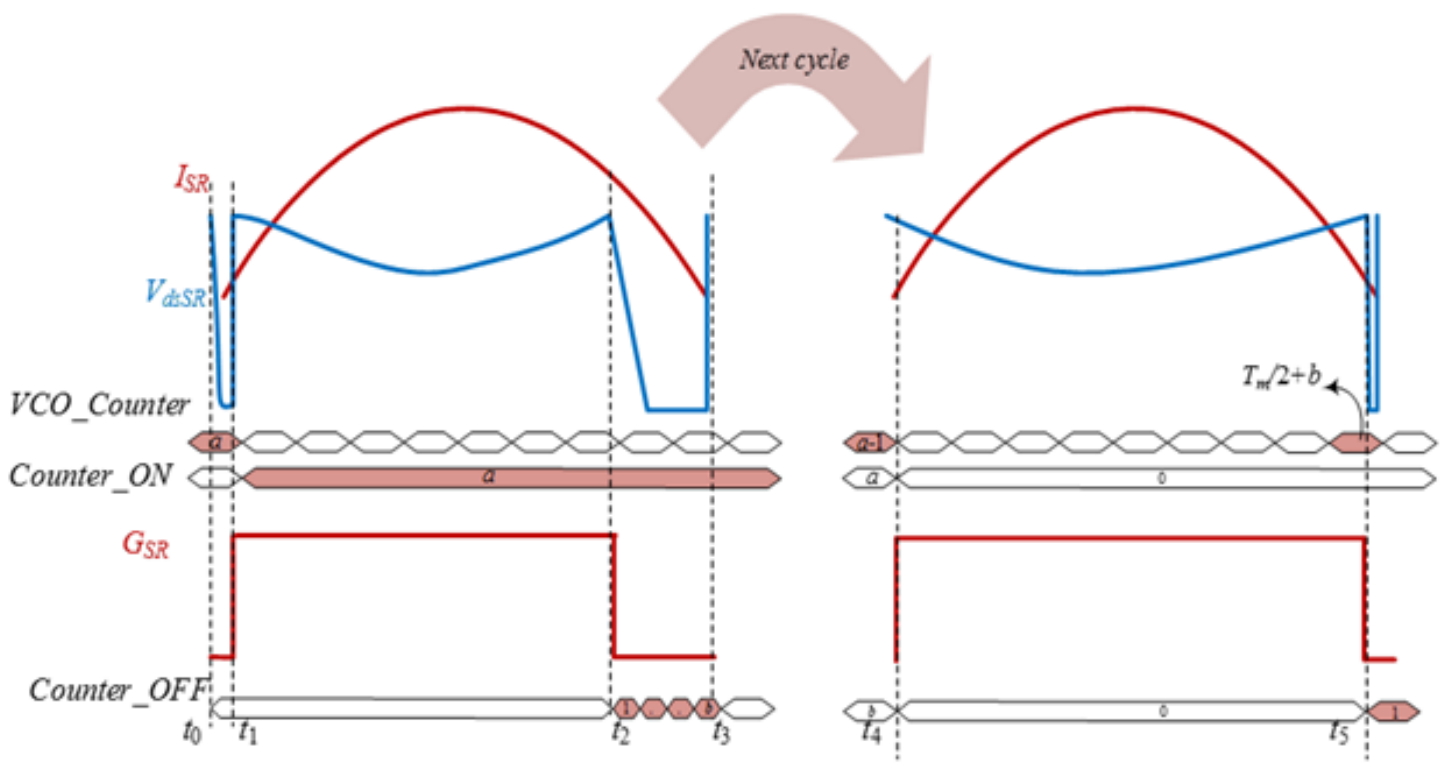

Figure 4-8: Timing diagram, $I_{S R}$ is the SR current, $V_{d s S R}$ is the SR switch drain to source voltage, $G_{S R}$ is the SR gating signal. 


\section{Chapter 5}

\section{Experimental Results}

To verify the performance of the introduced controller, a commercial development board [17] with a half-bridge $340 \mathrm{~W}, 400 \mathrm{~V}$ to $12 \mathrm{~V}$, LLC resonant converter is used and tested with the setup shown in Figure 5-1. The existing controller is replaced with a custom-made FPGA system. The controller is based on the diagram of Figure 3-3, Figure 3-5, and Figure 4-1 and its performance is verified both through simulation and experiment. To avoid any possible damage to the system, the PID compensator has been tuned through simulation.

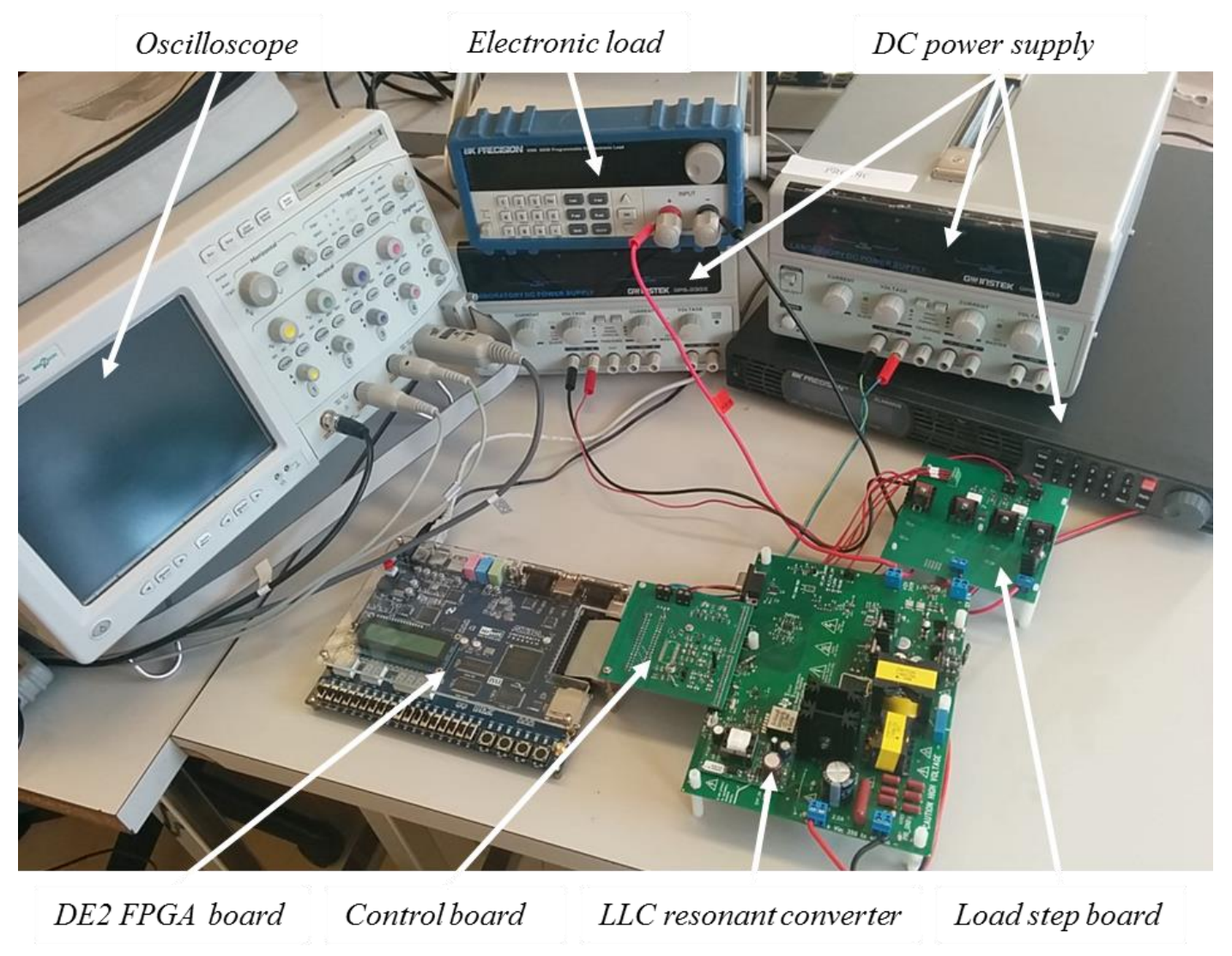

Figure 5-1: Experimental setup 
The introduced controller was tested and the experimental results were compared with a welltuned digital PID controller to show the dynamic performance improvement. A light to heavy and heavy to light load transients in both cases are shown in Figure 5-2 and Figure 5-3, respectively. The results show bump-less transition between different modes, confirming proper operation of the auto-tuning algorithm and, significant improvement compared to a well-tuned PID controller.

Figure 5-2 shows the transient response for a light to heavy load transient for a load step-up from 3 A to $15 \mathrm{~A}$. With transient suppression controller, the switching frequency is decreased to $64 \mathrm{kHz}$ from $88 \mathrm{kHz}$ for one cycle and goes to $83 \mathrm{kHz}$ when PID is re-activated. Figure 5-3 shows the transient response for a heavy to light load transient for a load step-down from $15 \mathrm{~A}$ to3 A. When the transient suppression controller is employed, the frequency is increased to 120 $\mathrm{kHz}$ from $83 \mathrm{kHz}$. The results show that the transient suppression block is working properly and changes the frequency after the transient until the voltage reaches the valley/peak. Then PID controls the system.

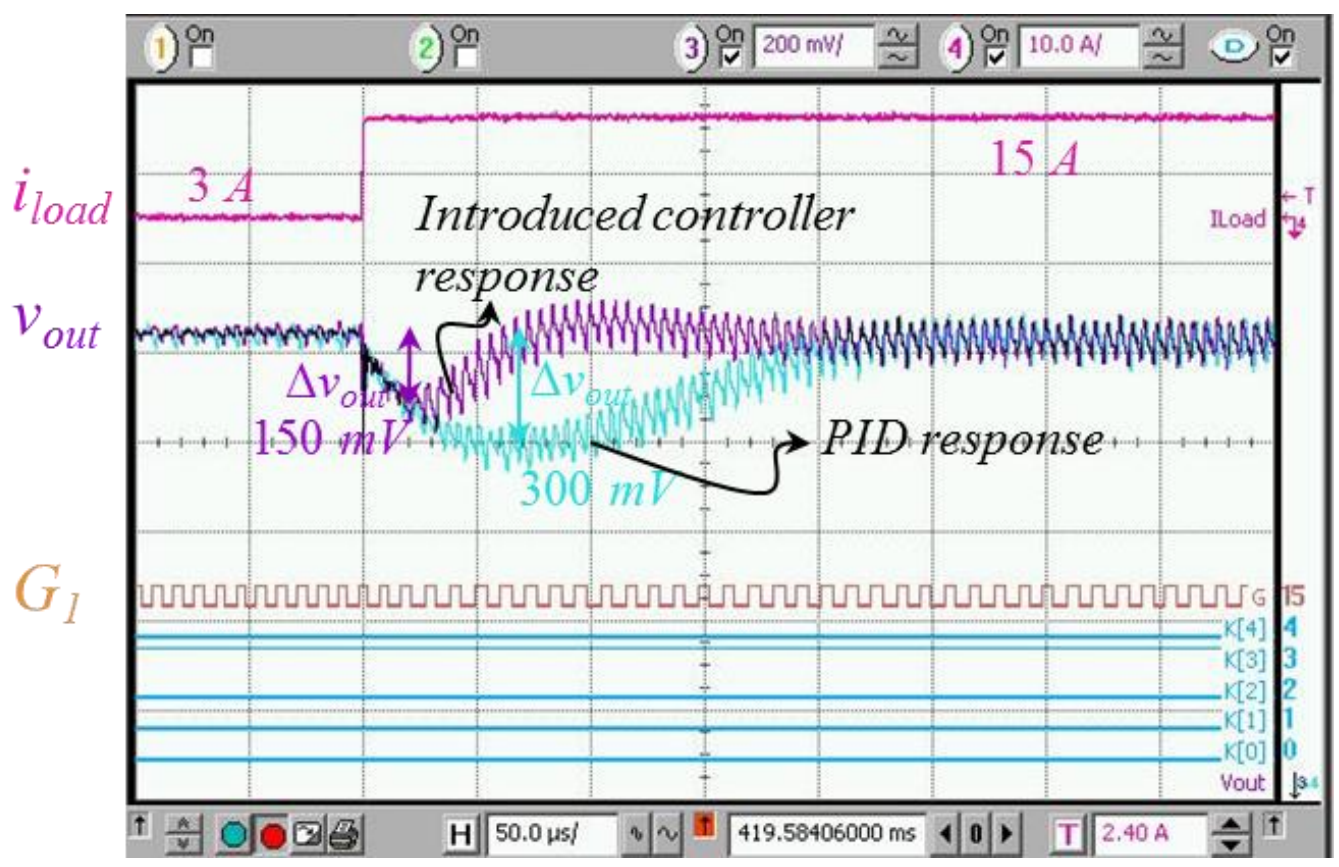

Figure 5-2: Dynamic response of LLC resonant converter for light to heavy load transient. $v_{\text {out }}$ is the output voltage measurement signal $(200 \mathrm{mV} / \mathrm{div}) . i_{\text {Load }}$ is the load step current $(10 \mathrm{~A} / \mathrm{div}) ; v_{\text {sw_node }}$ is the switching node voltage. 


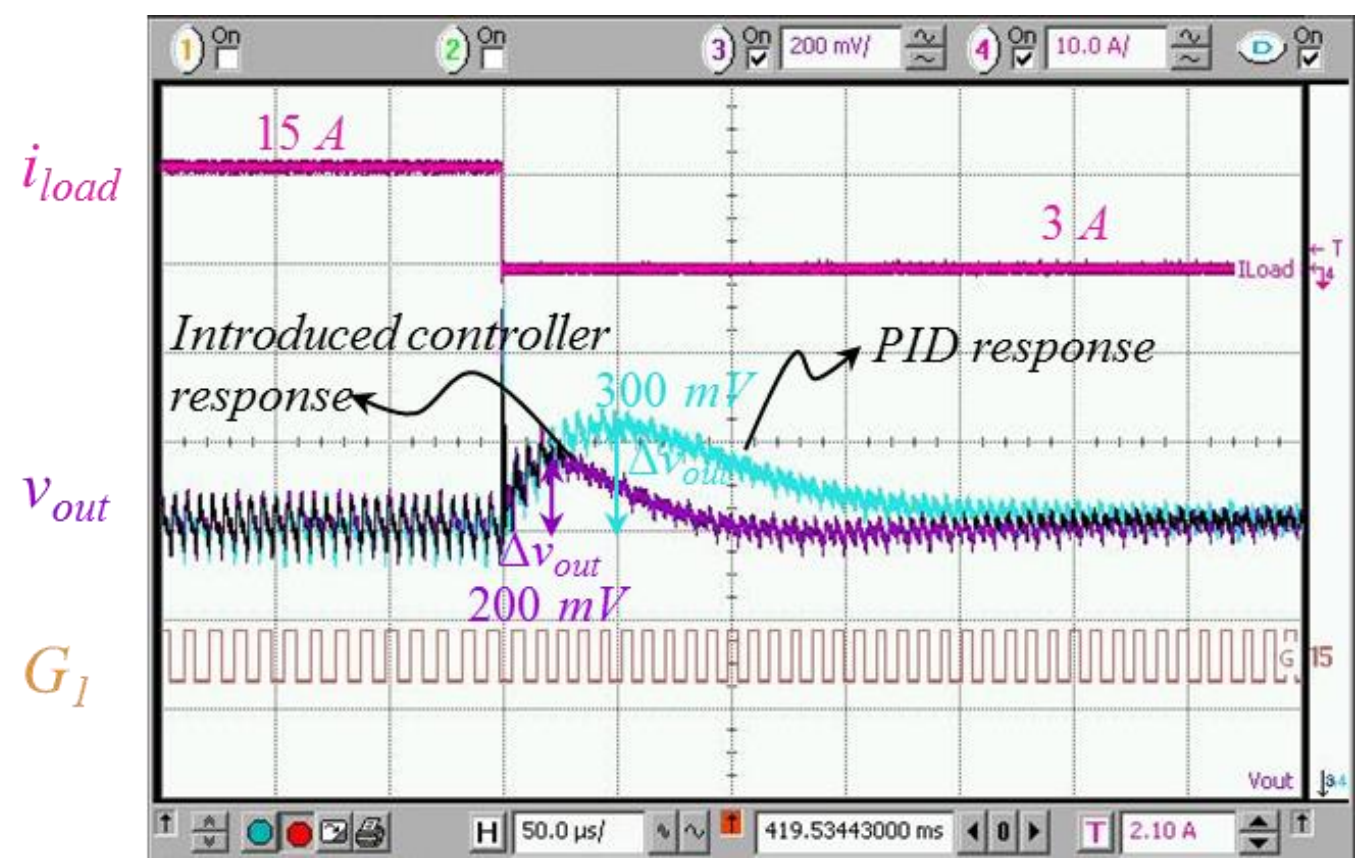

Figure 5-3: Dynamic response of LLC resonant converter for heavy to light load transient. $v_{\text {out }}$ is the output voltage measurement signal $(200 \mathrm{mV} / \mathrm{div}) ; i_{\text {Load }}$ is the load step current $(10 \mathrm{~A} / \mathrm{div}) ; v_{s w \_n o d e}$ is the switching node voltage.

It can be seen from the figures that, in both cases, the transient recovery process takes two switching cycles after transient and results in the minimum voltage deviation. First half switching cycle is the transient detection delay and the next half cycle is used to calculate value of the period. With the calculated period, i.e. frequency, the states variables reach new states in one cycle, at this point PID controller restarts operation with an initial value based on new load current.

In order to show the importance of the PID re-initialization the system is controlled with the introduced controller while the PID re-initialization block was disabled. The experiment results then compared with the experimental results from the fully functional controller.

Figure 5-4-a, and b show the transient response of the system for a 3 A to 15 A load step with and without PID re-initialization respectively. The experimental results show that without PID re-initializing system goes through another transient and with re-initializing system has faster response, as discussed previously. 


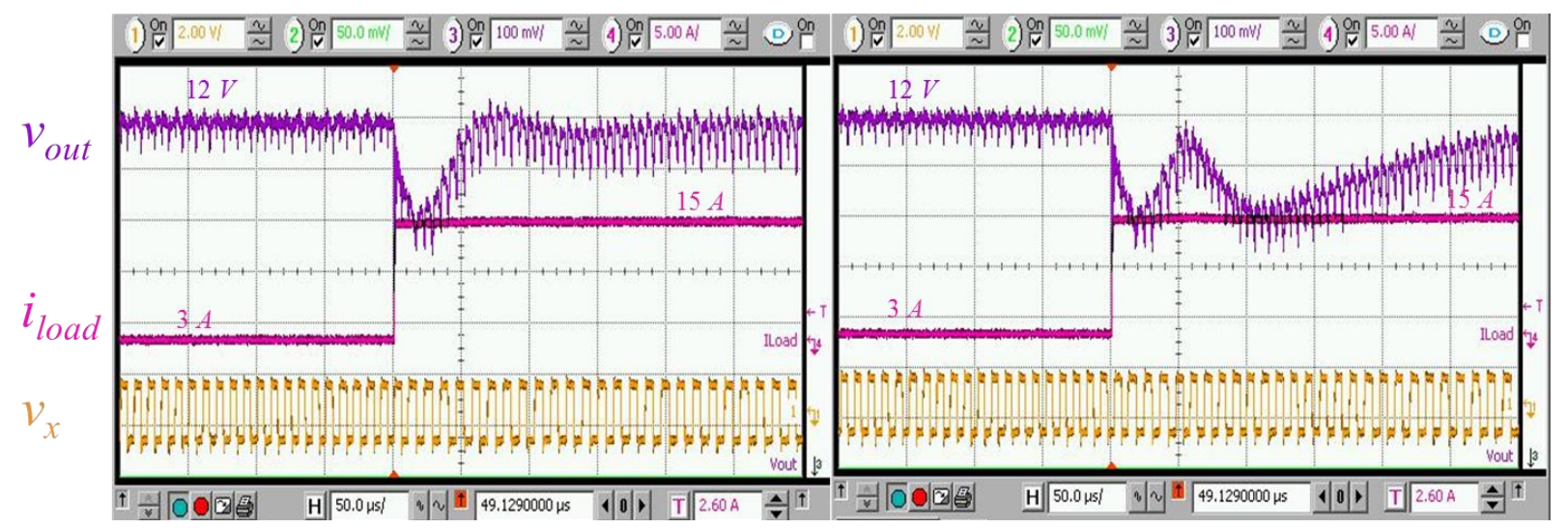

Figure 5-4: Transient response of a 3 to 15A load step a) with PID re-initialization, b) without PID reinitialization. $v_{\text {out }}$ is the output voltage measurement signal $(100 \mathrm{mV} / \mathrm{div}) . i_{\text {Load }}$ is the load step current (5A/div); $v_{s w \_n o d e}$ is the switching signal.

To find the minimum allowable output capacitor, the transient response of the introduced controller is compared to the transient response of a conventionally designed PID controller as a reference. In the conventional system the output capacitor is $2585 \mu \mathrm{F}$ while the output capacitor in the system with the introduced controller is $1645 \mu \mathrm{F}$. The conventional PID controller bandwidth is about $1 / 10^{\text {th }}$ of the switching frequency at the optimal load.

Figure 5-5-a shows the transient response of the introduced controller for a light to heavy load transient for a load step-up from 3 A to 21 A while Figure 5-5-b shows the results of the same experiment with the conventional controller. The results confirm superior performance of the introduced controller, near minimum possible output voltage deviation. The results also show that the introduced controller can achieve $40 \%$ smaller output voltage deviation compared to the conventional controller while utilizing $60 \%$ of the output capacitor size. This allows for more capacitor reduction. The introduced controller can potentially allow for utilization of $40 \%$ output capacitor size to achieve similar output voltage deviation. 


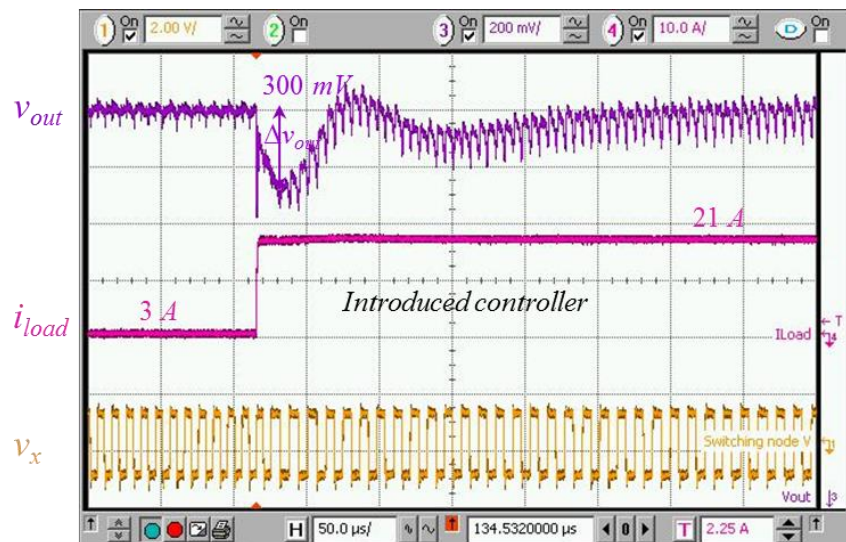

a)

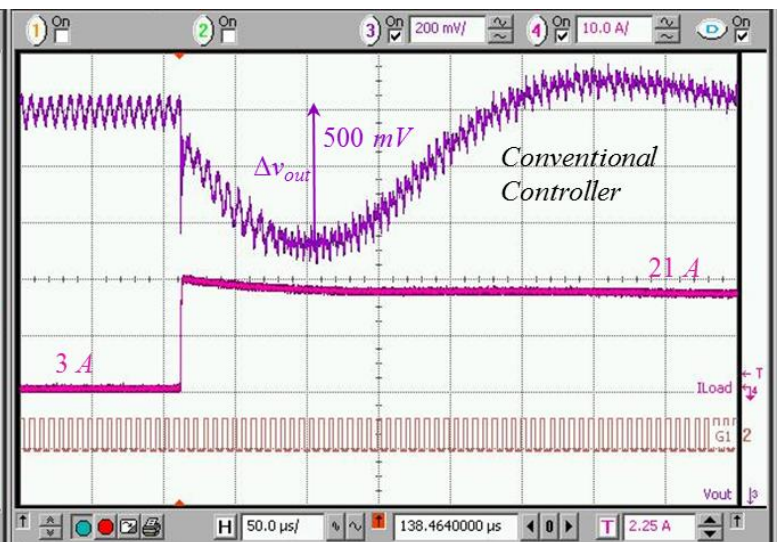

b)

Figure 5-5: Dynamic response of LLC resonant converter for light to heavy load transient a) with introduced controller and $C_{o u t}=1645 \mu \mathrm{F}, \mathrm{b}$ ) with conventional controller and $C_{\text {out }}=2585 \mu \mathrm{F}$. $v_{\text {out }}$ is the output voltage measurement signal $(200 \mathrm{mV} / \mathrm{div}) . i_{\text {Load }}$ is the load step current $(10 \mathrm{~A} / \mathrm{div}) ; v_{\text {sw_node }}$ is the gating signal; Time scale is 50us/div.

Figure 5-6 shows a repetitive load transient demonstrating the auto-tuning process of factor $K$, described by Equation (3-7). $K$ is applied to find the proper frequency after a light to heavy load transient. After each light to heavy load transient if the state variables of the system are not at their new states within one switching cycle after detecting the transient, $K$ is increased one step. The steps can be optimized based on the total number of transients until $\mathrm{K}$ reaches its final value. In this setup total number of eight transients takes until $K$ gets to its final value.

The zoomed in version of Figure 5-6 at the updating points of $K$ are shown in Figure 5-7. It can be seen from the figures that $K$ is increased each time that the number of cycles during the transient suppression block activation is more than two. 


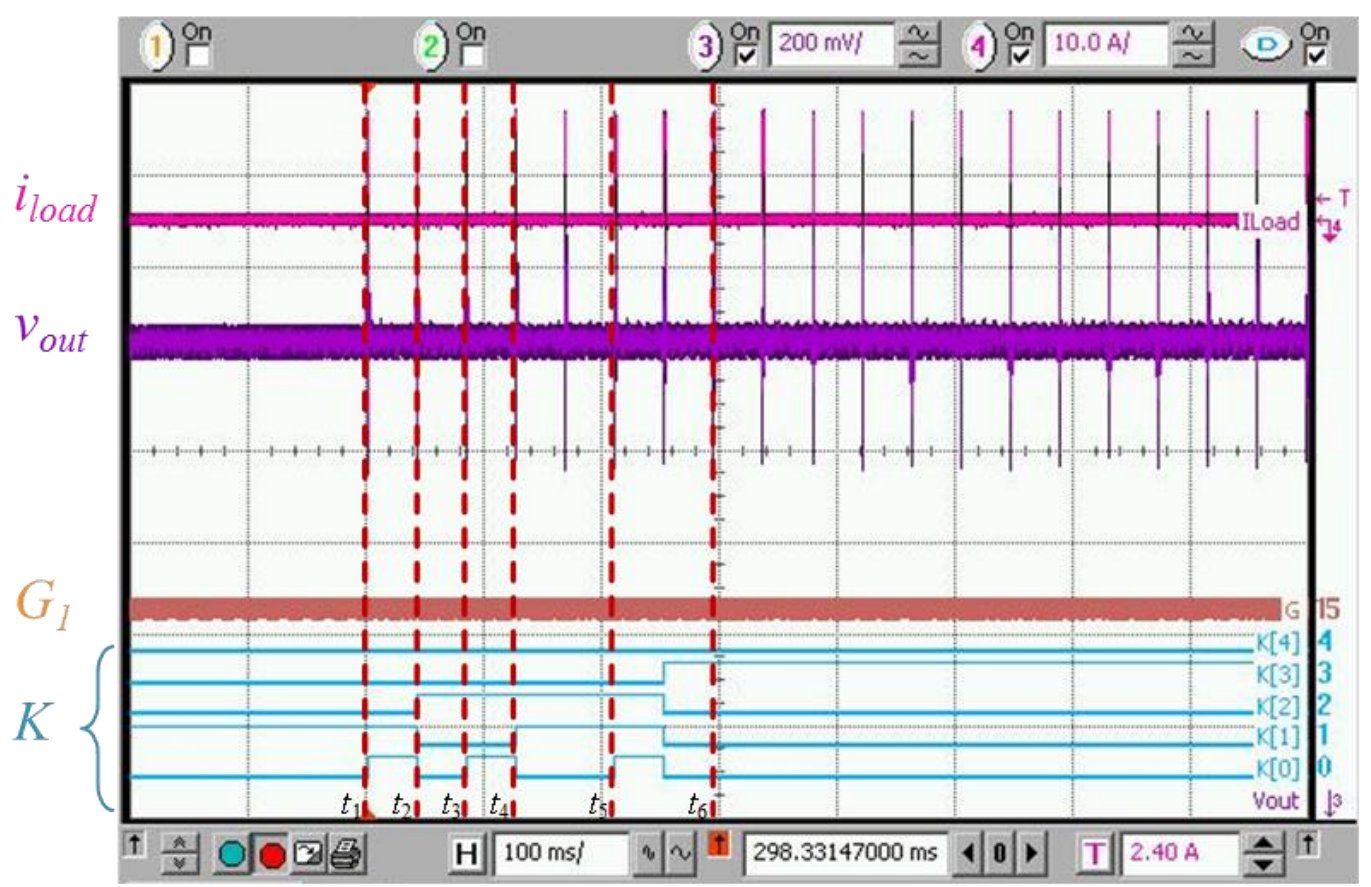

Figure 5-6: Auto-tune of factor $K$ for light to heavy load transients. $v_{\text {out }}$ is the output voltage measurement signal (200mV/div). $i_{\text {Load }}$ is the load step current (10A/div); $G_{1}$ is the gating signal and factor $\mathrm{K}$ is shown in 5 bits; Time scale is $100 \mathrm{~ms} / \mathrm{div}$.
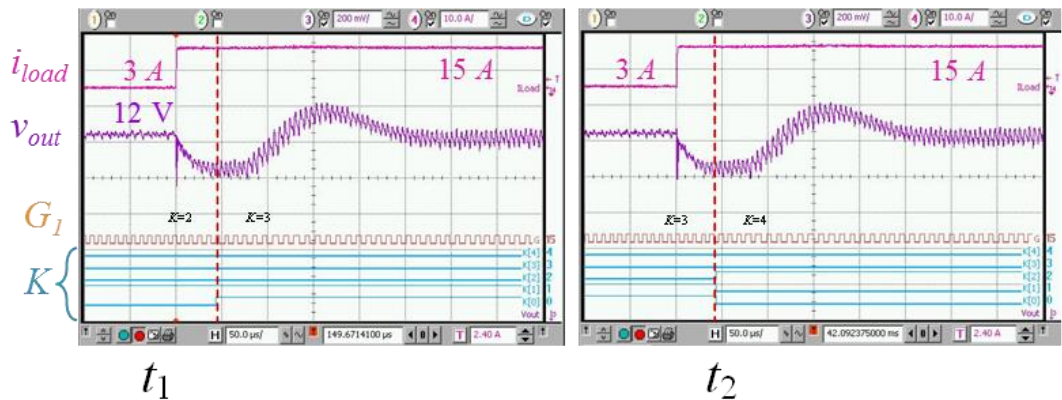

$t_{2}$

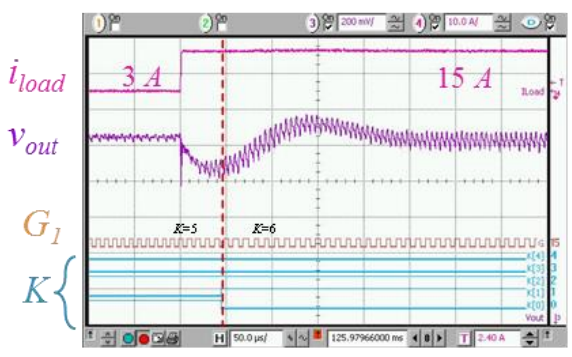

$t_{4}$

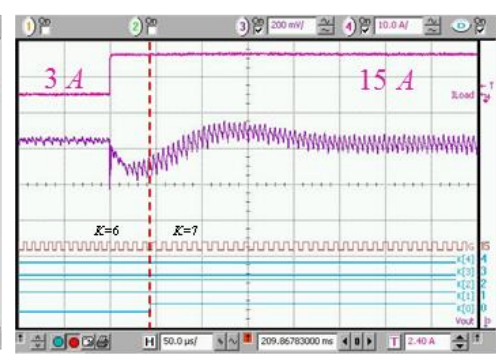

$t_{5}$

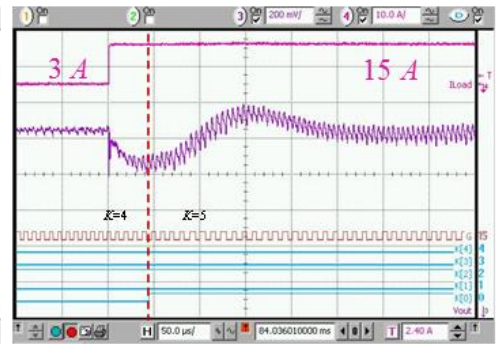

$t_{3}$

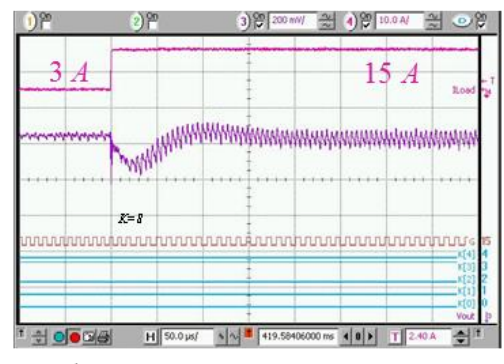

$t_{6}$

Figure 5-7: Zoomed in version of Figure 5-6 at updating times 
To verify the analysis presented in section 4.2 the SR switches are derived in synchronous with the primary side switches and the results are compared with the modified SR deriving scheme. Figure 5-8-a shows the experimental result while the SR turns on synchronously with the primary switch. As it can be seen from the experimental result body diode start conducting for some time in the beginning of the cycle. Figure 5-8-b is the same results with modified on time. The results show that with a proper on and off time the body diode conduction could be avoided.

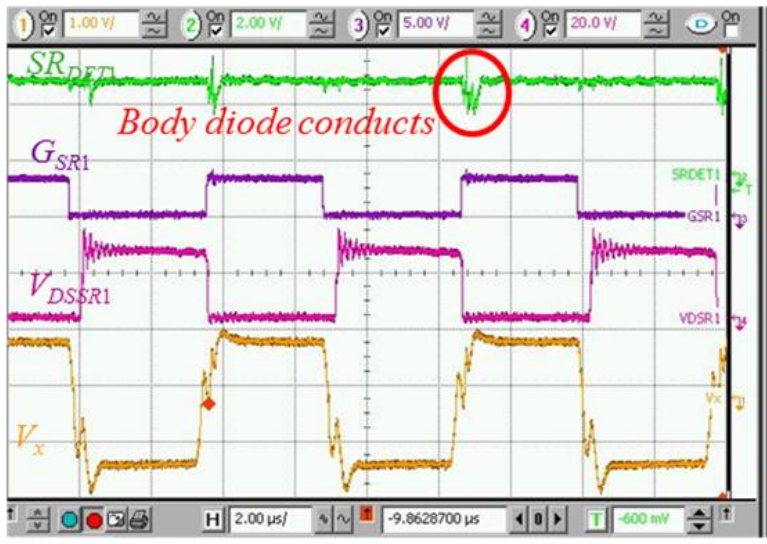

a)

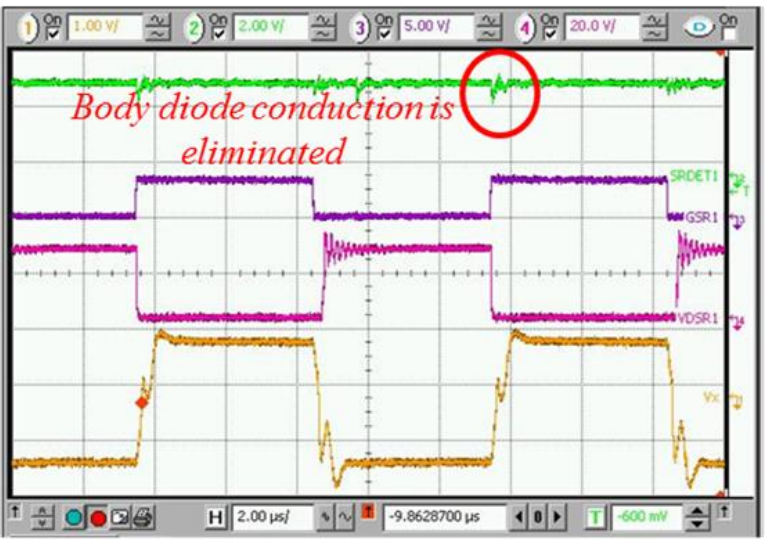

b)

Figure 5-8: Experimental results, a) SR driving signals in synchronous with the primary side switches; b) SR driving signals with modified on time. $S R_{D E T 1}$ is the $Q_{S R 1}$ body diode conduction detection signal; $G_{S R 1}$ is the $Q_{S R 1}$ gating signal; $v_{D S S R 1}$ is the $Q_{S R 1}$ drain to source voltage $20 \mathrm{~V} /$ div.; $v_{x}$ primary side witching node voltage. Time is 2 us/div.

These transient results show that the introduced controller is a suitable control technique for LLC resonant converters. It achieves minimal output voltage deviation during light-to-heavy and heavy-to-light load transients. The results show that the introduced controller can achieve better output voltage deviation than the conventional controller, allowing for output capacitor volume reduction. 


\section{Chapter 6}

\section{Conclusions and Future Work}

To improve the dynamic performance of the LLC resonant converter a practical auto-tuning digital controller that results in virtually smallest possible output voltage deviation during transients is presented. Also an addition controller for regulating operation of the SR is introduced.

The controller achieves fast transient response and seamless transition between steady-state and transient modes of operation by collecting information about the output voltage only. This eliminates the need for costly current sensors and complex calculations existing in other fast transient response solutions. The two frequency steps are determined through measurements of the initial voltage deviation after the transient and the output voltage ripple at the consecutive extreme output voltage deviation point. The values of those steps are dynamically adjusted through self-tuning processes. The effectiveness of the controller is demonstrated with experimental prototypes showing smooth transitions between the controller states and confirming practically minimum output voltage deviation allowing for a drastic reduction of the output capacitance value. Experimental results show up to $60 \%$ reduction in the output capacitance.

The fast auto-tuned digital controller block for optimization of the synchronous rectifiers' conduction times eliminates the body diode conduction and avoids the reverse SR current. Moreover, the controller prevents reverse current build up. Therefore, it limits the circulating energy and improves the efficiency. The driving scheme consists of two fast auto tuned process for turn-on and turn-off, which can tune the SR driving signal in one cycle. The advantages of this method over other existing methods are its precise driving signals and fast auto tuning, 
which result in lower power losses. The method could potentially be used in other dc-dc synchronous rectifier such as synchronous buck converter.

\subsection{Future work}

The introduced controller in this thesis improves the dynamic performance of the system as well as the overall efficiency. However, there are still some works can be done.

1. One of the important feature of LLC resonant converter is its ability to operate over a wide input voltage range. The effect of introduced controller to improve input voltage variation can also be analyzed. The trajectory analysis in this case would be more challenging due to variation of input and output voltages along with inductor current and capacitor voltage.

2. An input voltage feedforward also can be used to determine more accurate $\Delta T_{L H}$ after a light to heavy load transient. Factor $K$ of Equation (3-7) can be modified as:

$$
K=\frac{L_{m} C_{\text {out }}}{T_{s} n}
$$

3. The heavy to light load transients algorithm also can be implemented as an auto-tuned process so the controller could be generalized and extended to other converters. Based on the state trajectory analysis, the optimal frequency or duty ratio change needs to be formulized for different converters. 


\section{References}

[1] Bo, Yang, and F.C. Lee, "LLC resonant converter for front end DC/DC conversion," in Seventeenth Annual IEEE Applied Power Electronics Conference and Exposition, APEC 2002, 2002. vol.2: pp. 1 108- 1112.

[2] B.Yang and F.C. Lee, "Small-signal analysis for LLC resonant converter," in Proc. Center Power Electron. Syst. Semin., 2003, pp. 144-149.

[3] R. D. Middlebrook and S. Cuk, "A general unified approach to modeling switchingconverter power stages,” in Proc. IEEE Power Electron. Spec. Conf., 1976, pp. 36-57.

[4] Mattavelli, P.; Rossetto, L.; Spiazzi, G.; Tenti, P., "General-purpose fuzzy controller for DC/DC converters," Applied Power Electronics Conference and Exposition, 1995. APEC '95. Conference Proceedings 1995., Tenth Annual, vol., no.0, pp.723,730 vol.2, 5-9 Mar 1995.

[5] Hao Ma; Qinwei Liu; Jin Guo, "A sliding-mode control scheme for llc resonant DC/DC converter with fast transient response," IECON 2012 - 38th Annual Conference on IEEE Industrial Electronics Society, vol., no., pp.162,167, 25-28 Oct. 2012.

[6] Weiyi Feng; Lee, F.C.; Mattavelli, P., "Simplified Optimal Trajectory Control (SOTC) for LLC Resonant Converters," Power Electronics, IEEE Transactions on, vol.28, no.5, pp.2415,2426, May 2013.

[7] Chao Fei, Weiyi Feng, Fred C. Lee, Qiang Li., "State-trajectory Control of LLC Converter Implemented by Microcontroller," In Proc. IEEE APEC 2014, March 2014.

[8] Buccella, C.; Cecati, C.; Latafat, H.; Razi, K., "Comparative transient response analysis of LLC resonant converter controlled by adaptive PID and fuzzy logic controllers," IECON 2012 - 38th Annual Conference on IEEE Industrial Electronics Society , vol., no., pp.4729,4734, 25-28 Oct. 2012.

[9] Kurokawa, F.; Murata, K., "A new fast digital P-I-D control LLC resonant converter," Electrical Machines and Systems (ICEMS), 2011 International Conference on , vol., no., pp.1,5, 20-23 Aug. 2011.

[10] W. A. Tabisz, M. M. Jovanovic, and F. C. Lee, "Present and future of distributed power systems," in Applied Power Electronics Conference and Exposition, 1992. APEC '92. Conference Proceedings 1992., Seventh Annual, 1992, pp. 11-18.

[11] R. W. Erickson and D. Maksimovic', Fundamentals of Power Electronics. New York: Springer-Verlag, 2001. 
[12] B. Patella, A. Prodić, A. Zirger and D. Maksimović, "High-Frequency Digital Controller IC for DC/DC Converters," in Proc., IEEE Applied Power Electronics Conference (APEC), March 2002, pp. 374-380

[13] B. Yang, "Topology investigation for front end DC/DC power conversion for distributed power systems," Ph.D. dissertation, Center Power Electron. Syst., Virginia Tech, Blacksburg, 2003.

[14] Radić, A.; Lukic, Z.; Prodić, A.; De Nie, R., "Minimum deviation digital controller IC for single and two phase dc-dc switch-mode power supplies," Applied Power Electronics Conference and Exposition (APEC), 2010 Twenty-Fifth Annual IEEE , vol., no., pp.1,6, 2125 Feb. 2010.

[15] M. Peretz, B. Mahdavikhah, and A. Prodić, "Hardware-Efficient ProgrammableDeviation Controller for Indirect Energy Transfer Dc-Dc Converters," IEEE Trans. on Power Electronics.

[16] UCD3138LLCEVM-028 User's Guide, Digitally Controlled LLC Resonant Half-Bridge DC-DC Converter, (Texas Instruments Literature Number SLUU979A), 2013.

[17] (Apr. 2009). Texas Instrument, UCC25600EVM: LLC resonant half bridge converter 300 evaluation module [Online]. Available: http://www.ti.com/lit/ug/sluu361/sluu361.pdf.

[18] M. Joung, H. Kim, and J. Baek, "Dynamic analysis and optimal design of high efficiency full bridge LLC resonant converter for server power system," in Proc. IEEE Appl. Power Electron. Conf., Feb. 2012, pp. 1292- 1297.

[19] X. Xie, J. Liu, F. N. K. Poon, and M. Pong, “A novel high frequency current-driven SR applicable to most switching topologies," IEEE Trans. Power Electron., vol. 16, no. 5, pp. 635-648, Sep. 2001.

[20] D.Huang, D. Fu, and F. C. Lee, "High switching frequency, high efficiency CLL resonant converter with synchronous rectifier," in Proc. IEEE Energy Convers. Congr. Expo., 2009, pp. 804-809.

[21] D. Fu, Y. Liu, F. C. Lee, and M. Xu, "A novel driving scheme for synchronous rectifiers in LLC resonant converters," IEEE Trans. Power Electron., vol. 24, no. 5, pp. 1321-1329, May 2009.

[22] International Rectifier, "IR11672AS: Advanced smart rectifier control IC," (Jul. 2011). [Online]. Available: http://www.irf.com/product-info/ datasheets/data/ir11672aspbf.pdf

[23] X.Wu, G. Hua, J. Zhang, and Z. Qian, “A new current-driven synchronous rectifier for series-parallel resonant (LLC) DC-DC converter," IEEE Trans. Ind. Electron., vol. 58, no. 1, pp. 289-297, Jan. 2011. 
[24] Weiyi Feng; Lee, F.C.; Mattavelli, P.; Daocheng Huang, "A Universal Adaptive Driving Scheme for Synchronous Rectification in LLC Resonant Converters," Power Electronics, IEEE Transactions on , vol.27, no.8, pp.3775,3781, Aug. 2012

[25] Abe, Seiya; Yang, Sihun; Shoyama, Masahito; Zaitsu, Toshiyuki; Yamamoto, Junichi; Ueda, Shinji; Ninomiya, Tamotsu, "Adaptive driving of synchronous rectifier for LLC converter without signal sensing," Applied Power Electronics Conference and Exposition (APEC), 2013 Twenty-Eighth Annual IEEE , vol., no., pp.1370,1375, 17-21 March 2013

[26] Yu-Shan Cheng; Jing-hsiao Chen; Yi-hua Liu; Kuo-Liang Huang; Zong-zhen Yang, "Design of a digitally-controlled LLC resonant converter with synchronous rectification," Future Energy Electronics Conference (IFEEC), 2013 1st International, vol., no., pp.772,776, 3-6 Nov. 2013

[27] Ki-Bum Park; Byoung-Hee Lee; Gun-Woo Moon; Myung-Joong Youn, "Analysis on Center-Tap Rectifier Voltage Oscillation of LLC Resonant Converter," Power Electronics, IEEE Transactions on , vol.27, no.6, pp.2684,2689, June 2012

[28] L. Cheng, T. Liu, H. Gan, J. Ying, "Adaptive synchronous rectification control circuit and method thereof", U.S. Patent 7,495,934 B2, Feb.24, 2009.

[29] Texas Instruments, "UCC27223: High efficiency predictive synchronous buck driver with enable" [Online]. Available: http://focus.ti.com/lit/ds/slus558/slus558.pdf.

[30] B. Lu, W. Liu, Y. Liang, F. C. Lee, and J. D. van Wyk, "Optimal design methodology for LLC resonant converter," in Proc. IEEE APEC, 2006, pp.533-538. 


\section{Appendices}

\section{A Optimal Trajectory Analysis for Load Transients}

In this part, the trajectory analysis for LLC resonant converter in 2D state-plane is presented. LLC resonant converter is a multi-element resonant converter [6]. In order to analyze the trajectory in $2 \mathrm{D}$ state-plane first the converter needs to be analyzed and simplified based on different modes of operation, so the resonant elements can be reduced to two elements [6]. Afterwards, the steady-state and dynamic trajectories are illustrated in order to calculate the optimal trajectory loci for state variable to track after transient.

\section{A.1 LLC resonant steady state trajectory in 2D}

The LLC resonant converter can be divided to six modes of operation based on the state of the primary switches and secondary diodes [6]. In the first three modes $Q_{1}$ is conducting and in the rest $Q_{2}$ is conducting. To simplify the analysis the output voltage is assumed to be constant.

In mode I, II, IV, and V the magnetizing inductor $L_{m}$, is clamped with the output voltage reflection from the secondary side. Therefore the magnetizing inductor can be eliminated from the state variable equations [6]. In mode III and VI the magnetizing current participates in the resonance and make a resonant circuit in series with the tank inductor $L_{r}$ and tank capacitor $\mathrm{C}_{\mathrm{r}}$, so the magnetizing current is same as inductor current. Therefore in these cases the magnetizing inductor can be eliminated from the state variable equations as well. Although the LLC resonant converter is a multi-element resonant converter, it can be represented with two resonant element. The following figures show the LLC resonant converter in each mode of operation, and their equivalent circuit and trajectory in the corresponding mode. In the tables below each figure are the state variable differential equations derivatives and the trajectory equation. 


\section{Mode I}

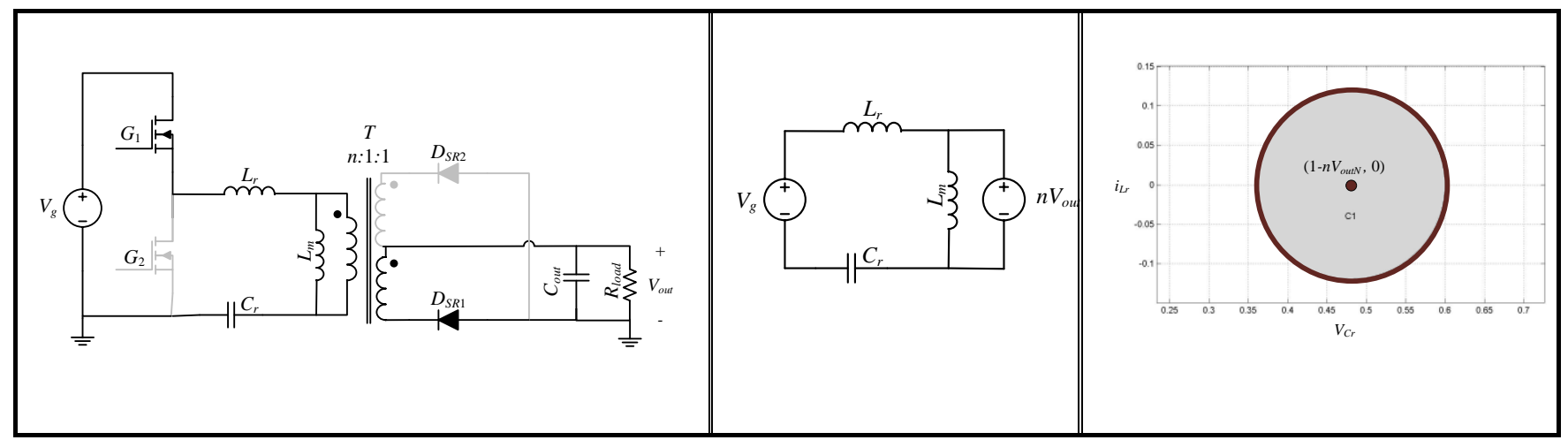

Figure A-1: LLC resonant converter equivalent circuit and its state space trajectory in Mode I

Table 1: Mode I

\begin{tabular}{|c|c|}
\hline State Variables & $\frac{d i_{L_{r}}}{d t}=\frac{1}{L_{r}}\left(V_{g}-n V_{o u t}-v_{C_{r}}\right), \quad \frac{d v_{C_{r}}}{d t}=\frac{1}{C_{r}} i_{L_{r}}$ \\
\hline $\begin{array}{l}\text { Characteristic impedance } \\
\text { Resonant frequency }\end{array}$ & $Z_{0}=\sqrt{\frac{L_{r}}{C_{r}}}, \omega_{0}=\frac{1}{\sqrt{L_{r} C_{r}}}$ \\
\hline Differentiate equations & $\begin{array}{c}i_{L_{r}}=I_{L_{r} 0} \cdot \cos \left[\omega_{0}\left(\mathrm{t}-\mathrm{t}_{0}\right)\right]-\frac{V_{C_{r} 0}-\left(V_{g}-n V_{\text {out }}\right)}{Z_{0}} \cdot \sin \left[\omega_{0}\left(\mathrm{t}-\mathrm{t}_{0}\right)\right] \\
v_{C_{r}}-\left(V_{g}-n V_{\text {out }}\right)=I_{L_{r} 0} \cdot Z_{0} \cdot \sin \left[\omega_{0}\left(\mathrm{t}-\mathrm{t}_{0}\right)\right]+\left[\mathrm{V}_{\mathrm{C}_{\mathrm{r}} 0}-\left(\mathrm{V}_{\mathrm{g}}-n V_{\text {out }}\right)\right] \cdot \cos \left[\omega_{0}\left(\mathrm{t}-\mathrm{t}_{0}\right)\right]\end{array}$ \\
\hline Normalized equations & $\begin{array}{c}i_{L_{r} N}=I_{L_{r} 0 N} \cdot \cos \left[\omega_{0}\left(\mathrm{t}-\mathrm{t}_{0}\right)\right]-\left[V_{C_{r} 0 N}-\left(1-n V_{\text {out } N}\right)\right] \cdot \sin \left[\omega_{0}\left(\mathrm{t}-\mathrm{t}_{0}\right)\right] \\
v_{C_{r} N}-\left(1-n V_{\text {out } N}\right)=I_{L_{r} 0 N} \cdot \sin \left[\omega_{0}\left(\mathrm{t}-\mathrm{t}_{0}\right)\right]+\left[\mathrm{V}_{\mathrm{C}_{\mathrm{r}} 0 N}-\left(1-n V_{\text {out }}\right)\right] \cdot \cos \left[\omega_{0}\left(\mathrm{t}-\mathrm{t}_{0}\right)\right]\end{array}$ \\
\hline State space trajectory equation & {$\left[v_{C_{r} N}-\left(1-n V_{\text {out } N}\right)\right]^{2}+i_{L_{r} N}{ }^{2}=\left(I_{L_{r} 0 N}\right)^{2}+\left[\mathrm{V}_{\mathrm{C}_{\mathrm{r}} 0 N}-\left(1-n V_{\text {out } N}\right)\right]^{2}$} \\
\hline
\end{tabular}




\section{Mode II}

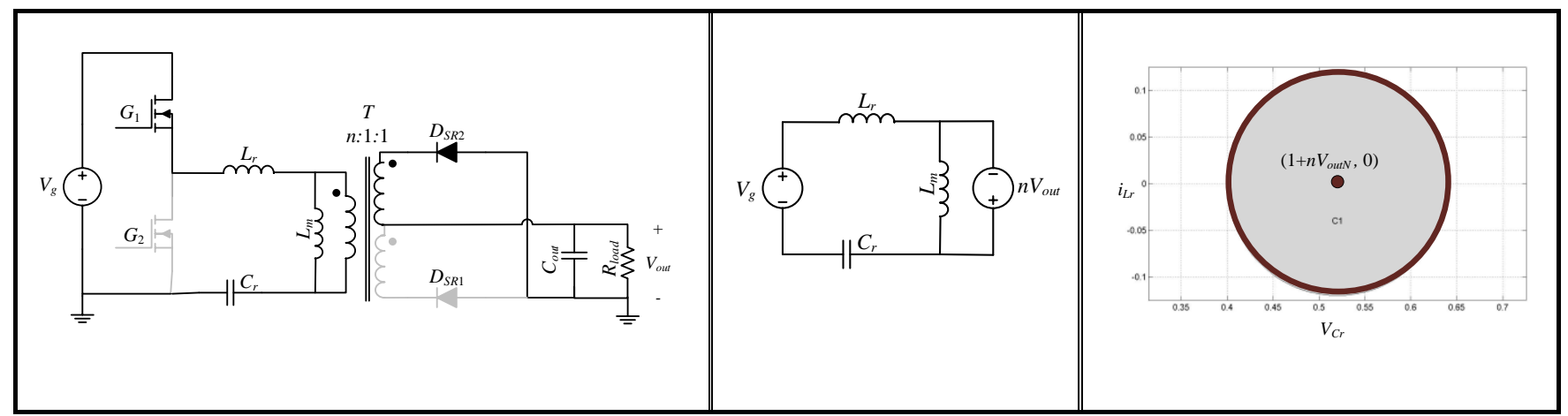

Figure A-2: LLC resonant converter equivalent circuit and its state space trajectory in Mode II

Table 2: Mode II

\begin{tabular}{|c|c|}
\hline State Variables & $\frac{d i_{L_{r}}}{d t}=\frac{1}{L_{r}}\left(V_{g}-n V_{\text {out }}-v_{C_{r}}\right), \frac{d v_{C_{r}}}{d t}=\frac{1}{C_{r}} i_{L_{r}}$ \\
\hline Characteristic impedance & $Z_{0}=\sqrt{\frac{L_{r}}{C_{r}}}$ \\
\hline Resonant frequency & $\omega_{0}=\frac{1}{\sqrt{L_{r} C_{r}}}$ \\
\hline Differentiate equations & $\begin{array}{c}i_{L_{r}}=I_{L_{r} 0} \cdot \cos \left[\omega_{0}\left(\mathrm{t}-\mathrm{t}_{0}\right)\right]-\frac{V_{C_{r} 0}-\left(V_{g}+n V_{\text {out }}\right)}{Z_{0}} \cdot \sin \left[\omega_{0}\left(\mathrm{t}-\mathrm{t}_{0}\right)\right] \\
v_{C_{r}}-\left(V_{g}-n V_{\text {out }}\right)=I_{L_{r} 0} \cdot Z_{0} \cdot \sin \left[\omega_{0}\left(\mathrm{t}-\mathrm{t}_{0}\right)\right]+\left[\mathrm{V}_{\mathrm{C}_{\mathrm{r}} 0}-\left(\mathrm{V}_{\mathrm{g}}-n V_{\text {out }}\right)\right] \cdot \cos \left[\omega_{0}\left(\mathrm{t}-\mathrm{t}_{0}\right)\right]\end{array}$ \\
\hline Normalized equations & $\begin{array}{c}i_{L_{r} N}=I_{L_{r} 0 N} \cdot \cos \left[\omega_{0}\left(\mathrm{t}-\mathrm{t}_{0}\right)\right]-V_{C_{r} 0 N}-\left(1+n V_{\text {out } N}\right) \cdot \sin \left[\omega_{0}\left(\mathrm{t}-\mathrm{t}_{0}\right)\right] \\
v_{C_{r} N}-\left(1-n V_{\text {out } N}\right)=I_{L_{r} 0 N} \cdot \sin \left[\omega_{0}\left(\mathrm{t}-\mathrm{t}_{0}\right)\right]+\left[\mathrm{V}_{\mathrm{C}_{\mathrm{r}} 0 N}-\left(1-n V_{\text {out }}\right)\right] \cdot \cos \left[\omega_{0}\left(\mathrm{t}-\mathrm{t}_{0}\right)\right]\end{array}$ \\
\hline State space trajectory equation & 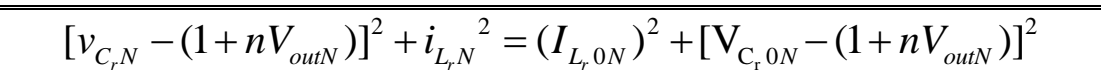 \\
\hline
\end{tabular}




\section{Mode III}

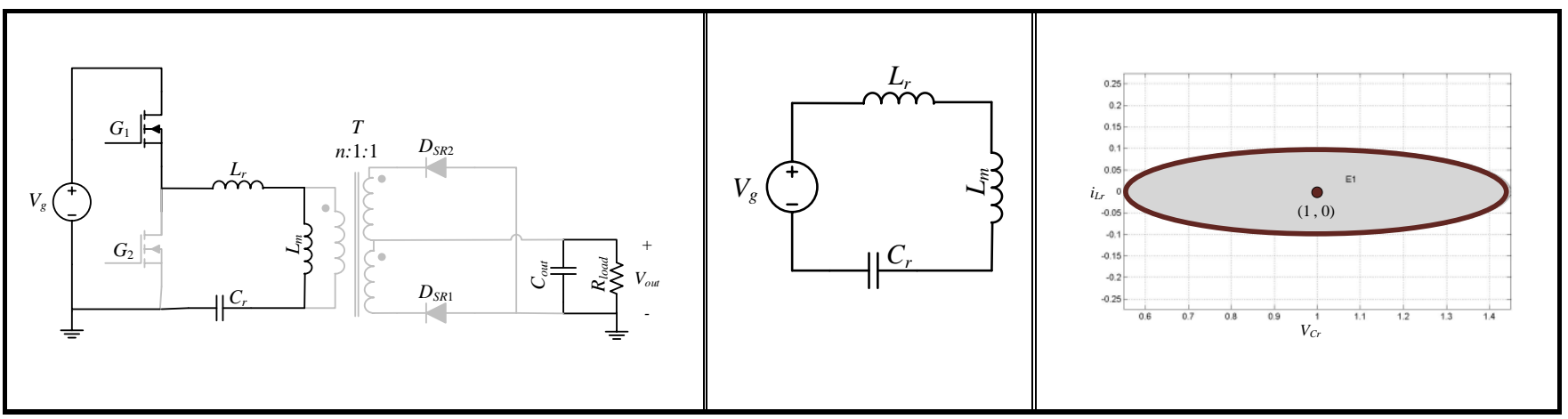

Figure A-3: LLC resonant converter equivalent circuit and its state space trajectory in Mode III

Table 3: Mode III

\begin{tabular}{|l|c|}
\hline State Variables & $\frac{d i_{L_{r}}}{d t}=\frac{1}{L_{r}+L_{m}}\left(V_{g}-v_{C_{r}}\right), \frac{d v_{C_{r}}}{d t}=\frac{1}{C_{r}} i_{L_{r}}$ \\
\hline Characteristic impedance & $Z_{1}=\sqrt{\frac{L_{r}+L_{m}}{C_{r}}}$ \\
\hline Resonant frequency & $\omega_{1}=\frac{1}{\sqrt{\left(L_{r}+L_{m}\right) C_{r}}}$ \\
\hline Differentiate equations & $i_{L_{r}}=I_{L_{r} 0} \cdot \cos \left[\omega_{1}\left(\mathrm{t}-\mathrm{t}_{0}\right)\right]-\frac{V_{C_{r} 0}-V_{g}}{Z_{1}} \cdot \sin \left[\omega_{1}\left(\mathrm{t}-\mathrm{t}_{0}\right)\right]$ \\
\hline State space trajectory equation & $v_{C_{r}}-V_{g}=I_{L_{r} 0} \cdot Z_{1} \cdot \sin \left[\omega_{1}\left(\mathrm{t}-\mathrm{t}_{0}\right)\right]+\left(V_{C_{r} 0}-V_{g}\right) \cdot \cos \left[\omega_{1}\left(\mathrm{t}-\mathrm{t}_{0}\right)\right]$ \\
\hline Normalized equations & $\frac{i_{L_{r} N}}{Z_{0} / Z_{1}}=\frac{I_{L_{r} 0 N}}{Z_{0} / Z_{1}} \cdot \cos \left[\omega_{1}\left(\mathrm{t}-\mathrm{t}_{0}\right)\right]-\left(V_{C_{r} 0 N}-1\right) \cdot \sin \left[\omega_{1}\left(\mathrm{t}-\mathrm{t}_{0}\right)\right]$ \\
\hline
\end{tabular}




\section{Mode IV}

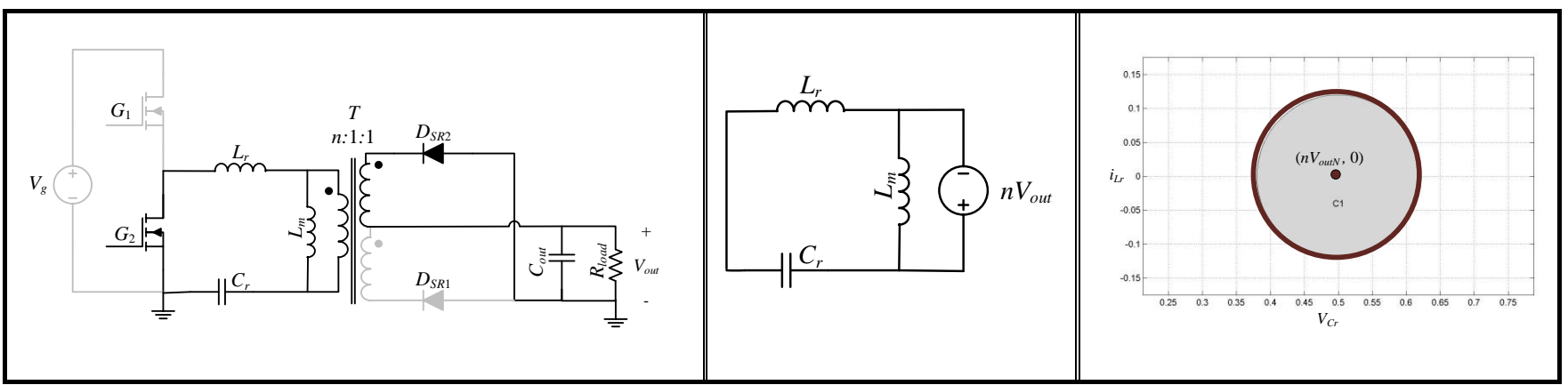

Figure A-4: LLC resonant converter equivalent circuit and its state space trajectory in Mode IV

Table 4: mode IV

\begin{tabular}{|l|c|}
\hline State Variables & $\frac{d i_{L_{r}}}{d t}=\frac{-1}{L_{r}}\left(v_{C_{r}}-n V_{\text {out }}\right), \frac{d v_{C_{r}}}{d t}=\frac{1}{C_{r}} i_{L_{r}}$ \\
\hline Characteristic impedance & $Z_{0}=\sqrt{\frac{L_{r}}{C_{r}}}$ \\
\hline Resonant frequency & $\omega_{0}=\frac{1}{\sqrt{L_{r} C_{r}}}$ \\
\hline Differentiate equations & $i_{L_{r}}=I_{L_{r} 0} \cdot \cos \left[\omega_{0}\left(\mathrm{t}-\mathrm{t}_{0}\right)\right]-\frac{V_{C_{r} 0}-n V_{\text {out }}}{Z_{0}} \cdot \sin \left[\omega_{0}\left(\mathrm{t}-\mathrm{t}_{0}\right)\right]$ \\
\hline Normalized equations & $v_{C_{r}}-n V_{\text {out }}=I_{L_{r} 0} \cdot Z_{0} \cdot \sin \left[\omega_{0}\left(\mathrm{t}-\mathrm{t}_{0}\right)\right]-\left(\mathrm{V}_{\mathrm{C}_{\mathrm{r}} 0}-n V_{\text {out }}\right) \cdot \cos \left[\omega_{0}\left(\mathrm{t}-\mathrm{t}_{0}\right)\right]$ \\
\hline State space trajectory equation & $v_{C_{r} N}-n V_{\text {out }}=I_{L_{r} 0 N} \cdot \sin \left[\omega_{0}\left(\mathrm{t}-\mathrm{t}_{0}\right)\right]-\left(\mathrm{V}_{\mathrm{C}_{\mathrm{r}} 0 N}-n V_{\text {out }}\right) \cdot \cos \left[\omega_{0}\left(\mathrm{t}-\mathrm{t}_{0}\right)\right]$ \\
\hline & $i_{L_{r} N}=I_{L_{r} 0 N} \cdot \cos \left[\omega_{0}\left(\mathrm{t}-\mathrm{t}_{0}\right)\right]-\left(V_{C_{r} 0 N}-n V_{\text {out }}\right) \cdot \sin \left[\omega_{0}\left(\mathrm{t}-\mathrm{t}_{0}\right)\right]$ \\
\hline & $\left(v_{C_{r} N}-n V_{\text {out }}\right)^{2}+i_{L_{r} N}{ }^{2}=\left(I_{L_{r} 0 N}\right)^{2}+\left(\mathrm{V}_{\mathrm{C}_{\mathrm{r}} 0 N}-n V_{\text {out }}\right)^{2}$ \\
\hline
\end{tabular}




\section{Mode V}

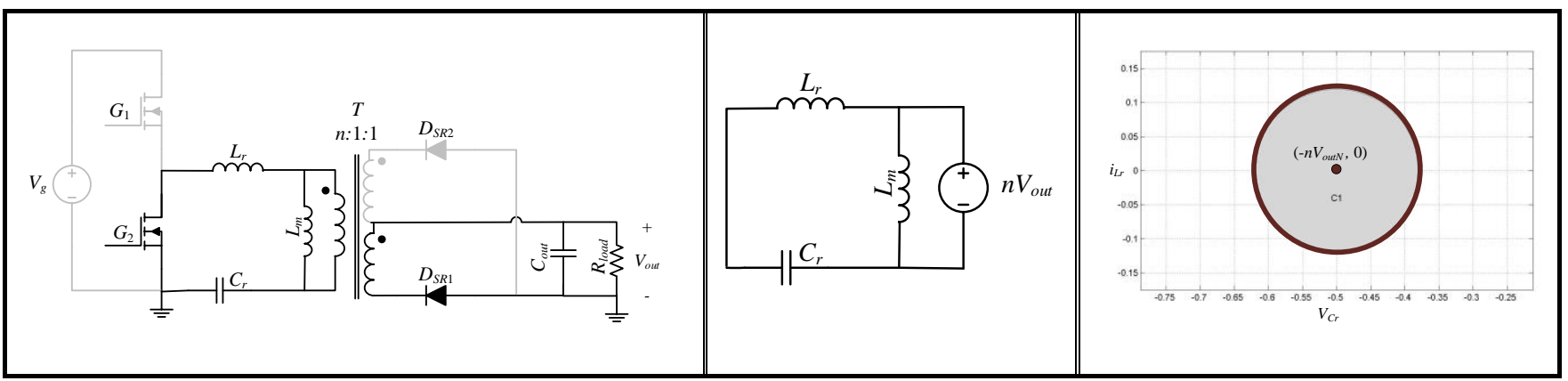

Figure A-5: LLC resonant converter equivalent circuit and its state space trajectory in Mode V

Table 5: Mode V

\begin{tabular}{|c|c|}
\hline State Variables & $\frac{d i_{L_{r}}}{d t}=\frac{-1}{L_{r}}\left(n V_{\text {out }}+v_{C_{r}}\right), \frac{d v_{C_{r}}}{d t}=\frac{1}{C_{r}} i_{L_{r}}$ \\
\hline Characteristic impedance & $Z_{0}=\sqrt{\frac{L_{r}}{C_{r}}}$ \\
\hline Resonant frequency & $\omega_{0}=\frac{1}{\sqrt{L_{r} C_{r}}}$ \\
\hline Differentiate equations & $\begin{array}{c}i_{L_{r}}=I_{L_{r} 0} \cdot \cos \left[\omega_{0}\left(\mathrm{t}-\mathrm{t}_{0}\right)\right]-\frac{V_{C_{r} 0}+n V_{\text {out }}}{Z_{0}} \cdot \sin \left[\omega_{0}\left(\mathrm{t}-\mathrm{t}_{0}\right)\right] \\
v_{C_{r}}+n V_{\text {out }}=I_{L_{r} 0} \cdot Z_{0} \cdot \sin \left[\omega_{0}\left(\mathrm{t}-\mathrm{t}_{0}\right)\right]-\left(\mathrm{V}_{\mathrm{C}_{\mathrm{r}} 0}+n V_{\text {out }}\right) \cdot \cos \left[\omega_{0}\left(\mathrm{t}-\mathrm{t}_{0}\right)\right]\end{array}$ \\
\hline Normalized equations & $\begin{array}{c}i_{L_{r} N}=I_{L_{r} 0 N} \cdot \cos \left[\omega_{0}\left(\mathrm{t}-\mathrm{t}_{0}\right)\right]-\left(V_{C_{r} 0 N}+n V_{\text {out } N}\right) \cdot \sin \left[\omega_{0}\left(\mathrm{t}-\mathrm{t}_{0}\right)\right] \\
v_{C_{r} N}+n V_{\text {out } N}=I_{L_{r} 0 N} \cdot \sin \left[\omega_{0}\left(\mathrm{t}-\mathrm{t}_{0}\right)\right]-\left(\mathrm{V}_{\mathrm{C}_{\mathrm{r}} 0 N}+n V_{\text {out } N}\right) \cdot \cos \left[\omega_{0}\left(\mathrm{t}-\mathrm{t}_{0}\right)\right]\end{array}$ \\
\hline State space trajectory equation & $\left(v_{C_{r} N}+n V_{\text {out } N}\right)^{2}+i_{L_{r} N}^{2}=\left(I_{L_{r} 0 N}\right)^{2}+\left(\mathrm{V}_{\mathrm{C}_{\mathrm{r}} 0 N}+n V_{\text {out } N}\right)^{2}$ \\
\hline
\end{tabular}




\section{Mode VI}

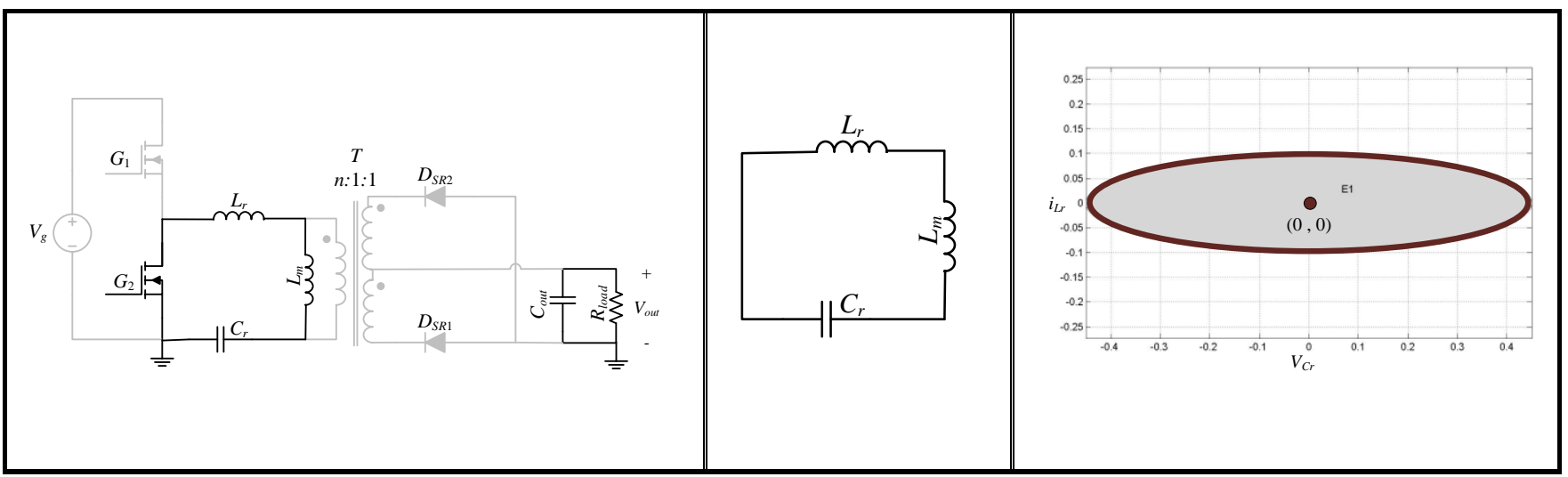

Figure A-6: LLC resonant converter equivalent circuit and its state space trajectory in Mode VI

Table 6: Mode VI

\begin{tabular}{|c|c|}
\hline State Variables & $\frac{d i_{L_{r}}}{d t}=\frac{-1}{L_{m}+L_{r}} \cdot v_{C_{r}}, \quad \frac{d v_{C_{r}}}{d t}=\frac{1}{C_{r}} i_{L_{r}}$ \\
\hline Characteristic impedance & $Z_{1}=\sqrt{\frac{L_{r}+L_{m}}{C_{r}}}$ \\
\hline Resonant frequency & $\omega_{1}=\frac{1}{\sqrt{\left(L_{r}+L_{m}\right) C_{r}}}$ \\
\hline Differentiate equations & $\begin{array}{c}i_{L_{r}}=I_{L_{r} 0} \cdot \cos \left[\omega_{1}\left(\mathrm{t}-\mathrm{t}_{0}\right)\right]-\frac{V_{C_{r} 0}}{Z_{1}} \cdot \sin \left[\omega_{1}\left(\mathrm{t}-\mathrm{t}_{0}\right)\right] \\
v_{C_{r}}=I_{L_{r} 0} \cdot Z_{1} \cdot \sin \left[\omega_{1}\left(\mathrm{t}-\mathrm{t}_{0}\right)\right]+V_{C_{r} 0} \cdot \cos \left[\omega_{1}\left(\mathrm{t}-\mathrm{t}_{0}\right)\right]\end{array}$ \\
\hline Normalized equations & $\begin{array}{c}\frac{i_{L_{r} N}}{Z_{0} / Z_{1}}=\frac{I_{L_{r} 0 N}}{Z_{0} / Z_{1}} \cdot \cos \left[\omega_{1}\left(\mathrm{t}-\mathrm{t}_{0}\right)\right]-V_{C_{r} 0 N} \cdot \sin \left[\omega_{1}\left(\mathrm{t}-\mathrm{t}_{0}\right)\right] \\
v_{C_{r} N}=\frac{I_{L_{r} 0 N}}{Z_{0} / Z_{1}} \cdot \sin \left[\omega_{1}\left(\mathrm{t}-\mathrm{t}_{0}\right)\right]+V_{C_{r} 0 N} \cdot \cos \left[\omega_{1}\left(\mathrm{t}-\mathrm{t}_{0}\right)\right]\end{array}$ \\
\hline State space trajectory equation & $v_{C_{r} N}{ }^{2}+\left(\frac{i_{L_{r} N}}{Z_{0} / Z_{1}}\right)^{2}=\left(\frac{I_{L_{r} 0 N}}{Z_{0} / Z_{1}}\right)^{2}+\mathrm{V}_{\mathrm{C}_{\mathrm{r}} 0 N}{ }^{2}$ \\
\hline
\end{tabular}




\section{A.2 LLC Load Transient Trajectories in State-Plane}

In this part the state-plane analysis during load transient is illustrated using the state trajectories studied in the previous section. In order to recover from the transient in the minimum possible time and avoid overshoot, the increment and decrement time period of the switching frequency is calculated using the graphic state-plane analysis [6].

\section{A.2.1 Light to Heavy Load Transient}

The LLC resonant converter usually operates close to the resonant frequency to achieve the highest efficiency, therefore the trajectories are circles and the radius depends on the load current. For a light load, $I_{L L}$ to heavy load $I_{H L}$ transient the state variables move from one circle with a smaller radius to a circle with a bigger radius.

In order to avoid unbalance current in the magnetizing inductor this transition needs to take place in two steps. As shown in Figure A-7 and Figure A-8 the state variables are located on the inner circle in the beginning at $\mathrm{t} 1$ they move to the middle circle moving on the ellipse of mode III. From $t_{2}$ to $t_{3}$ state variables are on the middle circle and at $t_{3}$ they move to the outer circle through the ellipse of mode VI. At time $t_{4}$ all state variables $\left(i_{L r}, V_{C r}\right.$ and $\left.i_{L m}\right)$ are settled [6].

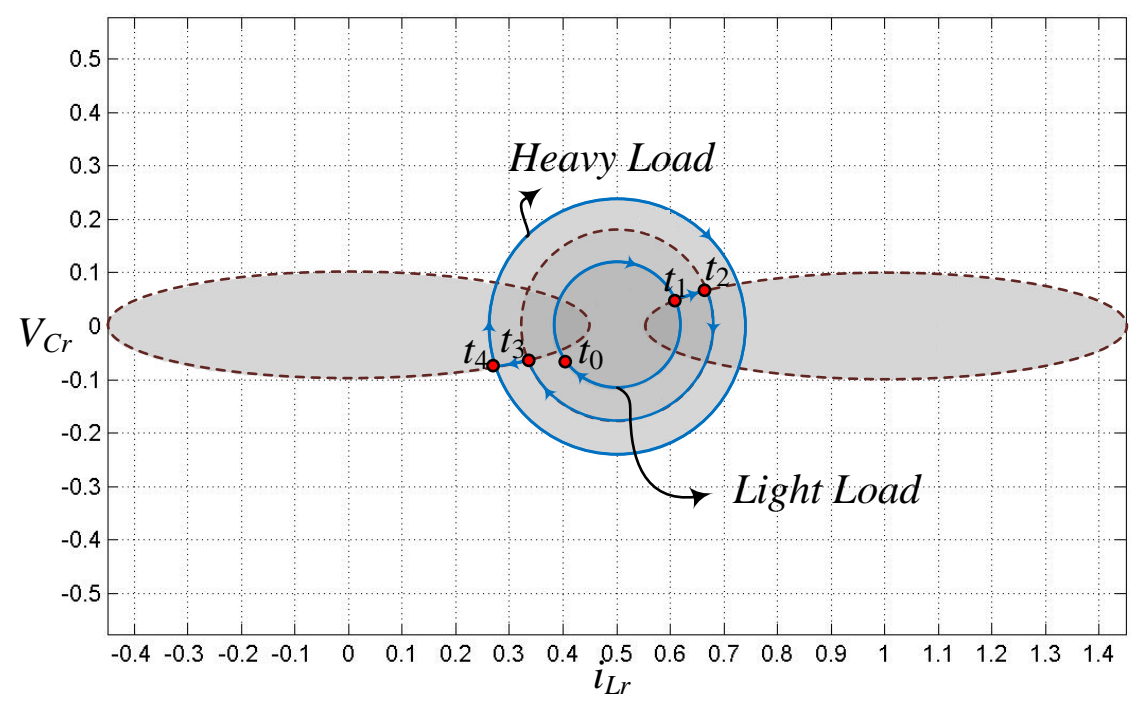

Figure A-7: State trajectory during load step up 


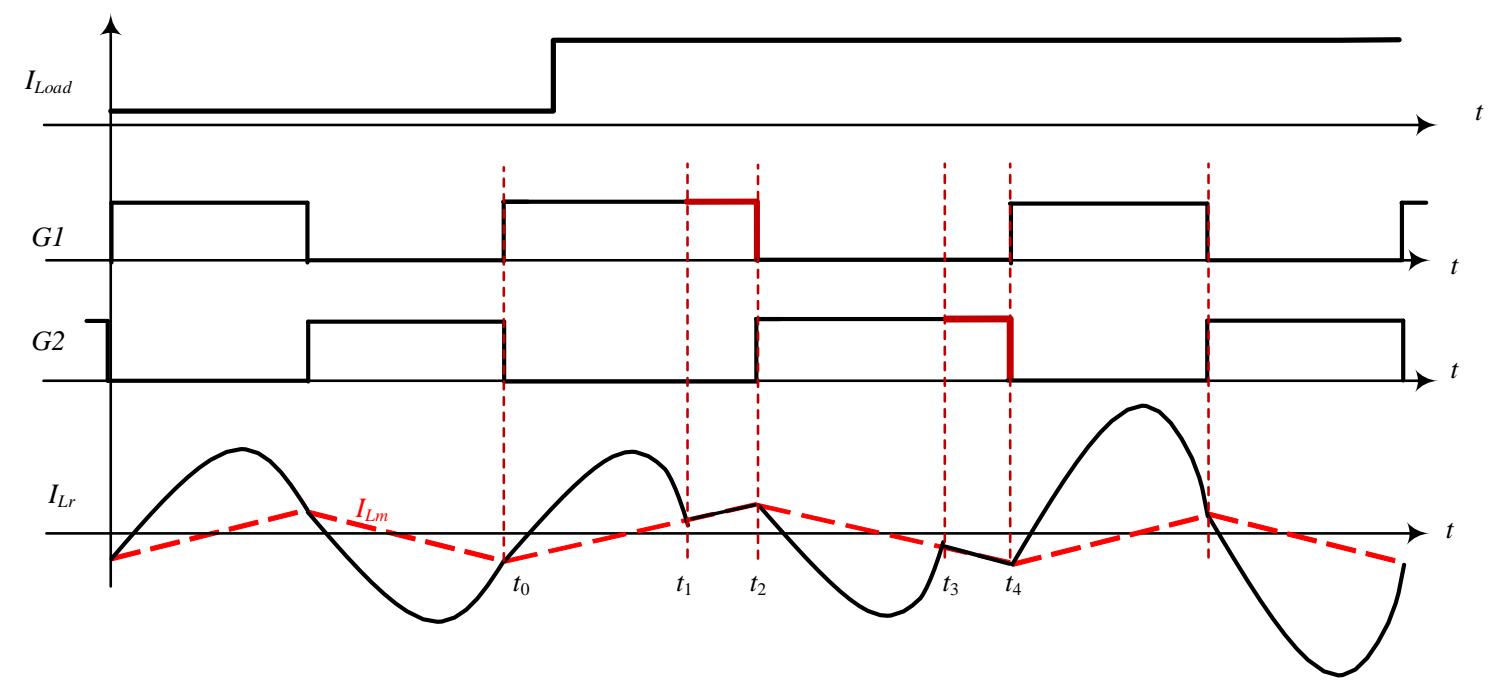

Figure A-8: LLC resonant converter waveforms during load step up

Now that we know the desired path on the trajectory, the objective is to calculate the time increment $\left(t_{2}-t_{1}\right)$ on the pulse width.

From [30] the RMS resonant inductor current, $I_{R M S}$ near the resonant frequency is :

$$
I_{R M S}=\frac{1}{4 \sqrt{2}} \cdot \frac{V_{\text {out }}}{n R_{L}} \sqrt{\frac{n^{4} R_{L}^{2} T^{2}}{L_{m}^{2}}+4 \pi^{2}}=\frac{1}{4 \sqrt{2}} \sqrt{\frac{n^{2} V_{\text {out }}^{2} T^{2}}{L_{m}^{2}}+4 \pi^{2}\left(\frac{\mathrm{i}_{\text {Load }}}{n}\right)^{2}}
$$

The radius of the trajectory circles presented in the previous part are the normalized peak current. Therefore (A-2) shows the relation between the $I_{R M S}$ and the radius of the trajectory circle.

$$
\rho=\frac{\sqrt{2} I_{R M S}}{V_{g} / Z_{0}}
$$

Initially the converter is operating in mode I and mode IV, so the magnetizing inductor is clamped with the reflection of the output voltage from the secondary side. Therefore the magnetizing inductor current $i_{L m}$ can be calculated based on the output voltage [6]. At $t_{1}$ the convertor enters mode III and $i_{L m}$ and resonant inductor $i_{L r}$ are in series in this mode. So the value of the $i_{L r}$ can be written as: 


$$
i_{L r}\left(t_{1}\right)=i L_{m}\left(t_{1}\right)=\frac{n V_{o u t}}{L_{m}} \cdot \frac{T}{4}
$$

The normalized form is:

$$
i_{L_{r} N}\left(t_{1}\right)=i L_{m N}\left(t_{1}\right)=\frac{n V_{\text {out }}}{L_{m}} \cdot \frac{T}{4} \cdot \frac{1}{V_{g} / Z_{0}}
$$

While converter is operating in the resonance the state trajectory is a circle centered at $(0.5,0)$ and the value of the $v_{C r N}$ is as follows:

$$
v_{C_{r} N}\left(t_{1}\right)=\sqrt{\rho^{2}-i_{L_{r} N}\left(t_{1}\right)^{2}}+0.5=\frac{\pi}{2} \cdot \frac{i_{\text {Load }}}{n} \cdot \frac{1}{V_{g} / Z_{0}}+0.5
$$

Load current at $t_{1}$ is the light load, $I_{L L}$ so:

$$
v_{C_{r} N}\left(t_{1}\right)=\frac{\pi}{2} \cdot \frac{I_{L L}}{n} \cdot \frac{1}{V_{g} / Z_{0}}+0.5
$$

Similarly $v_{C r}$ at $t_{4}$ can be calculated:

$$
v_{C r N}\left(t_{4}\right)=-\frac{\pi}{2} \cdot \frac{I_{H L}}{n} \cdot \frac{1}{V_{g} / Z_{0}}+0.5
$$

The normalized value of $v_{C r}$ at $t_{2}$ can be estimated by:

$$
v_{C r N}\left(t_{2}\right)=\frac{v_{C r N}\left(t_{1}\right)+\left(1-v_{C r N}\left(t_{4}\right)\right)}{2}=\frac{\pi}{2} \cdot \frac{\left(I_{L L}+I_{H L}\right) / 2}{n} \cdot \frac{1}{V_{g} / Z_{0}}+0.5
$$

Since the magnetizing inductor is large, from $t_{1}$ to $t_{2}, i_{L r}$ and $i_{L m}$ is considered to be constant.

$$
I=i_{L r}\left(t_{1}\right)=i_{L m}\left(t_{1}\right)=\frac{n V_{\text {out }}}{L_{m}} \cdot \frac{T}{4}=\frac{V_{g}}{L_{m}} \cdot \frac{T}{8}
$$

The resonant capacitor is charging during this time $\left(t_{1}\right.$ to $\left.t_{2}\right)$ so the time difference can be presented as: 


$$
\Delta T_{I N C}=t_{2}-t_{1}=\frac{C_{r} \cdot\left(v_{C r N}\left(t_{2}\right)-v_{C r N}\left(t_{1}\right)\right) \cdot \mathrm{V}_{\mathrm{g}}}{I}=\frac{L_{m} \cdot\left(I_{H L}-I_{L L}\right) / n}{V_{g}}
$$

\section{A.2.2 Heavy Light to Load Transient}

For heavy to light load transient the pulse width needs to get smaller, therefore the time decrement needs to be calculated. Initially converter is operating in mode I and IV at $t_{1}$ converter goes through mode $\mathrm{V}$ to middle circle. At $t_{3}$ converter enters mode II until $t_{4}$. At this point state variables reach their final values [6].

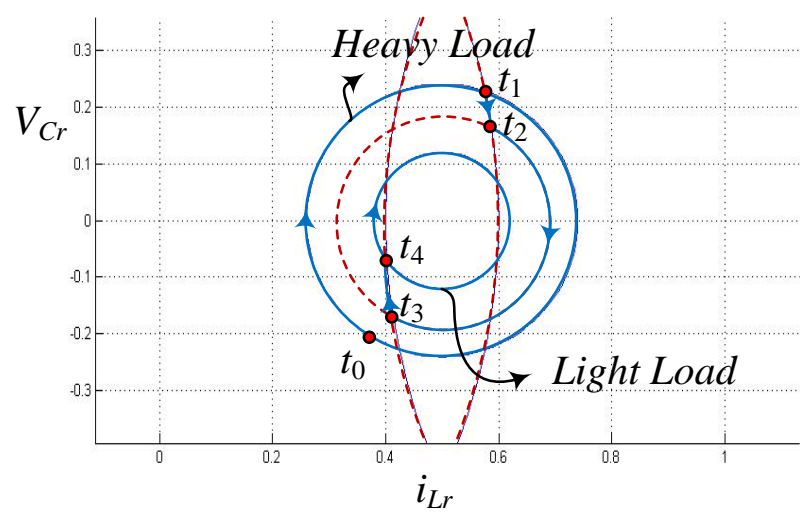

Figure A-9: State trajectory during load step down

The normalized resonant capacitor voltage at $t_{0}$ and $t_{4}$ are:

$$
\begin{aligned}
& V_{C r N}\left(t_{0}\right)=-\frac{\pi}{2} \cdot \frac{I_{H L}}{n} \cdot \frac{1}{V_{g} / Z_{0}}+0.5 \\
& V_{C r N}\left(t_{4}\right)=-\frac{\pi}{2} \cdot \frac{I_{L L}}{n} \cdot \frac{1}{V_{g} / Z_{0}}+0.5
\end{aligned}
$$




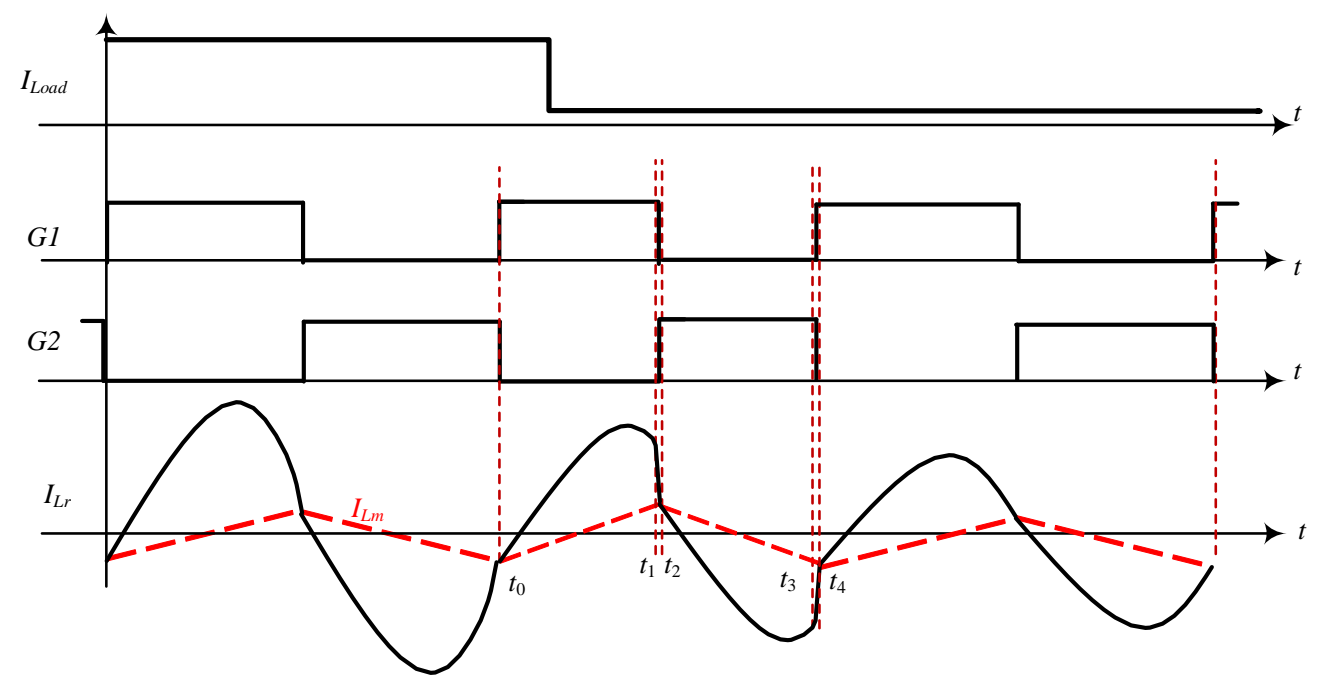

Figure A-10: LLC resonant converter waveforms during load step down

All the modes during heavy to light load transient are circles so the magnetizing inductor $L_{m}$ is always clamped by the output voltage $n v_{\text {out }}$.

Since the circles of modes $\mathrm{V}$ and II are much larger, the line from $t_{1}$ to $t_{2}$ and $t_{3}$ to $t_{4}$ assumed to be straight. Therefore $v_{C r N}\left(t_{1}\right)=v_{C r N}\left(t_{2}\right)$ and $v_{C r N}\left(t_{3}\right)=v_{C r N}\left(t_{4}\right)$. The equations for inductor current and capacitor voltage are as follow:

$$
\begin{aligned}
& \frac{v_{C r N}\left(t_{2}\right)-0.5}{0.5-v_{C r N}\left(t_{0}\right)}=\frac{0.5-v_{C r N}\left(t_{3}\right)}{v_{C r N}\left(t_{1}\right)-0.5}=\frac{i_{L m N}\left(t_{2}\right)}{-i_{L m N}\left(t_{0}\right)} \\
& v_{C r N}(t 2)=\sqrt{\left(0.5-v_{C r N}\left(t_{0}\right)\right) \cdot\left(0.5-v_{C r N}\left(t_{3}\right)\right)}+0.5=\frac{\pi}{2} \cdot \frac{\sqrt{I_{H L} \cdot I_{L L}}}{n} \cdot \frac{1}{V_{g} / Z_{0}}+0.5 \\
& i_{L r N}\left(t_{0}\right)=i_{\text {LmN }}\left(t_{0}\right)=-\frac{n V_{\text {out }}}{L_{m}} \cdot \frac{T}{4} \cdot \frac{1}{V_{g} / Z_{0}} \\
& i_{L m N}\left(t_{2}\right)=-i_{L m N}\left(t_{0}\right) \cdot \frac{v_{C r N}\left(t_{2}\right)-0.5}{0.5-v_{C r N}\left(t_{0}\right)}=\frac{n V_{\text {out }}}{L_{m}} \cdot \frac{T}{4} \cdot \frac{1}{V_{g} / Z_{0}} \cdot \sqrt{\frac{I_{L L}}{I_{H L}}}
\end{aligned}
$$

Using above equations the time duration from to to $t_{2}$ can be obtained: 


$$
T^{\prime}=t_{2}-t_{0}=\frac{L_{m} \cdot\left(i_{L m N}\left(t_{2}\right)-i_{L m N}\left(t_{0}\right)\right) \cdot \mathrm{V}_{\mathrm{g}} / Z_{0}}{n V_{\text {out }}}=\left(1+\sqrt{\frac{I_{L L}}{I_{H L}}}\right) \cdot \frac{T}{4}
$$

The decreases pulse width can be estimated by:

$$
\Delta T_{D E C}=\frac{T}{2}-T^{\prime}=\left(1-\sqrt{\frac{I_{L L}}{I_{H L}}}\right) \cdot \frac{T}{4}
$$




\section{B Implementation of Functional Blocks}

In this chapter the detailed implementation of some of the important blocks in the controller is explained. Figure B-1 shows the functional blocks used in the controller.

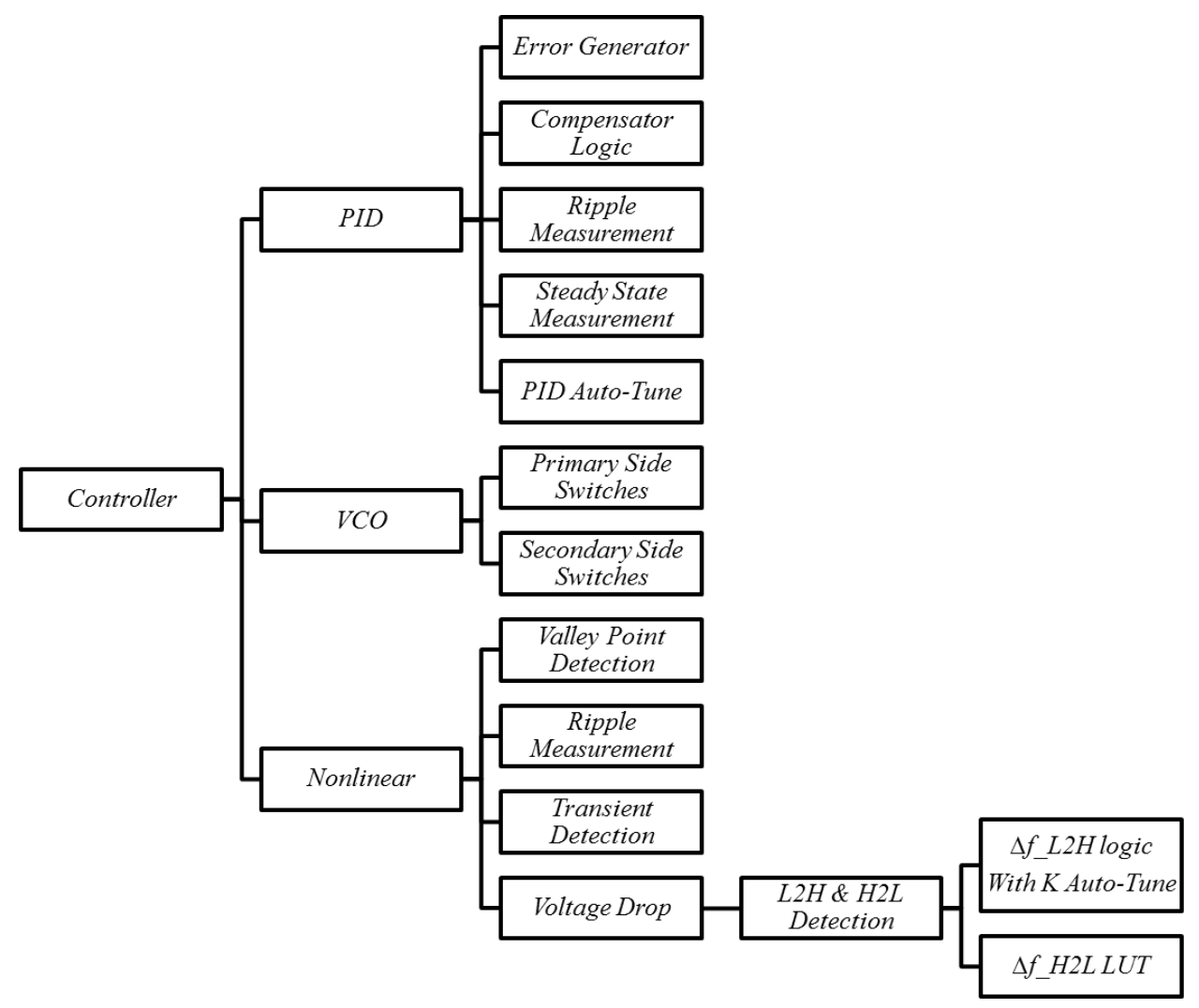

Figure B-1: Functional blocks used in the introduced controller

\section{B.1 VCO Block}

Figure B-2 shows a conventional VCO block that updates the frequency after each cycle. Since the introduced controller changes the switching frequency after transient, in some cases the conventional VCO is unable to properly drive the switches. Figure B-3 shows the experimental results with a conventional VCO in which the driving signal is faulty. In order to avoid this problem a universal VCO is designed as it is shown in Figure B-4. 


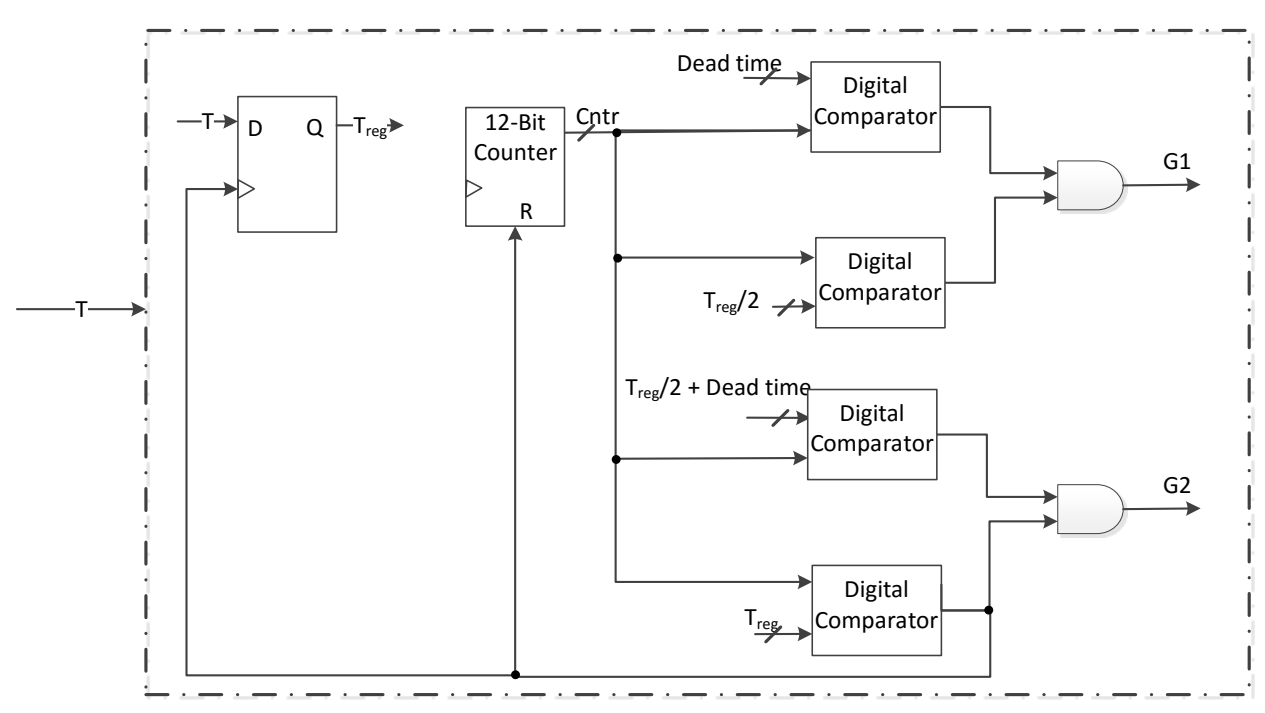

Figure B-2: Conventional VCO implementation

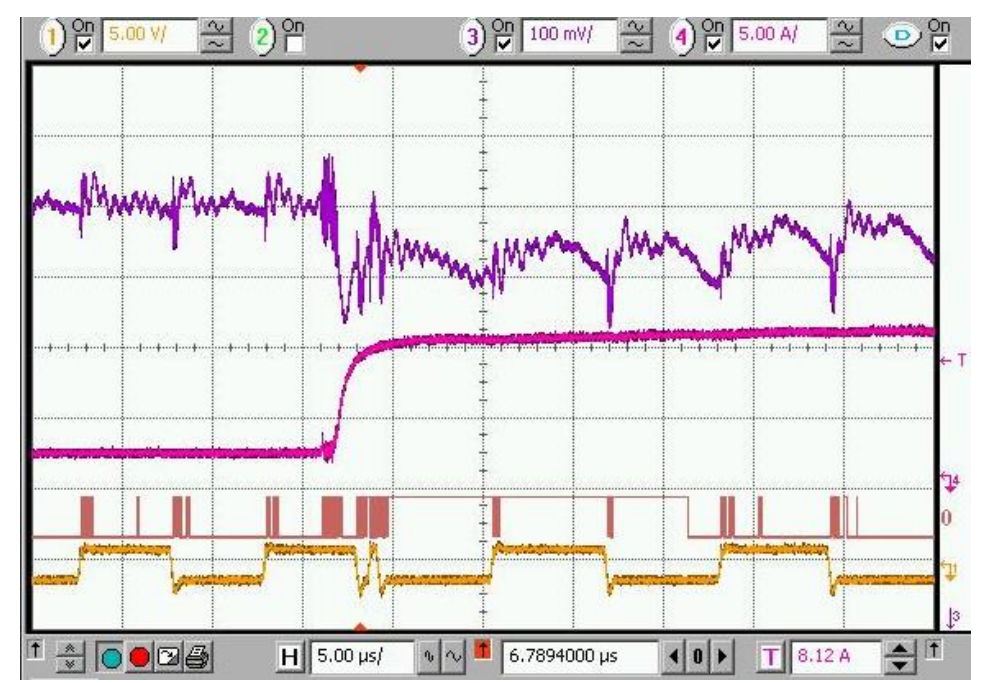

Figure B-3: Experimental result using conventional VCO

Universal VCO uses a counter that reset every half cycle. During normal operation in which PID is controlling the system VCO changes the frequency only after end of each cycle. Although it enables the nonlinear controller to change the frequency at the time that transient happens to make the system faster. Figure B-5shows the experimental result with the universal VCO. The comparison between the driving signals of conventional and universal VCO is shown in Figure B-6. 


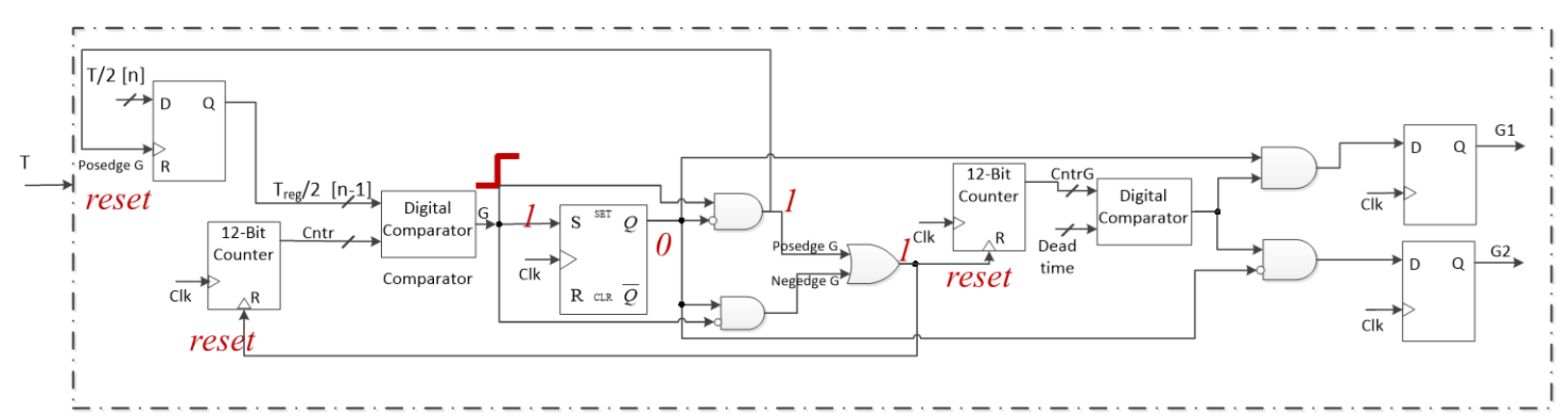

Figure B-4: Universal VCO implementation

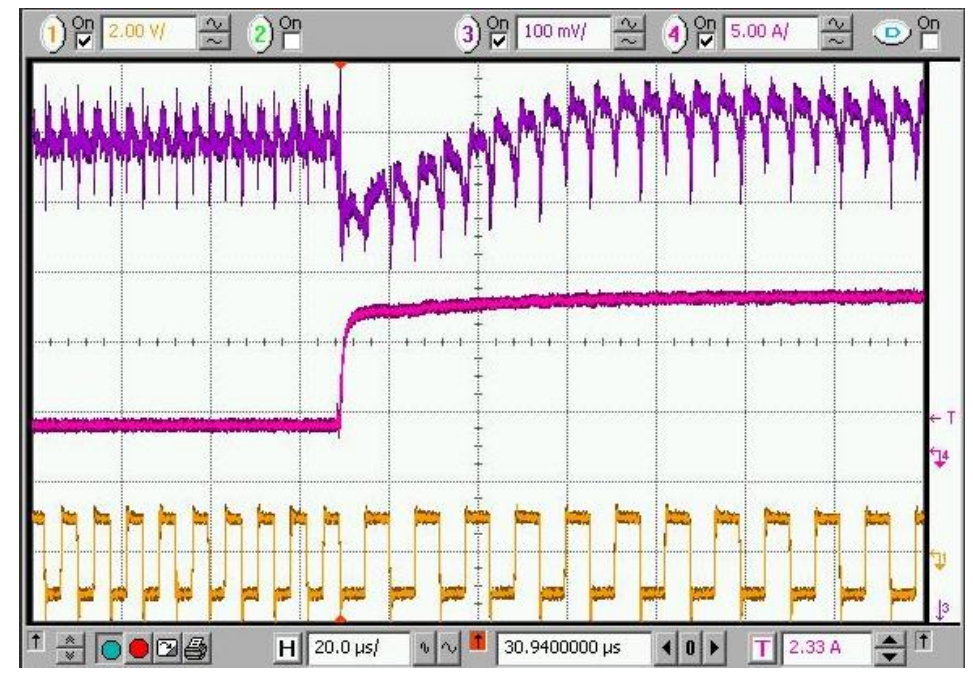

Figure B-5: experimental result using the universal VCO

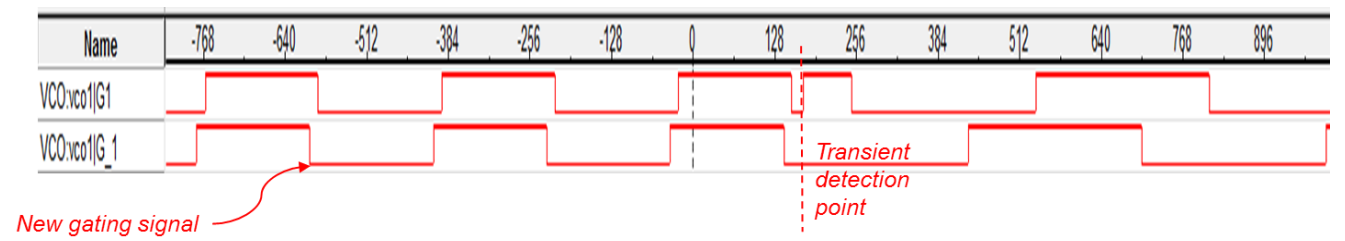

Figure B-6: Driving signal comparison using conventional and universal VCO

\section{B.2 Voltage Deviation, H2L and L2H Detection}

In order to find the voltage deviation after transient, the deference between value of output voltage at transient and half cycle after transient is measured as shown in Figure B-7. Based on the sign of the voltage drop the type of transient $(\mathrm{H} 2 \mathrm{~L}$ or $\mathrm{L} 2 \mathrm{H})$ is detected. 


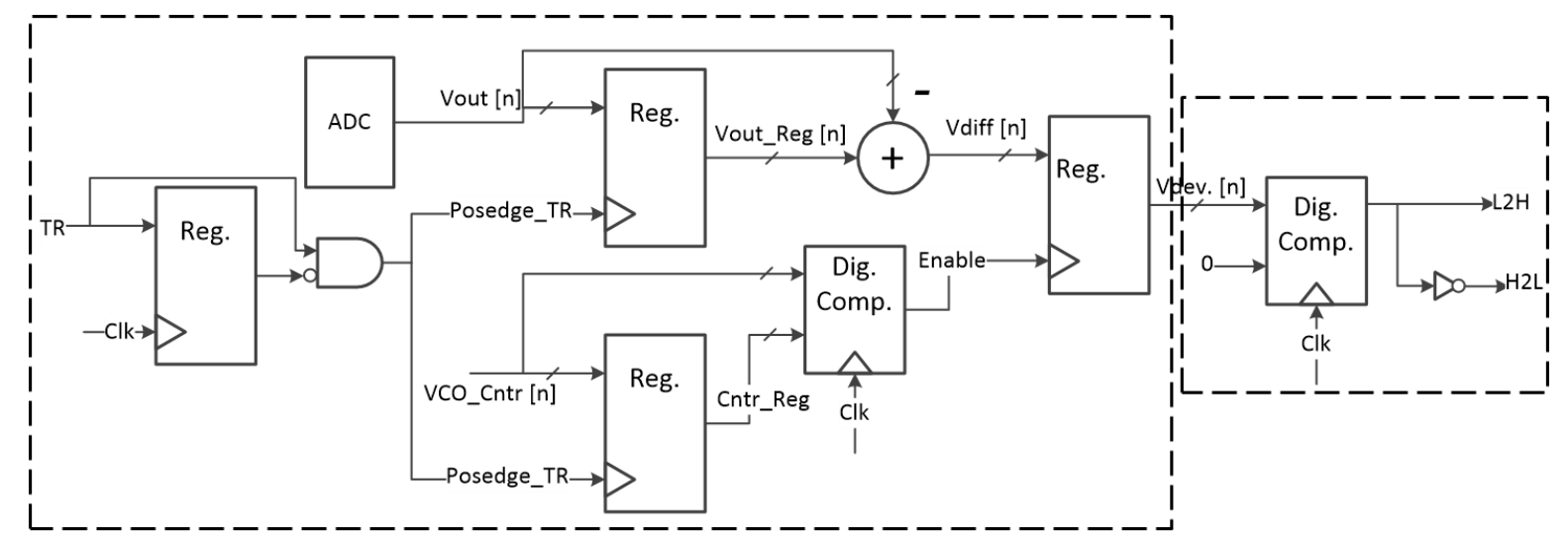

Figure B-7: Voltage Drop, H2L and L2H Detection

\section{B.3 Ripple measurement and PID Re-Initialization}

During over sampling, once at steady state for 20 cycles and once after transient, the deference between maximum and minimum of the output voltage in each cycle is measured as shown in Figure B-8. The output of ripple measurement block during transient is used to determine the initial value of the PID at valley point. Its output during steady state is used to update the frequency in PID look up table (LUT).

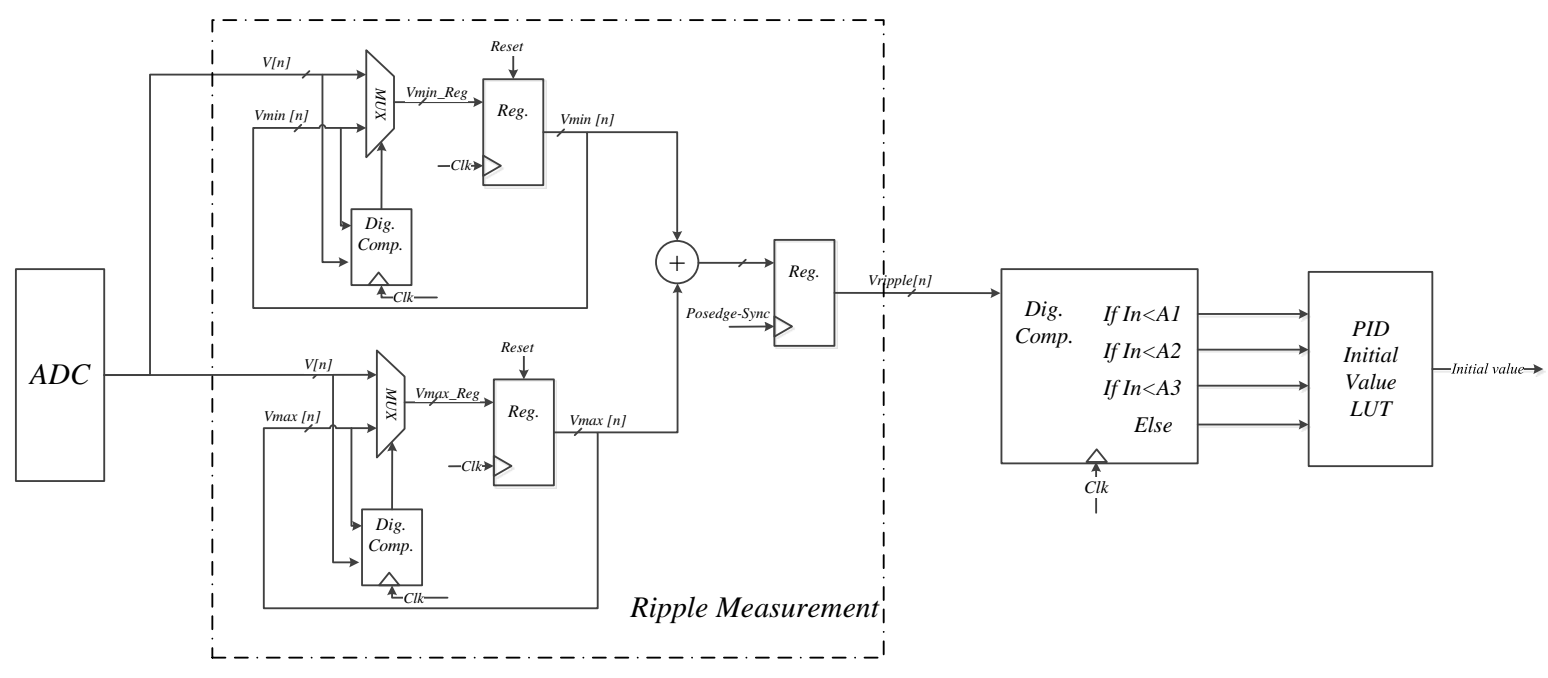

Figure B-8: Ripple measurement and PID Re-Initialization 


\section{Approximation for the Charge (Equation (3.13))}

The relation between the lost charge and the new load current value is described in this section.

The output voltage is:

$$
v_{\text {out }}=v_{c}+E S R . i_{c}
$$

Knowing

$$
\begin{gathered}
v_{c}=\frac{1}{C} \int i_{c} \cdot d t \\
i_{c}=I_{L}\left(\frac{\pi}{2}|\sin \omega t|-1\right) \\
\int_{0}^{t} i_{c} \cdot d t=I_{L}\left(\frac{-\pi}{2 \omega} \cos \omega t-t+\frac{\pi}{2 \omega}\right)
\end{gathered}
$$

$v_{\text {out }}$ can be written as:

$$
v_{\text {out }}=\frac{I_{L}}{C}\left(\frac{-\pi}{2 \omega} \cos \omega t-t+\frac{\pi}{2 \omega}\right)+\text { ESR. }_{L}\left(\frac{\pi}{2} \sin \omega t-1\right)+V_{0}
$$

In order to find the voltage ripple as it shown in Figure 3-3 the two extreme points of $v_{\text {out }}$ needs to be found.

$$
\begin{gathered}
\frac{d v_{\text {out }}}{d t}=\frac{I_{L}}{C}\left(\frac{\pi}{2} \sin \omega t-1\right)+E S R \cdot I_{L} \cdot \frac{\pi \omega}{2} \cos \omega t \\
\left.\frac{d v_{\text {out }}}{d t}\right|_{t=t_{1} \& t_{2}}=0 \\
\sin \omega t=\frac{2}{\pi}-\frac{C}{I_{L}} E S R \cdot I_{L} \cdot \omega \cdot \cos \omega t
\end{gathered}
$$




$$
\begin{aligned}
& \sqrt{1-\cos ^{2} \omega t}=\frac{2}{\pi}-\frac{C}{I_{L}} E S R \cdot I_{L} \cdot \omega \cdot \cos \omega t \\
& \cos ^{2} \omega t .\left((C \cdot E S R . \omega .)^{2}+1\right)-\frac{4}{\pi} \cdot C \cdot E S R \cdot \omega \cdot \cos \omega t+\frac{4}{\pi^{2}}-1=0 \\
& \text { C.ESR. } \omega=E \\
& \cos ^{2} \omega t \cdot\left(E^{2}+1\right)-\frac{4}{\pi} \cdot E \cdot \cos \omega t+\frac{4}{\pi^{2}}-1=0 \\
& \cos \omega t=\frac{\frac{4}{\pi} \cdot E \pm \sqrt{\frac{16}{\pi^{2}} \cdot E^{2}-4 \cdot\left(E^{2}+1\right) \cdot\left(\frac{4}{\pi^{2}}-1\right)}}{2 \cdot\left(E^{2}+1\right)} \\
& \cos \omega t=\frac{\frac{2}{\pi} \cdot E \pm \sqrt{E^{2}+1-\frac{4}{\pi^{2}}}}{\left(E^{2}+1\right)} \\
& \cos \omega t_{1}=\frac{\frac{2}{\pi} \cdot E+\sqrt{E^{2}+1-\frac{4}{\pi^{2}}}}{\left(E^{2}+1\right)}, \cos \omega t_{2}=\frac{\frac{2}{\pi} \cdot E-\sqrt{E^{2}+1-\frac{4}{\pi^{2}}}}{\left(E^{2}+1\right)} \\
& t_{1}=\frac{1}{\omega} \cos ^{-1}\left(\frac{\frac{2}{\pi} \cdot E+\sqrt{E^{2}+1-\frac{4}{\pi^{2}}}}{\left(E^{2}+1\right)}\right), t_{2}=\frac{1}{\omega} \cos ^{-1}\left(\frac{\frac{2}{\pi} \cdot E-\sqrt{E^{2}+1-\frac{4}{\pi^{2}}}}{\left(E^{2}+1\right)}\right) \\
& \sin \omega t_{1}=\frac{\sqrt{E^{4}+E^{2} \cdot\left(1-\frac{4}{\pi^{2}}\right)+\frac{4}{\pi^{2}}-\frac{4}{\pi} E \sqrt{E^{2}+1-\frac{4}{\pi^{2}}}}}{\left(E^{2}+1\right)} \\
& \sin \omega t_{2}=\frac{\sqrt{E^{4}+E^{2} \cdot\left(1-\frac{4}{\pi^{2}}\right)+\frac{4}{\pi^{2}}+\frac{4}{\pi} E \sqrt{E^{2}+1-\frac{4}{\pi^{2}}}}}{\left(E^{2}+1\right)}
\end{aligned}
$$




$$
\begin{aligned}
& \cos \omega t_{1}-\cos \omega t_{2}=\frac{2 \sqrt{E^{2}+1-\frac{4}{\pi^{2}}}}{\left(E^{2}+1\right)} \\
& \sin \omega t_{1}-\sin \omega t_{2}=\frac{\sqrt{E^{4}+E^{2} \cdot\left(1-\frac{4}{\pi^{2}}\right)+\frac{4}{\pi^{2}}-\frac{4}{\pi} E \sqrt{E^{2}+1-\frac{4}{\pi^{2}}}}-\sqrt{E^{4}+E^{2} \cdot\left(1-\frac{4}{\pi^{2}}\right)+\frac{4}{\pi^{2}}+\frac{4}{\pi} E \sqrt{E^{2}+1-\frac{4}{\pi^{2}}}}}{\left(E^{2}+1\right)} \\
& \Delta v_{\text {ripple }}=\frac{I_{L}}{C}\left(\frac{-\pi}{2 \omega}\left(\cos \omega t_{1}-\cos \omega t_{2}\right)-\left(t_{1}-t_{2}\right)\right)+E S R \cdot I_{L} \cdot \frac{\pi}{2}\left(\sin \omega t_{1}-\sin \omega t_{2}\right) \\
& \Delta v_{\text {ripple }}=\frac{I_{L}}{\omega C}\left(\frac{-\pi \sqrt{E^{2}+1-\frac{4}{\pi^{2}}}}{\left(E^{2}+1\right)}-\cos ^{-1}\left(\frac{\frac{2}{\pi} \cdot E+\sqrt{E^{2}+1-\frac{4}{\pi^{2}}}}{\left(E^{2}+1\right)}\right)+\cos ^{-1}\left(\frac{\frac{2}{\pi} \cdot E-\sqrt{E^{2}+1-\frac{4}{\pi^{2}}}}{\left(E^{2}+1\right)}\right)\right) \\
& + \text { ESR }_{L} I_{L} \cdot \frac{\pi}{2} \cdot \frac{\sqrt{E^{4}+E^{2} \cdot\left(1-\frac{4}{\pi^{2}}\right)+\frac{4}{\pi^{2}}-\frac{4}{\pi} E \sqrt{E^{2}+1-\frac{4}{\pi^{2}}}}-\sqrt{E^{4}+E^{2} \cdot\left(1-\frac{4}{\pi^{2}}\right)+\frac{4}{\pi^{2}}+\frac{4}{\pi} E \sqrt{E^{2}+1-\frac{4}{\pi^{2}}}}}{\left(E^{2}+1\right)} \\
& \Delta v_{\text {ripple }}=\frac{I_{L} T_{s}}{2 \pi C}\left[\frac{-\pi \sqrt{E^{2}+1-\frac{4}{\pi^{2}}}}{\left(E^{2}+1\right)}-\cos ^{-1}\left(\frac{\frac{2}{\pi} \cdot E+\sqrt{E^{2}+1-\frac{4}{\pi^{2}}}}{\left(E^{2}+1\right)}\right)+\cos ^{-1}\left(\frac{\frac{2}{\pi} \cdot E-\sqrt{E^{2}+1-\frac{4}{\pi^{2}}}}{\left(E^{2}+1\right)}\right)\right. \\
& \left.+\frac{E \pi}{2} \cdot \frac{\left.\sqrt{E^{4}+E^{2} \cdot\left(1-\frac{4}{\pi^{2}}\right)+\frac{4}{\pi^{2}}-\frac{4}{\pi} E \sqrt{E^{2}+1-\frac{4}{\pi^{2}}}}-\sqrt{E^{4}+E^{2} \cdot\left(1-\frac{4}{\pi^{2}}\right)+\frac{4}{\pi^{2}}+\frac{4}{\pi} E \sqrt{E^{2}+1-\frac{4}{\pi^{2}}}}\right]}{\left(E^{2}+1\right)}\right]
\end{aligned}
$$

As mentioned in chapter 3, in the experimental setup the ESR is negligible compare to the capacitor size. Therefore to find the approximate relation between voltage ripple and capacitor charge from the above equation, ESR is assumed to be zero. And $\Delta v_{\text {ripple }}$ can be simplified as:

$$
\Delta v_{\text {ripple }}=\frac{T_{s}}{9.5006 C_{\text {out }}} I_{L}
$$

